INDICADORES DE

COMPORTAMIENTO DE UN GREMIO

DE MESODEPREDADORES

OBTENIDOS POR METODOS

INDIRECTOS EN STO. TOMAS

OTLALTEPEC, PUEBLA
En México, D.F. se presentaron a las 11:00 horas del día 1 del mes de diciembre del año 2014 en la Unidad Iztapalapa de la Universidad Autónoma Metropolitana, los suscritos miembros del jurado:

MTRA. CAROLINA MUDESPACHER Y ZIEHL

M. EN C. GERARDO LOPEZ ORTEGA

DRA. BARBARA VARGAS MIRANDA

M. EN C. MARIA DE LA ASUNCION SOTO ALVAREZ
Bajo la Presidencia de la primera y con caracter de Secretario el último, se reunieron para proceder al Examen de Grado cuya denominación aparece al margen, para la obtención del grado de:

MAESTRO EN BIOLOGIA

DE: MIGUEL ANGEL TORIZ CASABAL

Y de acuerdo con el artículo 78 fracción III del Reglamento de Estudios Superiores de la universidad Autónoma Metropolitana, los miembros del jurado resolvieron:

\section{Aprobar}

Acto continuo, la presidenta del jurado comunicó al interesado el resultado de la evaluación y, en caso aprobatorio, le fue tomada la protesta.
LIC. JULIO CESARJELARA ISASS: DIRECTOR DE SSTEMAS ESCOLARES
REVISO

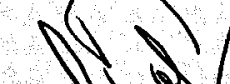

\&

X

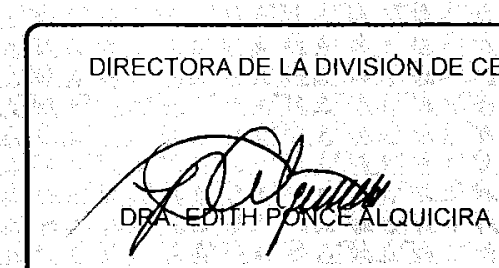

PRESIDENTA

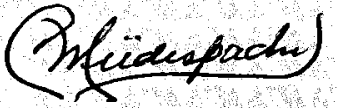

MTRA CAROLINA MUDESPACHER Y ZIEHL

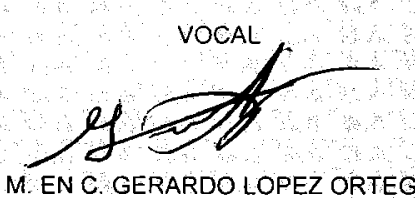

MEN G. GERARDO LOPEZ ORTEGA
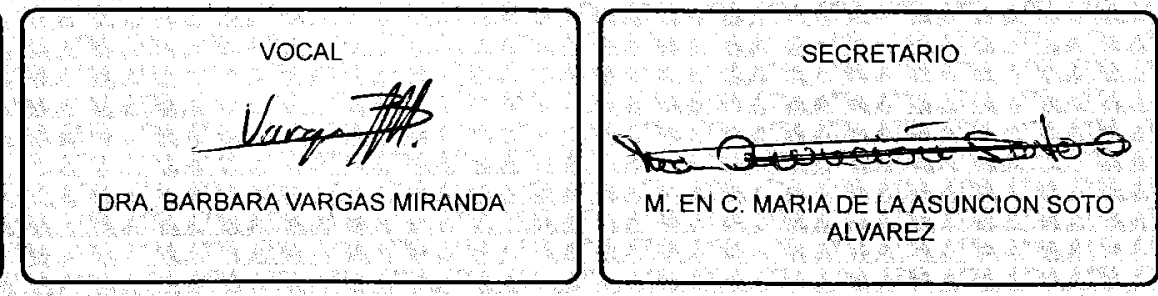


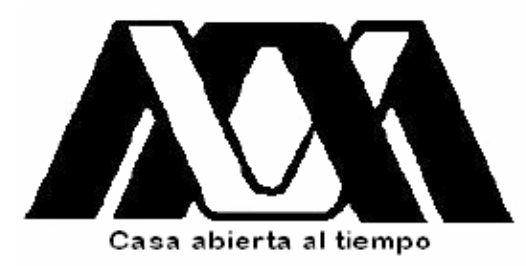

Universidad Autónoma Metropolitana

listapalapa

\title{
Indicadores de Comportamiento en un Gremio de Mesodepredadores Obtenidos por Métodos Indirectos en Santo Tomás Otlaltepec, Puebla.
}

\author{
Tesis
}

Que para obtener el grado de

Maestro en Biología

P R E S E N T A

Miguel Ángel Toriz Casabal 
La Maestría en Biología de la Universidad Autónoma Metropolitana pertenece al Padrón de Postgrados de Calidad del CONACyT. 


\section{El jurado designado por la \\ División de Ciencias Biológicas y de la Salud}

de la Unidad Iztapalapa aprobó la tesis que presentó

\section{Miguel Ángel Toriz Casabal}

El día 1ro. de diciembre del año de 2014.

\section{Comité Tutoral y Jurado}

Tutor:Dr. Miguel Ángel Armella Villalpando

Asesor: M. en C. María de la Asunción Soto Álvarez

Asesor: M. en C. Gerardo López Ortega

Sinodal: M. en C. Carolina Müdespacher Ziehl

Sinodal: Dra. Bárbara Vargas Miranda 


\section{Dedicatoria}

Este trabajo de investigación está dedicado a todas las víctimas de la ciencia. Criaturas sin voz a las cuales les fueron arrebatados sus derechos. Vivisección, nunca más

\section{Agradecimientos}

A Nino, Kyara, Tico y Camy por estar ahí. Por ser mis hermanos y mi apoyo en cada momento de mi vida. ¡Los quiero, chaparros!

A mi mamá, Dolores Casabal Tallabs, que hace todo lo que puede por nosotros.

A mi abuela, Carmen Tallabs Flores, por ser el pilar de esta familia.

A mi hermana, Susana del Carmen Toriz Casabal, quien siempre celebró y contribuyó de forma significativa a este proyecto.

A mi hermana, Ana Laura Toriz Casabal, por su apoyo durante mi carrera.

Al Dr. Miguel Ángel Armella Villalpando, por su atenta guía y por compartir mucho más que sólo estadística.

A la M. en C. María Pia Soto Álvarez, quien se arriesgó hasta el final conmigo en este trabajo que parecía tan lejano.

Al M. en C. Gerardo López Ortega, por sus firmes correcciones a lo largo de toda la tesis.

A la Dra. Bárbara Vargas Miranda, quien, en poco tiempo, aportó ideas clave a este trabajo.

A la M. en C. Carolina Müdespacher Ziehl, por tener la mirada de un águila y una sonrisa bondadosa.

A la Sra. Cira Solis, por su esencial apoyo y compañía.

A la familia Amador, quienes me abrieron su casa y su corazón. Más que mis amigos, son mi familia en Santo Tomás Otlaltepec.

Al Sr. Juan, quien resultó ser un gran guía, conversador y amigo. Una verdadera fortuna contar con su amistad.

Al Dr.Abel Sentíes Granados, por llevar su labor más allá del deber y convertirse en un verdadero amigo.

A la M. en C. Itandehui Mallinali Gomezcaña Alanis, por ser digna de levantar a Mjolnir y mostrarme uno de los mejores rostros de la humanidad.

A la M. en C. Nora Lambert Izquierdo, quien realizó aportaciones invaluables a los métodos de esta investigación y por compartir tantas y tan deliciosas tazas de café. Ojalá haya muchas más. 
A la Dra. Esther Jiménez, quien desde hace muchos años ha sido un luz en la oscuridad y por ser mi hermana no-biológica.

A la Biól. Patricia Moreno Melo, por creer en mí a lo largo de los años y por seguir ahí.

A todo el Looser Club, Rocío, Rosalba, Lalo, Netz y Arcadi. Les debo más de lo que se imaginan y espero que me lo paguen pronto... bueno, algo así.

A Omara, Ariadna, Terminator, Deivid, Gaby, Adrian, Jairzinio, Talib y todo el querido grupo de CentroGeo. Gracias por sus enseñanzas y por su amistad. Ojalá que algún día los meridianos nos vuelvan a reunir.

A Ale, Dama, Lupita, Gerardo y todo el equipo de ASyR, por su apoyo y comprensión durante tantos meses, tardes y noches. Nos hacen falta más tardes de donas.

A Laura (Bender), Rosa, Nancy, Julio y Eréndira, por su juventud, energía, compañía y tardes de papas con salsa. Los aprecio sinceramente.

A todos los chicos del Laboratorio de Ecología del Comportamient,o por su apoyo y por continuar el trabajo con indicadores indirectos de comporta

A la Srita. Elvia Patricia del Pilar Reyes, por compartir tantos sueños, películas y tiempo.

A la Biól. Ana Laura Aguilar, quien pronto deberá ser M. en C. y quien siempre ha creído en mí a pesar de tener un coxis de titanio.

A la querida Lucy (Nut Tut), por luchar por aquellos que no tienen voz y por compartir este viaje en la Nave de la Imaginación. Gracias, querida amiguita.

A la Biól. Jeimy Tangananica Pedraza Cepeda, por ser tan inteligente, leal y bondadosa. A pesar de la distancia, sigues estando presente.

A mi comadre querida Angélica J. Mauro, por su ejemplo, por compartir tanto tiempo conmigo y por nunca rendirse.

A la Maestra Morgana, por luchar con la mente, las manos, los pies y con cada fibra de su ser para que la liberación sea algún día una realidad. Mi respeto y admiración siempre.

A todos los que han participado en el colectivo 269: Guadalupe, Perro, Gata, Pato, Alejandro, Frida, Alfredo, Dahiana, Sophie, Revo, Perla, Susana, Ellie, Alec, Damian, Yizus y a todos. Gracias por luchar para que este mundo sea un mejor lugar.

A todo el grupo de Music Heals the Soul, por llevar música adonde las calles no tienen nombre y por convertir cada noche en el cielo o Las Vegas. Ojalá que sus adorables cabezas sigan haciendo ruido por mucho tiempo más y que Romina y Elvira los besen por mí.

A Carl Sagan por haberme enseñado que el Universo está lleno de cosas por descubrir. Gracias, Carl. 
A Konrad Lorenz por haberme prestado el anillo del rey Salomón. Lo seguiré usando hasta que muera. 


\section{Índice}

Pertenencia CONACYT

Página

Dedicatoria

Agradecimientos

Índice

Resumen

Abstract

Introducción General

Capítulo I

Introducción

Objetivos

Método

Resultados

Discusión y Conclusiones

Capítulo II

Introducción

Objetivos

Método

Resultados

Discusión y Conclusiones

Capítulo III

Introducción

Objetivos

Método

Resultados

Discusión y Conclusiones

Conclusión General

Bibliografía

Anexos

Anexo I. Mesodepredadores registrados en

el área de estudio

Anexo II. Otras especies de fauna silvestre

registradas en el área de estudio

Anexo III. Especies de mesodepredadores

registradas por fototrampeo

Anexo IV. Otras especies de fauna

registradas por fototrampeo 


\section{$\underline{\text { Resumen }}$}

Se utilizaron métodos indirectos para obtener indicadores de comportamiento en una comunidad de mesodepredadores en una zona semiárida y semiperturbada en Santo Tomás Otlaltepec, Puebla. Por medio de cámaras-trampa se registró la presencia y horarios de actividad de nueve especies de mesodepredadores, los cuales tienen un horario de actividad preferentemente nocturno. Las excretas frescas de estas especies fueron colectadas y se les asignó un valor de marcaje. Usando tablas de contingencia y la prueba de $\mathrm{Ji}^{2}$, se comprobó que el valor de marcaje de las excretas es independiente para la especie y la estación en que las muestras fueron colectadas. Finalmente, usando técnicas de EIA, se extrajeron y cuantificaron hormonas esteroides, lo que permitió determinar las concentraciones de de P4, E2 y T para Canis latrans, Urocyon cinereoargenteus y Procyon lotor a lo largo de un ciclo anual.

\section{$\underline{\text { Abstract }}$}

Indirect methods were used to obtain behavior indicator in a mesopredator community in a semiarid and semiperturbed zone in Santo Tomás Otlaltepec, Puebla. With camera-traps the presence and activity hours of nine mesopredators were registered, finding that they have preference for nocturne activity. The fresh feces of this species were collected and a marking value were assigned to each one. Using contingency tables and the $\mathrm{Ji}^{2}$ test $\mathrm{I}$ confirmed that the marking value is independent for species and weather station of sample collect. Finally, using EIA techniques steroid hormones were extracted and quantified, allowing to determine the P4, E2, and $\mathrm{T}$ concentrations for Canis latrans, Urocyon cinereoargenteus and Procyon lotor through an annual cycle. 


\section{Introducción General}

La ecología del comportamiento, en sentido estricto, estudia la función o el valor adaptativo de la conducta animal (Tinbergen, 1963; Cuthill, 2005). La disciplina adquirió su denominación actual a finales de la década de 1970 y ha sido la fuerza dominante en la etología durante los últimos 30 años, aunando esta con la biología evolutiva y la ecología (Krebs y Davies, 1993; Barnard, 2004).

Dentro de este marco de conocimiento, los trabajos de investigación que estudian la relación del individuo con su ambiente, realizados con animales en vida libre, han tomado fuerza por la información que aportan y los métodos que deben ser utilizados para poder estudiar un animal sin afectar sus actividades y desarrollo. El mismo Lorenz (1986) declaró: “...la observación de los animales en su hábitat natural es siempre imprescindible. Sin embargo, la principal ventaja que presenta la observación in situ consiste en poder captar directamente la adaptación ecológica de la especie estudiada”.

Además de la preferencia por la observación y el estudio del comportamiento animal, hubo otro factor decisivo para buscar integrarme a un proyecto de investigación que tuviera como base la ecología del comportamiento: El uso de métodos indirectos, que no pusieran en riesgo alguno la integridad de los individuos estudiados. Es alarmante la cantidad de estudios biológicos que utilizan la captura y manipulación de animales para estudiarlos. El trampeo con jaulas Tomahawk, redes de niebla y trampas Sherman, pueden aportar datos relativamente significativos para estudios de poblaciones, pero invariablemente se deja de lado la cantidad de animales heridos y muertos durante el muestreo. Parecería que mientras más sabemos de una especie, o de un grupo de fauna, menos los respetamos. Es mi intención dar un paso atrás y obtener información acerca del comportamiento de otros animales en vida libre, interfiriendo en sus vidas lo menos posible.

En el Laboratorio de Ecología de la UAM Iztapalapa, encontré la forma de desarrollar un proyecto con estas características, puesto que es uno de los pocos centros de estudio que aplica la ecología del comportamiento en sus trabajos de investigación.

Desde el principio, el proyecto contó con los siguientes elementos constitutivos:

a) Se seleccionaron mesodepredadores, es decir, todas aquellas especies de mamíferos de tamaño medio y cuya alimentación tiene componentes animales. 
b) Un área de trabajo con un ecosistema propicio para la existencia de mesodepredadores: La zona occidental de la Reserva de la Biosfera de TehuacánCuicatlán (RBTC), que es un área poco estudiada. Esta zona tiene una diversidad significativa de cactáceas columnares y una comunidad de matorral xerófilo muy bien conservado con asociaciones características de Yuca sp, y la presencia de Echinocactus platyacanthus. La cercanía del pueblo de Santo Tomás Otlaltepec le otorga además características propias de un área semi-perturbada por actividades de siembra, ganadería, extracción de leña y cacería, lo que ofrecía la posibilidad de encontrar guías que tuvieran conocimiento en la fauna de la zona. En esta área se ha reportado la presencia de especies de mesodepredadores como el coyote (Canis latrans), la zorra o zorra gris (Urocyon cinereoargenteus), el gato montés (Lynx rufus), el mapache (Procyon lotor), el cacomixtle (Bassariscus astutus), el coatí (Nasua narica), el zorrillo cadeno (Conepatus leuconotus), el zorrillo rayado (Mephitis macroura) y el tlacuache (Didelphis virginiana) (Ramírez y Martínez, 2007) .

c) Una temática insertada en el marco de la ecología del comportamiento: El objetivo general del trabajo fue buscar indicadores del uso de recursos por parte del gremio de los mesodepredadores.

d) Uso de métodos indirectos. Se optó por el uso de métodos que no afectaran las actividades de los animales y que no representaran riesgo alguno para ellos.

En las búsquedas de información de los trabajos con fauna silvestre realizados en la Reserva de la Biosfera de Tehuacán-Cuicatlán y su área de influencia, no fue posible encontrar ningún trabajo de ecología del comportamiento. Por ello, este trabajo abre una ventana de oportunidad para estudiar este tema utilizando diversos métodos indirectos como la colecta de excretas, la cuantificación de hormonas a partir de heces fecales y el registro de actividad con cámaras-trampa como métodos de estudio de fauna silvestre.

Estos métodos estuvieron enfocados a obtener indicadores de comportamiento. ¿Cuáles son los principales horarios de actividad de los mesodepredadores? ¿El comportamiento de marcaje fecal es diferente entre especies? ¿Cuál es la variación hormonal a lo largo de un ciclo anual? 
Cada uno de estos métodos tiene objetivos propios y provee indicadores de comportamiento particulares, por lo que se decidió presentar los resultados de manera independiente. Cada capítulo de esta tesis contiene su propia introducción, métodos, resultados y conclusiones, de forma que el lector pueda tener una lectura clara de los resultados en cada una de las fases de investigación. 


\section{Capítulo I.}

\section{Determinación de la riqueza y horarios de actividad de los mesodepredores que habitan en el área sur de la zona de influencia de la RBTC por medio de fototrampeo.}

\section{Introducción}

Los carnívoros de talla media o mesodepredadores son especies con amplios rangos ecológicos, alimenticios y de distribución. Habitan en zonas silvestres que presentan poca perturbación, así como áreas rurales y semi-urbanas perturbadas, pues su tamaño y habilidad les permite desarrollarse en diversos ámbitos. Por la noche, estas especies presentan mayor actividad, si bien pueden dedicar parte del amanecer y del crepúsculo a la búsqueda de refugio y alimento (Bekoff, 1977; Lotze \& Anderson, 1979; Fritzell \& Haroldson, 1982; Gompper, 1995; Larivière \& Walton, 1997; Hwang \& Larivière, 2001; Castellanos, 2006; Kasper et al., 2009; Roemer et al., 2009; Gwinn et al,. 2011).

La manera más confiable y ampliamente utilizada para evaluar la diversidad biológica de un área particular, es por medio de muestreos de campo y revisión de colecciones científicas, con el objeto de generar información sobre las especies que habitan en un lugar determinado (Ramírez y Martínez, 2007).

En la RBTC, en el estado de Puebla, se han realizado inventarios de fauna silvestre con diversos métodos. En 1994 García-Chávez et al. determinaron la riqueza de especies de mamíferos carnívoros por medio de huellas y excretas en los alrededores de Zapotitlán de Salinas, Puebla. En este trabajo se registraron cuatro especies de mesodepredadores: zorra gris (Urocyon cinereoargenteus), coyote (Canis latrans), cacomixtle (Bassariscus astutus) y zorrillo rayado (Mephitis macroura).

En la misma zona con el uso de cámaras-trampa, Botello y sus colaboradores (2006), lograron los primeros registros de tigrillo (Leopardus wiedii) en los municipios de Concepción Pápalo y de Santiago Nacaltepec, así como de gato montés (Lynx rufus) en el municipio de Santa María Tecomavaca, todos en Oaxaca. 
Uno de los trabajos más reconocidos es el realizado por Ramírez y Martínez (2007), en el cual reportan la presencia de tres especies de tlacuaches (Didelphis marsupialis, Didelphis virginiana y Marmosa canescens), tres especies de zorrillos (Conepatus leuconotus, Mephitis macroura y Spilogale putorius), coyote (Canis latrans), zorra gris (Urocyon cinereoargenteus), cacomixtle (Bassariscus astutus), coatí (Nasua narica) y mapache (Procyon lotor), con un total de 12 especies de mesodepredadores en la zona. Para el levantamiento del inventario de mesodepredadores, usaron trampas Tomahawk y registros indirectos como huellas y excretas.

Entre los métodos de registro de fauna silvestre que se han utilizado en los trabajos citados, se encuentra el fototrampeo. Es un método no invasivo de muestreo de fauna silvestre, que consiste en utilizar cámaras automáticas para registrar la presencia y actividad de fauna silvestre. Se ha aplicado con eficiencia para la identificación de especies de mamíferos de talla mediana a grande, considerando desde ardillas y coatíes hasta osos y alces, con la ventaja de que el equipo no tiene que ser monitoreado constantemente, y los horarios de actividad de los animales pueden ser registrados con gran detalle, pues la cámara guarda la hora y la fecha en cada fotografía. Además, los animales no sufren ningún tipo de perturbación, por lo que contribuye no sólo al conocimiento de las especies, sino también a la conservación de las mismas (Cutler y Swann, 1999; McCullough et al., 2000; Ramírez y Martínez, 2007; Giman et al., 2007; Lyra-Jorge et al., 2008; Reed, 2011; Vilchis et al., 2011).

\section{$\underline{\text { Objetivos }}$}

1. Realizar un listado de las especies de mesodepredadores que habitan en los terrenos comunales de Santo Tomás Otlaltepec, al sur del área de influencia de la Reserva de la Biosfera de Tehuacán-Cuicatlán.

2. Determinar los horarios de actividad para las especies de mesodepredadores que habitan en la zona de estudio. 


\section{$\underline{\text { Método }}$}

\section{Área de estudio}

El estudio se realizó en los terrenos comunales de Santo Tomás Otlaltepec, municipio de Atexcal, Puebla. Consta de un área semirural de matorral rosetófilo donde se practica la siembra de temporal y el pastoreo de ganado vacuno, mular y caprino. Está conformada por lomeríos que descienden con orientación este-oeste. El área seleccionada se ubica al Este del poblado de Santo Tomás Otlaltepec. Se localiza en el área de influencia de la Reserva de la Biosfera de Tehuacán-Cuicatlán, cerca del límite sur de la misma y se encuentra aproximadamente a $4 \mathrm{~km}$ de la frontera Norte de Oaxaca. Las coordenadas del centro del pueblo son $\mathrm{N} 18^{\circ} 17^{\prime} 07.1^{\prime \prime}$ y O $97^{\circ} 44^{\prime} 59.5^{\prime}$. El tipo de clima predominante es BS1hw: semiárido, templado, temperatura media anual mayor de $18^{\circ} \mathrm{C}$, temperatura $10 \%$ del mes más frío menor de $18^{\circ} \mathrm{C}$, temperatura del mes más caliente mayor de $22{ }^{\circ} \mathrm{C}$; con lluvias en verano del 5\% al 10.2\% anual. La altitud promedio es 2220 m.s.n.m. El tipo de suelo predominante es el leptosol (Arriaga et al., 2000; INEGI, 2009).

\section{Selección de sitios para fototrampeo}

Fueron seleccionados lugares que resultaran de interés para la fauna silvestre, tales como pasos naturales, veredas y cuerpos de agua. Para cada sitio de fototrampeo la cámara tuvo un período de ensayo de un mes. Si durante ese lapso la cámara no captaba ninguna imagen de las especies de interés, se cambiaba de lugar.

La colocación de las cámaras-trampa se realizó tras una prospección de la zona de estudio en febrero de 2012. Se buscaron sitios que pudieran ser apropiados para la instalación de las cámaras-trampa y se identificó la fisiografía del área, así como los recursos hidrológicos principales y los sitios potenciales de paso de fauna silvestre. A lo largo del tiempo del estudio, las cámaras se instalaron en 11 sitios, de los cuales sólo seis fueron exitosos. Las seis cámaras funcionaron en periodos irregulares entre febrero y noviembre de 2012 (Figura 1). 


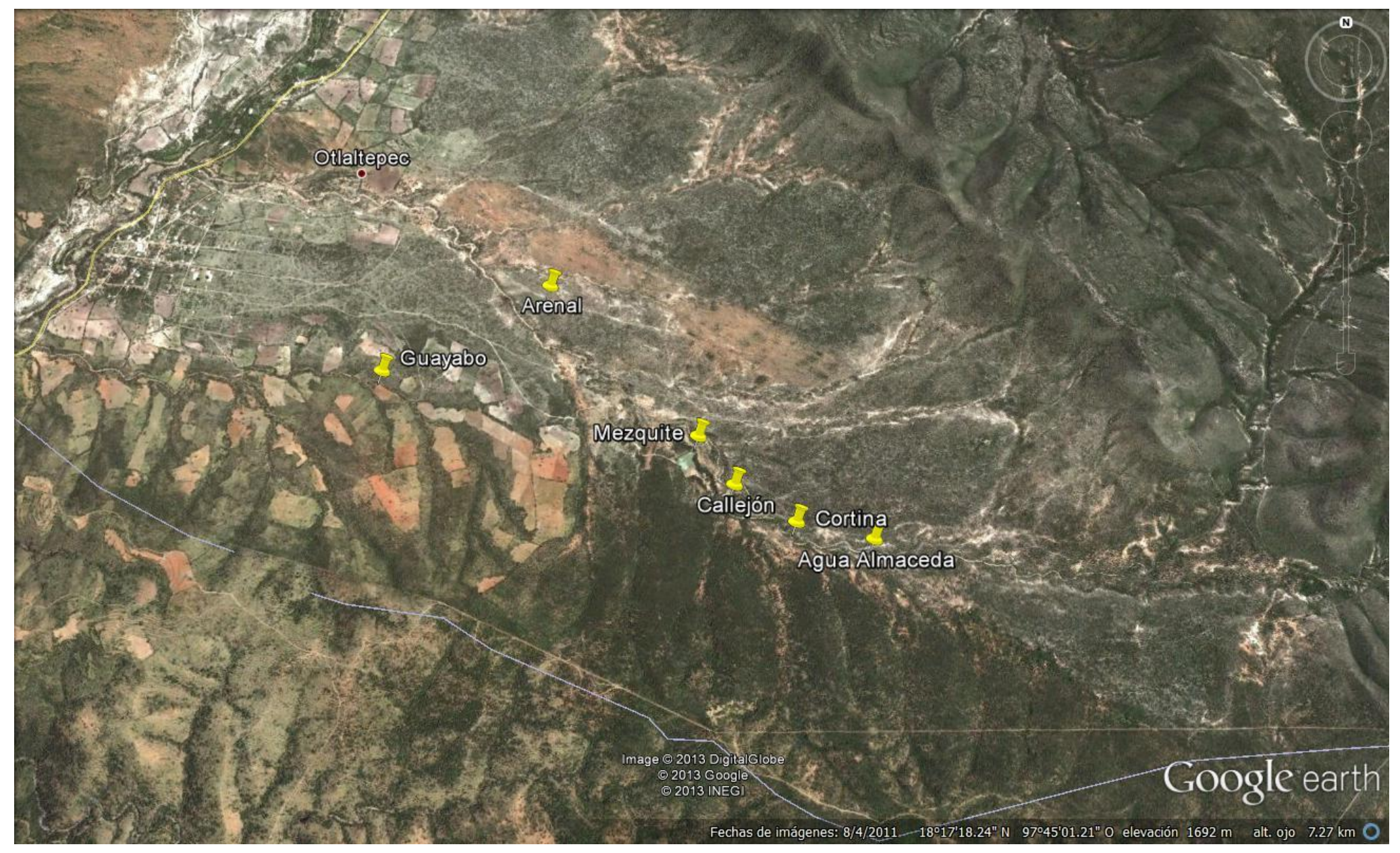

Figura 1. Ubicación de las cámaras que obtuvieron registros de mesodepredadores en el área de trabajo. 


\section{Programación de las cámaras}

Se usaron cuatro cámaras Wildview, modelo TGLX8IR y dos cámaras Tasco, modelo 119255CW. Ambos tipos de cámaras cuentan con sensores y leds infrarrojos.

Cada cámara tiene un rango de captura de $48^{\circ}$ con capacidad para detectar movimiento a 10 $\mathrm{m}$ de distancia. Todas las cámaras utilizadas en este estudio contaban con la tecnología PIR (Passive Infrared), que activa el disparador de la cámara cuando detecta movimiento o calor. Cada cámara fue programada para tomar tres fotos consecutivas en cada activación PIR, por lo que fue posible obtener más de una fotografía correspondiente a un mismo animal.

Se consideró un registro cada fotografía o grupo de fotografías que correspondiesen al mismo animal o animales, en un lapso no mayor a 30 segundos.

\section{Análisis de la actividad}

Puesto que cada registro fotográfico tiene la fecha y hora en que fue capturada la fotografía, fue posible calcular las horas de mayor actividad para los organismos de estudio.

Para el análisis de los datos se utilizó el programa de estadística circular Oriana 4.01 (Kovach Computing Services). La información obtenida permitió describir los patrones de actividad para algunos mesodepredadores. Con este programa también se obtuvieron estadísticos que permitieron describir la distribución de los registros a lo largo del estudio.

\section{$\underline{\text { Resultados }}$}

\section{Cámaras}

Las cámaras se colocaron a mediados de febrero 2012 y se retiraron a mediados de diciembre de ese mismo año. No fue posible tener instaladas las cámaras durante todo el lapso de tiempo del estudio, pues varias veces fueron removidas e incluso robadas, probablemente por cazadores furtivos.

Aun así, se logró un esfuerzo total de 854.33 días, considerado como la suma de los días por trampa que cada cámara trampa permaneció activa (Cuadro 1). 
Cuadro 1. Días por cámara trampa y esfuerzo total

\begin{tabular}{|l|r|}
\hline Cámara & $\begin{array}{l}\text { Esfuerzo por } \\
\text { cámara (días) }\end{array}$ \\
\hline Guayabo & 178.85 \\
\hline Madriguera_Callejón & 79.68 \\
\hline Cortina & 116.18 \\
\hline Arenal & 190.36 \\
\hline Agua Almaceda & 191.07 \\
\hline Mezquite & 98.20 \\
\hline & \\
\hline Esfuerzo total (días): & $\mathbf{8 5 4 . 3 3}$ \\
\hline
\end{tabular}

\section{Especies registradas de mesodepredadores}

De febrero a octubre de 2012 las cámaras-trampa obtuvieron en total de 40 registros de mesodepredadores, correspondientes a cinco familias, nueve géneros y nueve especies, de las cuales ninguna se encuentra en alguna categoría de riesgo en la NOM-059 (Anexos I y II). 
Cuadro 2. Cámaras instaladas que obtuvieron registros de mesodepredadores.

Ubicación

\begin{tabular}{|c|c|c|c|c|c|c|c|c|c|}
\hline Paraje & $\mathbf{N}$ & & Tipo de sitio & $\begin{array}{l}\text { Fecha de } \\
\text { instalación }\end{array}$ & $\begin{array}{l}\text { Fecha de } \\
\text { recuperación/ } \\
\text { último } \\
\text { registro }\end{array}$ & $\begin{array}{l}\text { Total de } \\
\text { registros }\end{array}$ & Ubicación & Estatus & Observaciones \\
\hline $\begin{array}{l}\text { Agua } \\
\text { Almaceda }\end{array}$ & $\begin{array}{l}\text { N } 1816 \\
58.7\end{array}$ & W 974434.7 & $\begin{array}{l}\text { Encharcamiento } \\
\text { en arroyo }\end{array}$ & 09-jun-12 & 28-nov-12 & 1 & $\begin{array}{l}380 \mathrm{~m} \text { al } \mathrm{E} \\
\text { de la Cortina }\end{array}$ & Recuperada & $\begin{array}{l}\text { Sólo se logró captar la } \\
\text { imagen parcial de un } \\
\text { coyote. }\end{array}$ \\
\hline Cortina & $\begin{array}{l}\text { N } 1817 \\
06.3\end{array}$ & W 974458.4 & $\begin{array}{l}\text { Vereda en brazo } \\
\text { de arroyo; letrina }\end{array}$ & 09-jun-12 & 18-nov-12 & 28 & $\begin{array}{l}350 \mathrm{~m} \text { al SE } \\
\text { de } \\
\text { Madriguera- } \\
\text { Callejón }\end{array}$ & Extraviada & $\begin{array}{l}\text { Esta fue la cámara que } \\
\text { captó la mayor cantidad de } \\
\text { registros, lo cual puede } \\
\text { deberse a que el sitio es } \\
\text { una letrina y una vereda } \\
\text { que es acceso clave para } \\
\text { llegar a un cuerpo de agua. }\end{array}$ \\
\hline $\begin{array}{l}\text { Madriguera } \\
\text { - Callejón }\end{array}$ & $\begin{array}{l}\text { N } 1817 \\
07.1\end{array}$ & W 974459.6 & $\begin{array}{l}\text { Vereda paralela a } \\
\text { madriguera en } \\
\text { brazo de arroyo }\end{array}$ & $17-f e b-12$ & 28-nov-12 & 1 & $\begin{array}{l}310 \mathrm{~m} \text { al } \mathrm{S} \\
\text { de Mezquite } \\
1\end{array}$ & Recuperada & $\begin{array}{l}\text { Aquí se encuentra una } \\
\text { madriguera que se } \\
\text { encontraba activa en el } \\
\text { momento de la instalación } \\
\text { de la cámara. Se logró } \\
\text { captar la imagen de una } \\
\text { zorra desplazándose. }\end{array}$ \\
\hline Mezquite 1 & $\begin{array}{l}\text { N } 1817 \\
14.7\end{array}$ & W 974502.7 & $\begin{array}{l}\text { Árbol ubicado } \\
\text { cerca de cuerpo } \\
\text { de agua y del } \\
\text { camino principal; } \\
\text { letrina }\end{array}$ & 10 -jun-12 & 28-nov-12 & 1 & $\begin{array}{l}1.03 \mathrm{~km} \text { al } \\
\text { NO del } \\
\text { Arenal } 1\end{array}$ & Recuperada & $\begin{array}{l}\text { Se captó la imagen borrosa } \\
\text { de un cacomixtle } \\
\text { descendiendo por la rama } \\
\text { del árbol. }\end{array}$ \\
\hline
\end{tabular}




\section{Ubicación}

\begin{tabular}{|c|c|c|c|c|c|c|c|c|c|}
\hline Paraje & $\mathbf{N}$ & & Tipo de sitio & $\begin{array}{l}\text { Fecha de } \\
\text { instalación }\end{array}$ & $\begin{array}{l}\text { Fecha de } \\
\text { recuperación/ } \\
\text { último } \\
\text { registro }\end{array}$ & $\begin{array}{l}\text { Total de } \\
\text { registros }\end{array}$ & Ubicación & Estatus & Observaciones \\
\hline Arenal & $\begin{array}{l}\text { N } 1817 \\
49.3\end{array}$ & W 974538.4 & $\begin{array}{l}\text { Vereda en } \\
\text { paralela a arroyo; } \\
\text { letrina }\end{array}$ & 10-jun-12 & 28-nov-12 & 1 & $\begin{array}{l}890 \mathrm{~m} \text { al NE } \\
\text { de Guayabo }\end{array}$ & Recuperada & $\begin{array}{l}\text { El único registro } \\
\text { correspondió a un coyote } \\
\text { desplazándose vereda } \\
\text { abajo. }\end{array}$ \\
\hline Guayabo & $\begin{array}{l}\text { N } 1817 \\
25.6\end{array}$ & W 974557.1 & $\begin{array}{l}\text { Ojo de agua en } \\
\text { arroyo }\end{array}$ & 18 -feb-12 & 04-nov-12 & 10 & $\begin{array}{l}940 \mathrm{~m} \text { al SE } \\
\text { del límite } \\
\text { del pueblo }\end{array}$ & Extraviada & $\begin{array}{l}\text { Esta cámara fue una de las } \\
\text { más productivas. Se instaló } \\
\text { en el único ojo de agua } \\
\text { disponible durante la } \\
\text { temporada de secas, al cual } \\
\text { se tiene acceso por una } \\
\text { vereda y un arroyo } \\
\text { somero.. }\end{array}$ \\
\hline
\end{tabular}


La especie con mayor cantidad de registros fue Bassariscus astutus (12), seguida de Canis latrans (10), Conepatus leuconotus (4), Urocyon cinereoargenteus (4) y finalmente Procyon lotor (3). Las demás especies obtuvieron dos registros o menos (Figura 2).

Las cámaras que obtuvieron mayor cantidad de registros de mesodepredadores fueron la Cortina (26) y el Guayabo (10).

\section{Otras especies registradas}

Si bien el objetivo principal fue realizar un inventario de mesodepredadores, las cámarastrampa también lograron registrar otras cuatro especies de fauna silvestre. Tres de éstas correspondientes a la clase Aves, y una más correspondiente a la Clase Mammalia, en particular a la Familia Leporidae (Anexo III). Estos registros no se tomaron en cuenta para los conteos finales ni para los cálculos de los horarios de actividad, pues ninguna de las especies pertenece al grupo de estudio.

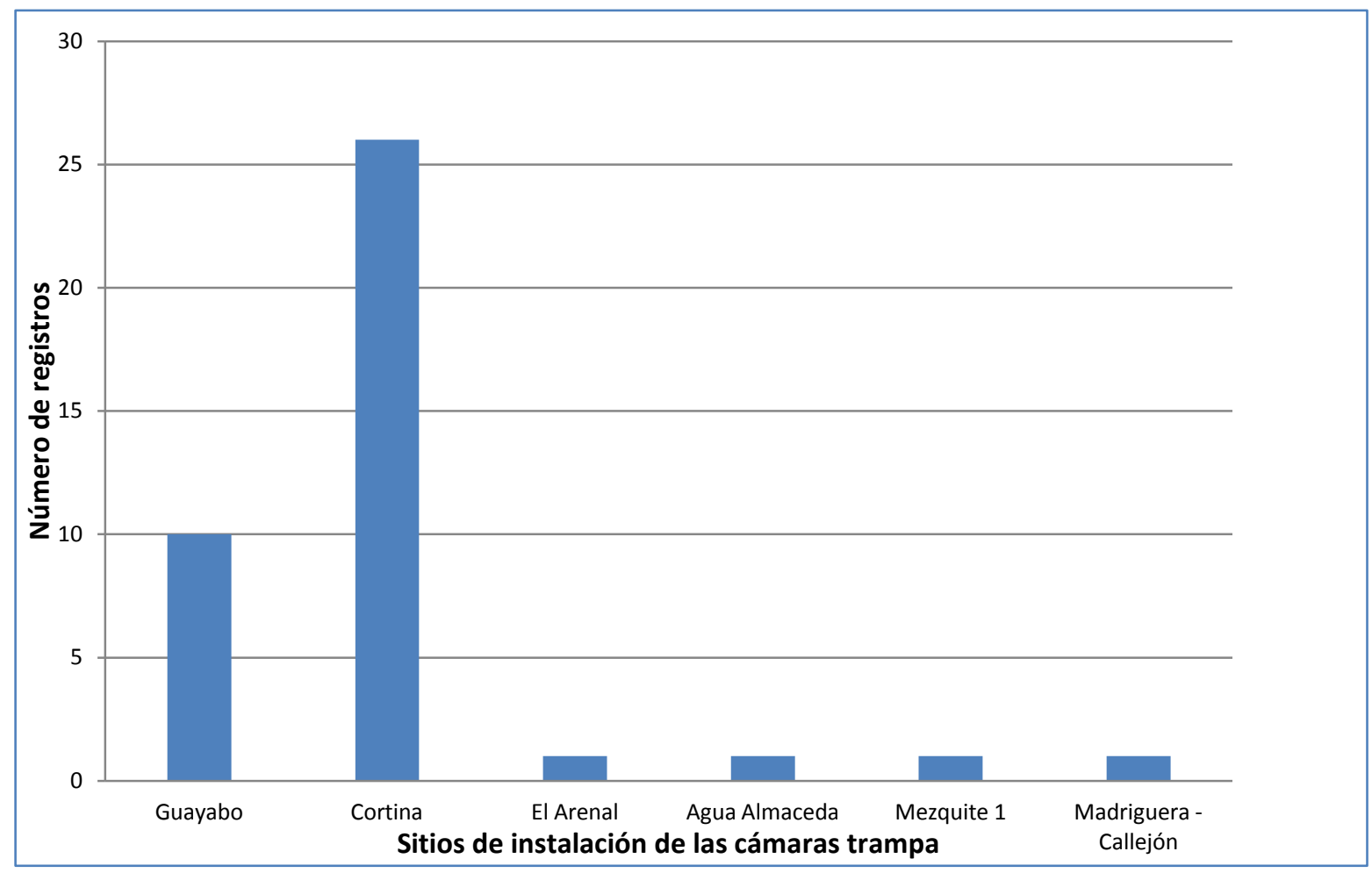

Figura 2. Total de registros de mesodepredadores obtenidos por cámara. 


\section{Los registros fotográficos como indicadores de actividad}

Se identificaron seis diferentes actividades a partir de los registros fotográficos. Las actividades más representativas fueron Desplazándose, que ocupó el 57\% de los registros, seguido de Bebiendo con el 22\%. Las actividades Parado y Olfateando tuvieron el 8\%, finalmente Lavándose que obtuvo el 3\% y Defecando sólo con el 2\% (Figura 3).

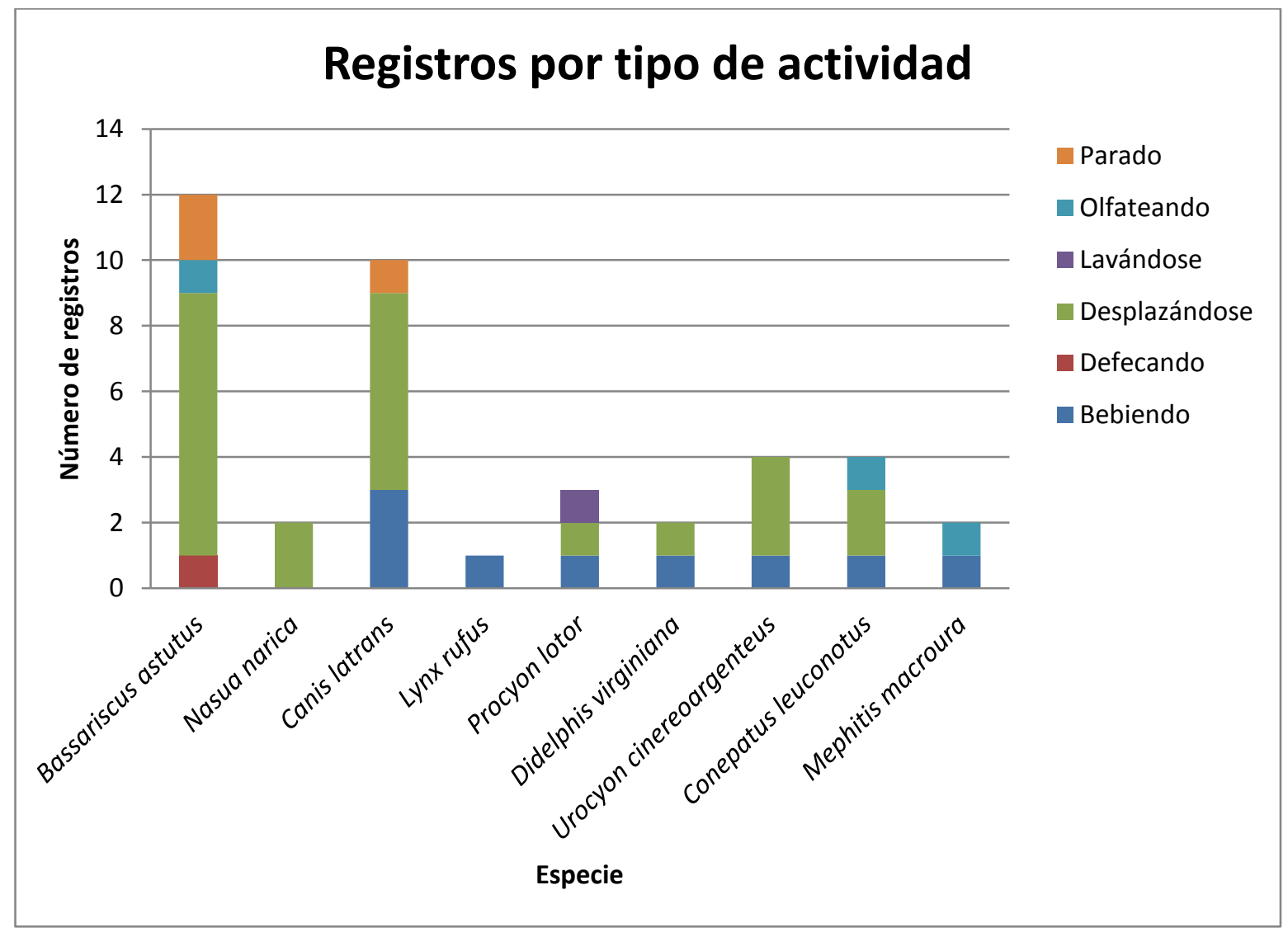

Figura 3. Registros de actividad por especie. 


\section{Horarios de actividad}

Para analizar los horarios de actividad de cada especie se realizó un histograma circular apilado. El ángulo medio se ubica a las 00:44 hrs y los intervalos de confianza fueron del 95\%. Los registros fueron agrupados según la hora promedio en que fueron obtenidos (Figura 5).

En el histograma circular cada registro está representado por un rectángulo de color sobre los radios de un círculo cuyos ángulos expresan las 24 horas del día. Los registros quedaron agrupados en 11 ángulos o azimuts. Se puede observar que las horas de mayor actividad fueron aproximadamente las 20:45 hrs con ocho registros correspondientes a seis especies, las 06:00 hrs, también con ocho registros pertenecientes a cinco especies y las 00:30 hrs, con seis registros correspondientes a cuatro especies.

\section{Registros/Hora}

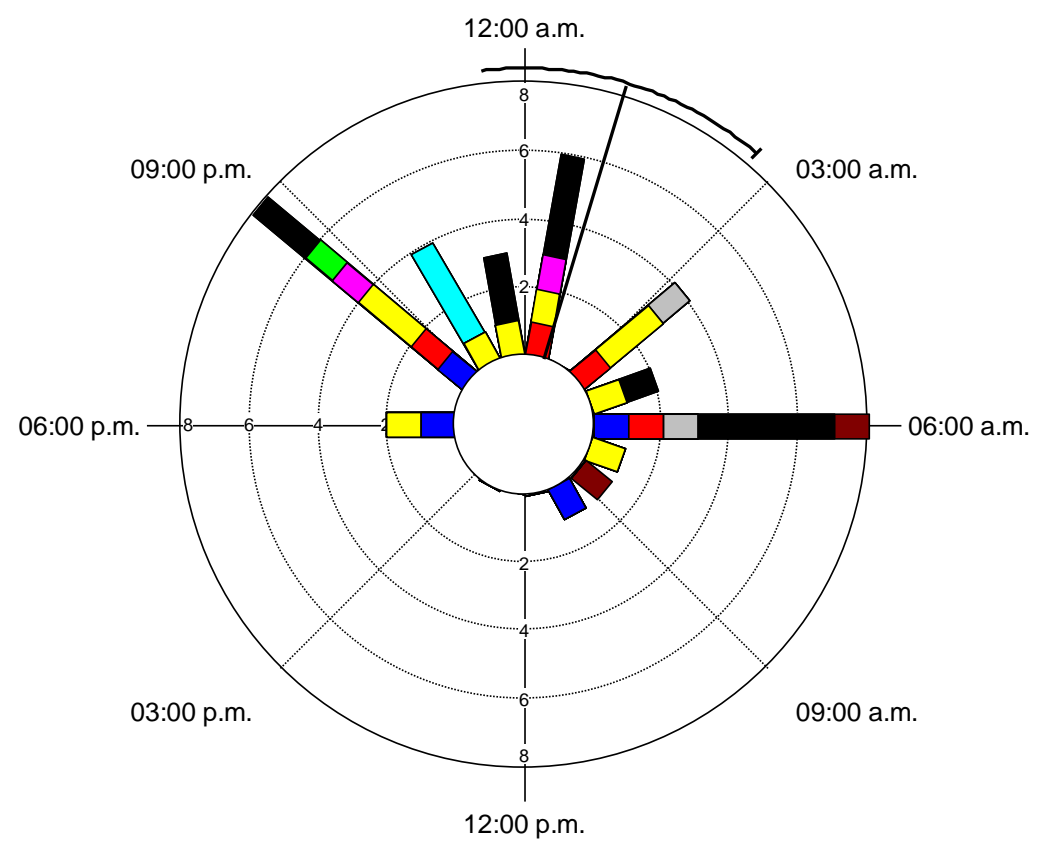

\section{Especie}

Urocyon cinereoargenteus

Conepatus leuconotus

Canis latrans

Didelphys virginiana

Mephitis macroura

Lynx rufus

Procyon lotor

Bassariscus astutus

Nasua narica

Figura 5. Registros por hora en un histograma circular apilado. La distribución de los datos es multimodal. El ángulo medio se encuentra a las 00:44 hrs.

En la Figura 5 se pueden apreciar las propiedades del ángulo medio: a) Dirección ( $\mu=$ 00:44 hrs), que representa la media aritmética de todos los ángulos y horas en el círculo. Este resultado refleja el carácter preferentemente nocturno de los mesodepredadores; b) 
Longitud ( $r=0.443$ ), es una expresión de la concentración de los datos y puede tener un valor entre 0 y 1 . Mientras mayor sea el valor de $r$, mayor será la concentración de los datos. Para este caso, el valor de $r$ señala una concentración media.

\section{Discusión y Conclusiones}

Con base en los registros obtenidos se puede decir que la especie con mayor actividad en el área es Bassariscues astutus, seguida de Canis latrans, Urocyon cinereoargenteus y Conepatus leuconotus (Figura 2).

Los horarios de actividad coinciden con lo reportado en la literatura para las especies de interés. Canis latrans es señalada como una especie de hábitos preferentemente nocturnos (Beekoff, 1977). Lo mismo para la Urocyon cinereoargenteus (Fritzell \& Haroldson, 1982) y el L. rufus (Larivière \& Walton, 1997). Si bien todas las especies registradas en este estudio pueden ser observadas a plena luz del día, todos los autores concuerdan en que la mayor parte de su actividad la realizan durante la noche (Dragoo \& Sheffield, 2009; Hwang \& Larivière, 2001; Lotze \& Anderson, 1979; McManus, 1974; Poglayen-Neuwall \& Toweill, 1988). Lo anterior queda confirmado por la hora media señalada en el histograma circular apilado (Figura 4), que indica las 00:44 hrs.

La especie que registró un mayor rango de horario de actividad fue Urocyon cinereoargenteus. Es la única especie de la cual se obtuvieron registros matutinos (06:39 y 09:48 hrs), vespertinos (17:44 hrs) y nocturnos (20:39 hrs; Cuadro 2; Figura 4). Esta especie es uno de los depredadores más grandes de la zona, junto con Canis latrans y Lynx rufus, y considerando su amplia alimentación y actividades de cacería, un horario de actividad extenso le puede proporcionar mayores oportunidades de obtener recursos (Fritzell \& Haroldson, 1982).

Sólo dos especies fueron reportadas en parejas o en grupos, Procyon lotor y Bassariscus astutus. En la cámara El Guayabo se registraron tres mapaches entre las 21:24 y las 22:03 del 19 de marzo de 2012, por lo que se puede suponer que se trata del mismo grupo. La cámara La Cortina también captó a Procyon lotor desplazándose el 10 de septiembre a las 21:37. Esta misma cámara logró captar una pareja de Bassariscus astutus el 10 de octubre de 2012 a las 20:29 hrs. En los otros listados realizados para la zona, no se han encontrado 
registros que señalen actividad mesodepredadores en parejas o en grupos (Ramírez y Martínez, 2007).

Las cámaras que obtuvieron una mayor cantidad de registros y una mayor variedad de especies fueron aquellas que se encontraban en sitios de interés o sitios clave para la fauna silvestre. Las características de estos sitios sugieren que aquí es más probable el paso de fauna. Esto puede ser ocasionado por la cercanía de un cuerpo de agua, la presencia de excretas, árboles o arbustos con frutos y el cruce de veredas o caminos. Lo anterior se cumple para las cámaras que obtuvieron más registros (Figura 3). La cámara El Guayabo se instaló en un árbol apuntando hacia un ojo de agua, el cual es el único disponible en la temporada de secas en el área de estudio. Este ojo de agua tiene acceso por una vereda y por un arroyo somero. En cuanto a la cámara La Cortina, se instaló en el cauce de un arroyo somero que su vez es utilizado como paso natural de pastores con ganado y fauna silvestre. En este cauce se encuentra una barda de piedra que es parte de una pequeña represa, y sobre la cual se encontraron excretas, lo cual señalaba que este era un paso frecuente de las especies de mesodepredadores. Ambas cámaras fueron robadas hacia finales de 2012 .

Hay que enfatizar el hecho de que las cámaras-trampa lograron registrar especies que no estaban en el grupo objetivo en este estudio (Cuadro 2).

Muy posiblemente se pudo haber obtenido una mayor cantidad de registros usando atrayentes, pero como ya se ha mencionado, éste inventario de mesodepredadores con cámaras-trampa forma parte de un estudio de ecología del comportamiento donde se buscan indicadores de los horarios de actividad de mesodepredadores en vida libre, por lo que se decidió utilizar métodos que no alteraran el comportamiento de los animales.

Tomando en cuenta los resultados obtenidos por las cámaras-trampa, es posible afirmar que las cámaras-trampa pueden ser utilizadas efectivamente en el levantamiento de inventarios de fauna para grupos específicos, como es el caso de los mesodepredadores. En este estudio se logró registrar nueve de las doce especies de mesodepredadores listadas por Ramírez y Martínez (2007) para la RBTC y su área de influencia, es decir, se identificó el 75\% de las especies del área usando métodos indirectos. Por supuesto, es necesario evaluar si se 
utilizan atrayentes o no, pues sin estos el esfuerzo y el tiempo dedicado al inventario es mayor. En todo caso, siempre se requiere de una prospección del área en busca de sitios clave para la fauna, así como apoyarse con el conocimiento de los habitantes del área.

Los estudios de ecología del comportamiento con especies en vida libre usando cámarastrampa para evaluar horarios y patrones de actividad son posibles. Monroy-Vilchis et al. (2011), han establecido que se necesitan por lo menos 11 registros fotográficos independientes por especie para poder definir un patrón de actividad confiable. Considerando que en el presente estudio únicamente Bassariscus astutus obtuvo 12 registros y Canis latrans sólo 10, se decidió calcular los horarios de actividad de las especies considerándolas como un gremio. Los resultados señalan que los mesodepredadores en las áreas comunales de Santo Tomás Otlaltepec, si bien tienen un amplio horario de actividad, tienden a mostrar un mayor desplazamiento en el horario nocturno, el cual inicia en el crepúsculo (18:00 hrs) y termina en el amanecer (06:00 hrs). En los horarios matutino (06:30 - 12:00 hrs) y vespertino (12:00 - 18:00 hrs) las acciones detectables por las cámaras se reducen considerablemente. 


\section{Capítulo II.}

Colecta, identificación y determinación de la función de marcaje de excretas de mesodepredadores

\section{Introducción}

Las excretas de la fauna silvestre, principalmente en el caso de los mamíferos proveen de una gran cantidad de información ecológica como puede ser la presencia, densidad, distribución, dieta, incluso el estado de salud y endocrinología. A la disciplina que estudia las excretas, su naturaleza y la información que aporta con respecto a la fauna se le denomina escatología (Reynolds y Aebischer, 1991). El estudio de las heces provee una base no-invasiva y de bajo costo para determinar la dieta de una especie y evaluar sus relaciones ecológicas (Livingstone et al., 2005).

La escatología puede tener diferentes aplicaciones en los estudios con fauna silvestre. Para estudiar la persistencia de las excretas de carnívoros en el desierto de Sonora y el contenido nutricional en las mismas, Sánchez et al., (2004), colectaron sólo las excretas frescas de $C$. latrans en los caminos de su área de estudio. Posteriormente analizaron los contenidos y compararon la forma y estructura de las excretas de coyotes silvestres con excretas de coyotes en cautiverio, evaluando también el tiempo de persistencia de una excreta a la intemperie, el cual fue de 11 días en promedio. Otro ejemplo es el estudio de Harrison et al., (2004), que realizaron una evaluación de las poblaciones de Vulpes vulpes (zorra del desierto) por medio de la colecta de todas las excretas que encontraron en los caminos aledaños al Río Pecos, Nuevo México. Sus resultados sugieren que, para índices de población relativa, la colecta de excretas por sí misma es poco confiable y se necesitan estudios a largo plazo.

Por medio de las excretas también se pueden analizar las señales odoríferas, que son la principal fuente de transmisión de información entre carnívoros, en particular para aquellos que tienen hábitos nocturnos (Barja y List, 2006).

El marcaje odorífero ha sido definido como la aplicación de secreciones y excreciones por un animal sobre áreas u objetos en su ambiente (Wells y Bekoff, 1981). Entre los cánidos y 
otras especies, el marcaje odorífero puede servir como un mecanismo para el mantenimiento del territorio o de reconocimiento de sexo o como un indicador de la condición sexual, la madurez y sincronía, así como de información interna para orientar a miembros del grupo y dispersar animales que puedan entrar en territorios ocupados (Gese y Ruff, 1997).

Al respecto, Barja et al. (2008) han estudiado acerca del marcaje de Canis lupus signatus en vida libre, encontrando que existe una preferencia en cuanto a la selección del sustrato y de la apariencia física de las plantas seleccionadas para usar como marcaje. Para determinar si una excreta tiene función de marcaje o no toman en cuenta factores como su ubicación en el camino o sendero, si se encuentra a nivel del suelo o por arriba de éste, el tipo de sustrato y la cantidad. En un trabajo similar, Barja y List (2006), analizaron la selección de letrinas de marcaje de Bassariscus astutus, demostrando que la distribución espacial de las letrinas no es aleatoria, sino que se distribuyen con base en el tipo de sustrato y las zonas que hacen más efectivo el marcaje fecal.

El presente estudio se realizó al sur del área de influencia de la RBTC, Puebla, donde la colecta e identificación de excretas ha permitido la identificación exitosa de especies con pocos registros en la zona. Tal es el caso de la nutria de río (Lontra longicaudis), cuya presencia confirmaron Botello et al., (2006), al colectar e identificar excretas de esta especie en el cauce del Río Grande, municipio de Quiotepec, Oaxaca.

En el marco de un estudio de ecología del comportamiento, se colectaron excretas frescas de carnívoros de talla mediana en las áreas comunales de Santo Tomás Otlaltepec, Puebla. A este grupo de mamíferos se le denomina gremio de mesodepredadores.

Usando cámaras-trampa se ha comprobado la presencia de nueve especies de mesodepredadores en el área de trabajo, por lo que la identificación de excretas es mucho más confiable. 


\section{$\underline{\text { Objetivos }}$}

1. Identificar a qué especies pertenecen las excretas de mesodepredadores.

2. Evaluar la función de marcaje de las excretas a lo largo de un ciclo anual.

\section{Método}

\section{Colecta de excretas}

De febrero de 2012 a abril de 2013 se colectaron excretas frescas de mesodepredadores. Se seleccionó un ciclo anual para incluir las temporadas reproductivas y no reproductivas de las especies de interés. Siguiendo recorridos preestablecidos de entre 0.3 y $3.11 \mathrm{~km}$ (Cuadro 1). Se colectaron todas aquellas excretas que tuvieran apariencia de tener menos de 12 horas, las demás fueron levantadas para evitar confusiones en futuras colectas. La frescura de cada excreta se determinó con base en su textura, olor, suavidad y color, según el método propuesto por Barja et al. (2008). Los recorridos de colecta iniciaban en cuanto amanecía y había luz de día.

Para cada muestra se registraron los siguientes datos en una libreta de campo:

a. Clave de muestra. Se asignó una clave y un número consecutivo a cada muestra para su identificación en la base de datos.

b. Especie. El nombre de la especie a la cual correspondía la excreta.

c. Fecha de coleta.

d. Coordenadas geográficas. Para cada excreta se registró su posición con un GPS.

e. Sitio. Los sitios de colecta se clasificaron en: arroyo, vereda o camino principal

f. Características de la excreta. Color, tamaño, contenido general.

g. Características del sustrato. Si la excreta se encontró a nivel del suelo o por arriba del nivel del suelo; si estaba en suelo de tierra, roca desnuda, suelo rocoso o pasto; si se encontraba en una letrina o era una excreta única en el sitio.

h. Función de marcaje. La función marcadora de cada muestra fue determinada con el método modificado a partir de Barja y List (2006) y Barja et al. 
(2008), el cual consiste en evaluar las características relacionadas con la deposición de la excreta: Si se encontraba a más $4 \mathrm{~cm}$ por arriba del nivel del suelo, si estaba en una intersección de dos o más caminos, si había sido depuesta junto a otras excretas con función marcadora y si era conspicua o notable desde un punto de vista a $30 \mathrm{cms}$ del suelo entonces se considera que la muestra tiene una función verdadera de marcaje.

i. Notas sobre la muestra. Notas adicionales registradas en campo.

\section{Identificación de excretas}

Con manuales de campo para la identificación de rastros de fauna silvestre (Bang y Dahlsron, 1974; Murie, 1974; Aranda, 2000) y con ayuda de pobladores del lugar que contaban con experiencia en la cacería y rastreo de la fauna local, se identificó a qué especie pertenecía cada excreta colectada.

Un caso de particular atención fue la diferenciación de excretas de Urocyon cinereoargenteus y Bassariscus astutus, pues suelen tener una alimentación y apariencia similares. Los guías de campo coincidieron con lo mencionado por Aranda (2000) en cuanto a que el olor de las excretas de Urocyon cinereargenteus es más fuerte. También coincidieron en que Bassariscus astutus no suele defecar en caminos y lugares lejanos a los arroyos y cuerpos de agua, por lo que se tomaron estos criterios para definir a qué especie pertenecían las excretas colectadas.

\section{Recorridos de colecta}

Se seleccionaron recorridos de colecta que representaran los hábitats más utilizados por las especies de estudio en caminos, veredas y arroyos, utilizando los métodos descritos por Aranda (2000). Dentro del área de terrenos comunales de Santo Tomás Otlaltepec se seleccionaron los siguientes recorridos (Cuadro 1; Figura 1): 
Cuadro 1. Recorridos para recolección de excretas en el área de estudio.

\begin{tabular}{|c|c|c|c|}
\hline Recorrido & Descripción & $\begin{array}{l}\text { Ancho } \\
\text { promedio }\end{array}$ & $\begin{array}{l}\text { Longitud } \\
\text { aproximada }\end{array}$ \\
\hline Camino principal & $\begin{array}{l}\text { Camino de terracería que parte del } \\
\text { pueblo y llega hasta el sitio conocido } \\
\text { como El Jagüey. Es un camino por } \\
\text { donde pueden circular ocasionalmente } \\
\text { vehículos, tractores y camiones de carga, } \\
\text { pero principalmente transitan, habitantes } \\
\text { del lugar con vacas, caballos y burros } \\
\text { para transportar leña }\end{array}$ & $5 \mathrm{~m}$ & $1.88 \mathrm{~km}$ \\
\hline $\begin{array}{ll}\text { Vereda } & \text { del } \\
\text { Arenal } & \end{array}$ & $\begin{array}{l}\text { Vereda que corre paralela al arroyo de } \\
\text { temporal del Arenal. En esta vereda } \\
\text { circulan comúnmente pastores con hatos } \\
\text { de cabras y ocasionalmente vacas }\end{array}$ & $1.70 \mathrm{~m}$ & $0.49 \mathrm{~km}$ \\
\hline $\begin{array}{l}\text { Vereda de la } \\
\text { Piedra Cruz }\end{array}$ & $\begin{array}{l}\text { Conecta el camino principal con un } \\
\text { arroyo temporal del Arenal. También es } \\
\text { utilizada para pastoreo de cabras y } \\
\text { vacas. }\end{array}$ & $1.70 \mathrm{~m}$ & $0.39 \mathrm{~km}$ \\
\hline Vereda de la Y & $\begin{array}{l}\text { Conecta el camino principal con el } \\
\text { arroyo temporal del Guayabo. Utilizada } \\
\text { principalmente para pastoreo de cabras. } \\
\text { Es lo suficientemente ancha para que } \\
\text { puedan circular vehículos. }\end{array}$ & $3 \mathrm{~m}$ & $0.47 \mathrm{~km}$ \\
\hline $\begin{array}{l}\text { Vereda del Palo } \\
\text { Blanco }\end{array}$ & $\begin{array}{l}\text { Conecta el arroyo de El Guayabo con el } \\
\text { camino principal. Cruza entre } \\
\text { sembradíos y el pastoreo en esta vereda } \\
\text { es poco común. }\end{array}$ & $1.50 \mathrm{~m}$ & $0.30 \mathrm{~km}$ \\
\hline $\begin{array}{ll}\text { Arroyo } & \text { del } \\
\text { Arenal } & \end{array}$ & $\begin{array}{l}\text { Arroyo temporal donde se encuentra un } \\
\text { ojo de agua permanente conocido como } \\
\text { "Agua El Pajarito", aproximadamente a } \\
1 \mathrm{~km} \text { de los límites del pueblo. Este } \\
\text { arroyo tiene paredes que pueden laderas } \\
\text { que pueden tener hasta } 5 \mathrm{~m} \text { de altura. Es } \\
\text { común que sea utilizada para pastorear } \\
\text { vacas, burros y cabras. }\end{array}$ & $8 \mathrm{~m}$ & $3.11 \mathrm{~km}$ \\
\hline $\begin{array}{ll}\text { Arroyo } & \text { del } \\
\text { Guayabo } & \end{array}$ & $\begin{array}{l}\text { Arroyo somero de temporal que se } \\
\text { encuentra al SE del pueblo y corre entre } \\
\text { sembradíos de maíz. Aquí se encuentra } \\
\text { un ojo de agua temporal, } \\
\text { aproximadamente a } 800 \mathrm{~m} \text { de los límites } \\
\text { del pueblo. El pastoreo en este arroyo es } \\
\text { poco común. }\end{array}$ & $2 \mathrm{~m}$ & $0.4 \mathrm{~km}$ \\
\hline
\end{tabular}




\begin{tabular}{|l|l|l|l|}
\hline Recorrido & Descripción & $\begin{array}{l}\text { Ancho } \\
\text { promedio }\end{array}$ & $\begin{array}{l}\text { Longitud } \\
\text { aproximada }\end{array}$ \\
\hline \multicolumn{2}{|l|}{ Longitud total aproximada de recorridos en caminos y veredas: } & $3.53 \mathrm{~km}$ \\
\hline \multicolumn{2}{|l|}{ Longitud total aproximada de recorridos en arroyos: } & $3.15 \mathrm{~km}$ \\
\hline
\end{tabular}

\section{Base de datos de excretas}

Los datos colectados en campo se capturaron en una base de datos (Cuadro 2).

Cuadro 2. Variables y tipo de contenido y formato de las mismas en la base de datos de excretas.

\begin{tabular}{|c|c|c|c|}
\hline Variable & Contenido & Formato & Uso \\
\hline Clave de muestra & $\begin{array}{l}\text { Clave única de cada } \\
\text { muestra }\end{array}$ & Texto & Referencial \\
\hline Especie & $\begin{array}{l}\text { Nombre de la especie a la } \\
\text { cual pertenece la muestra }\end{array}$ & Texto & Estadístico \\
\hline Fecha de colecta & $\begin{array}{l}\text { Día en que se obtuvo la } \\
\text { muestra }\end{array}$ & Fecha & $\begin{array}{l}\text { Referencial } \\
\text { / Estadístico }\end{array}$ \\
\hline Coordenadas & $\begin{array}{l}\text { Coordenadas tomadas con } \\
\text { el GPS o a partir de algún } \\
\text { punto de referencia }\end{array}$ & Texto & Referencial \\
\hline Secas & \multirow{15}{*}{ Uno o cero } & \multirow{15}{*}{ Numérico } & Estadístico \\
\hline Lluvias & & & Estadístico \\
\hline A nivel del suelo & & & Funcional \\
\hline Suelo: Barda o construcción humana & & & Descriptivo \\
\hline Suelo: Roca aislada & & & Descriptivo \\
\hline $\begin{array}{l}\text { Suelo: Roca que sobresale en suelo de roca } \\
\text { desnuda }\end{array}$ & & & Descriptivo \\
\hline Suelo: Roca desnuda & & & Descriptivo \\
\hline Suelo: Suelo rocoso & & & Descriptivo \\
\hline Suelo: Vegetal & & & Descriptivo \\
\hline Suelo: Desnudo & & & Descriptivo \\
\hline Camino principal & & & Descriptivo \\
\hline Vereda & & & Descriptivo \\
\hline Lecho de río & & & Descriptivo \\
\hline Letrina & & & Funcional \\
\hline Cruce de caminos & & & Funcional \\
\hline
\end{tabular}




\begin{tabular}{|c|c|c|c|}
\hline Variable & Contenido & Formato & Uso \\
\hline Sin heces a menos de $2 \mathrm{~m}$ & & & Funcional \\
\hline Más oscura que el suelo. Color llamativo. & & & Funcional \\
\hline Punto por arriba del nivel del suelo & & & Funcional \\
\hline Sobre planta, arbusto o árbol & & & Funcional \\
\hline Gran cantidad & & & Funcional \\
\hline Conspicua & & & Funcional \\
\hline Marcaje & De cero a cuatro & & Categórico \\
\hline Índice de marcaje & Índice de marcaje asignado & Texto & Categórico \\
\hline Notas & $\begin{array}{l}\text { Notas significativas sobre } \\
\text { la excreta }\end{array}$ & Texto & Descriptivo \\
\hline
\end{tabular}




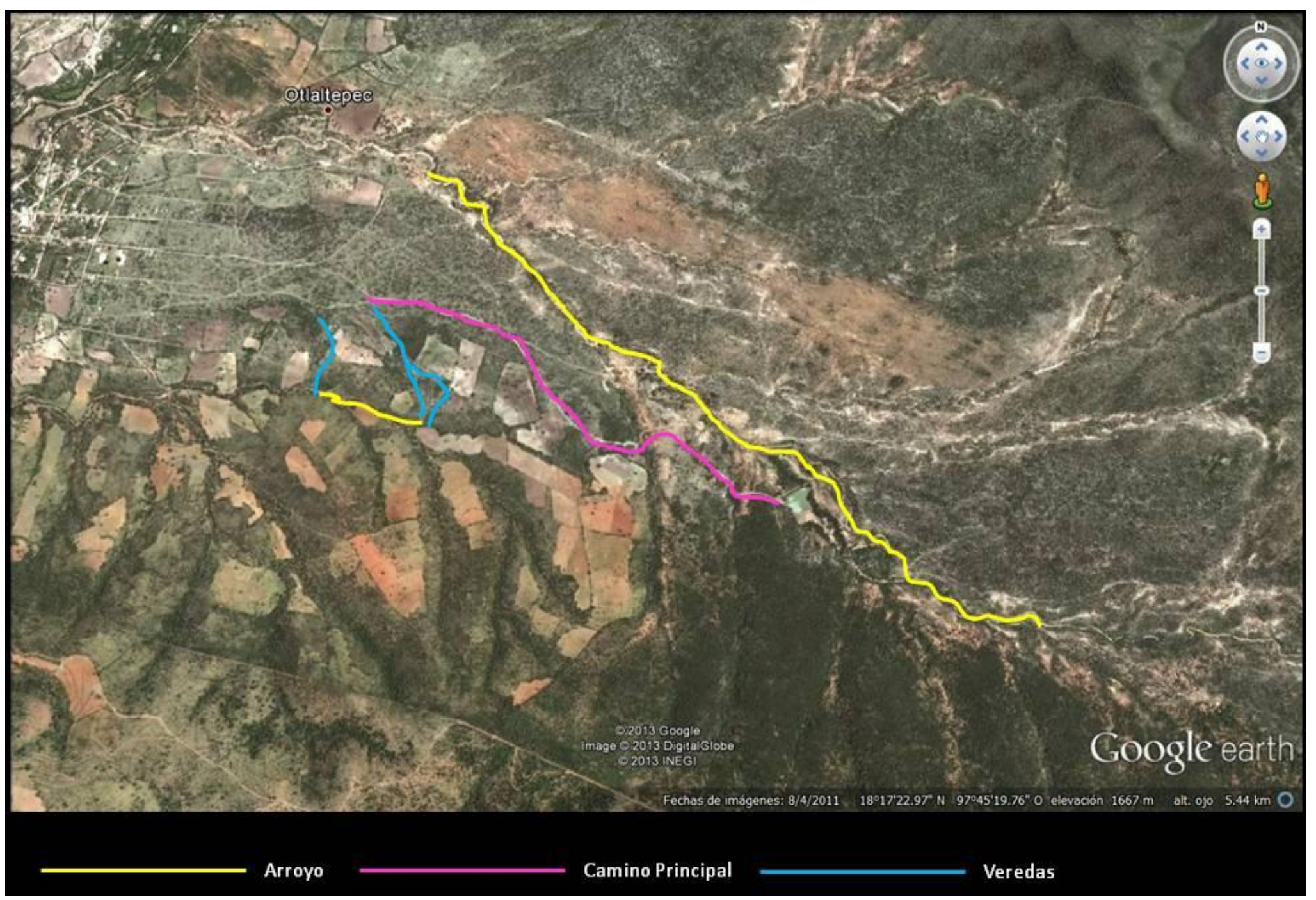

Figura 1. Recorridos de colecta de excretas en la zona de estudio. 


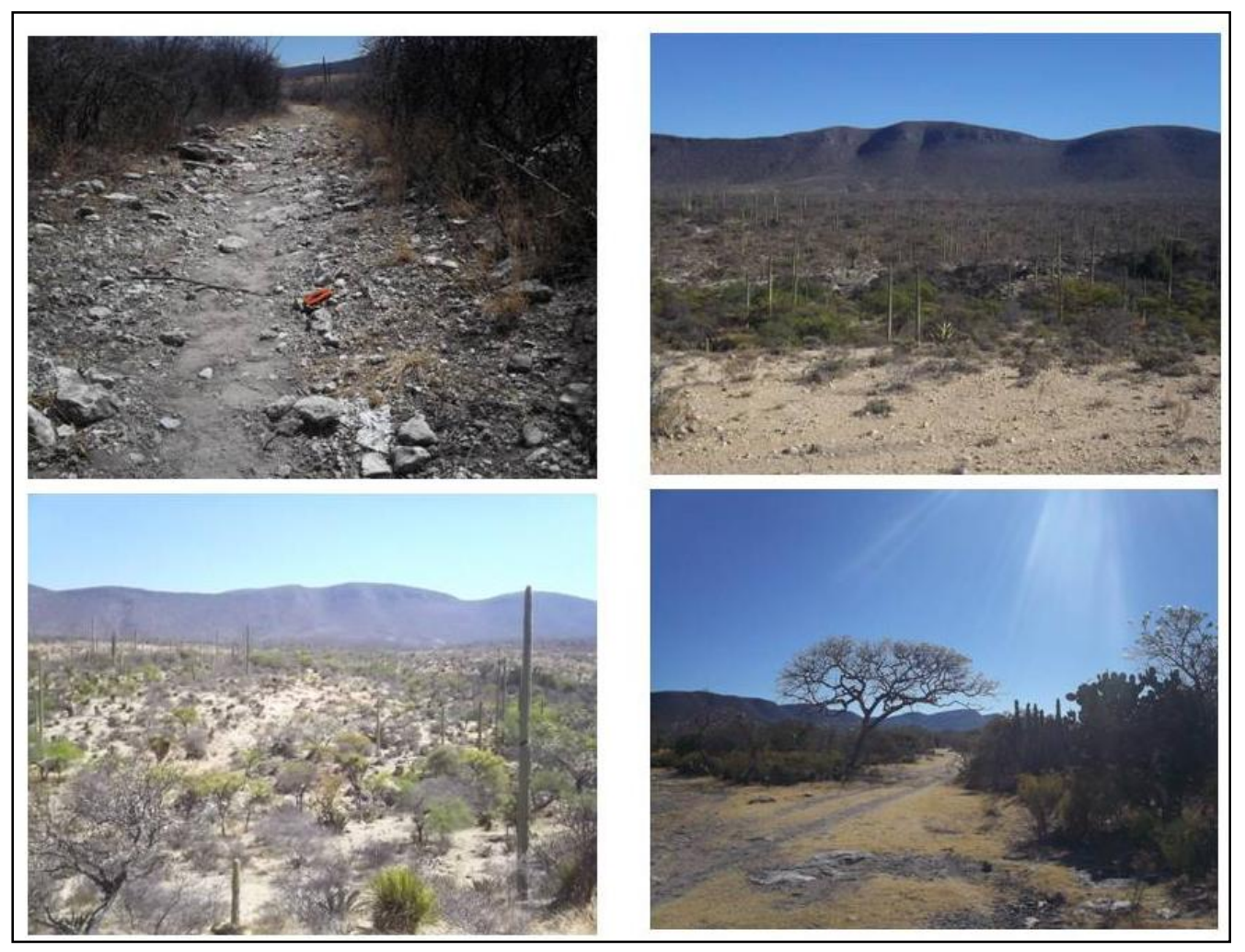

Figura 2. Vistas de los caminos y paisajes en el área de estudio.

\section{Índice de marcaje}

Con el objetivo de homogeneizar la información y poder realizar análisis a cada una de las variables relacionadas con una excreta, se clasificaron estas variables de acuerdo a si representaban una característica descriptiva, estadística o funcional. Las variables con uso funcional permitieron establecer lo que se denominó el índice de marcaje de cada excreta.

Para el presente trabajo se tomaron en cuenta las características de la posición y ubicación exacta de la muestra para establecer el índice de marcaje. Siguiendo los criterios de Barja et al. (2008) se daba un valor de 1 cuando la excreta presentaba características de ser usada como señal: Si se encontraba en un punto al nivel del suelo tenía valor 0 , pero si se encontraba $4 \mathrm{~cm}$ sobre el nivel del suelo en una roca, planta o árbol tenía valor 1; si estaba en un cruce de caminos o si era conspicua desde el punto de vista de los animales también recibía un 1; para definir si una excreta era conspicua, los colectores se colocaron a gatas, lo que permitía tener un punto de vista a $30 \mathrm{~cm}$ del suelo aproximadamente. 
De esta forma, con base en sus características, se logró establecer un índice de marcaje para cada muestra colectada.

Índice de marcaje $=($ Punto por arriba del nivel del suelo + Cruce de caminos + Sobre planta arbusto o árbol + Conspicua)

A partir de esta valoración, una excreta podía tener cuatro diferentes valores a partir de la puntuación acumulada (Cuadro 3)

Cuadro 3. Puntuaciones y valores asignados a cada muestra colectada.

\begin{tabular}{|c|c|}
\hline $\begin{array}{l}\text { Puntuación } \\
\text { acumulada }\end{array}$ & $\begin{array}{l}\text { Índice de } \\
\text { marcaje }\end{array}$ \\
\hline 0 & Nulo \\
\hline 1 & Bedio \\
\hline 2 & Alto \\
\hline 3 & \\
\hline
\end{tabular}

Una vez que se obtuvo el índice de marcaje de cada excreta, se determinó si existía alguna dependencia con los factores relacionados con la misma (Figura 3).

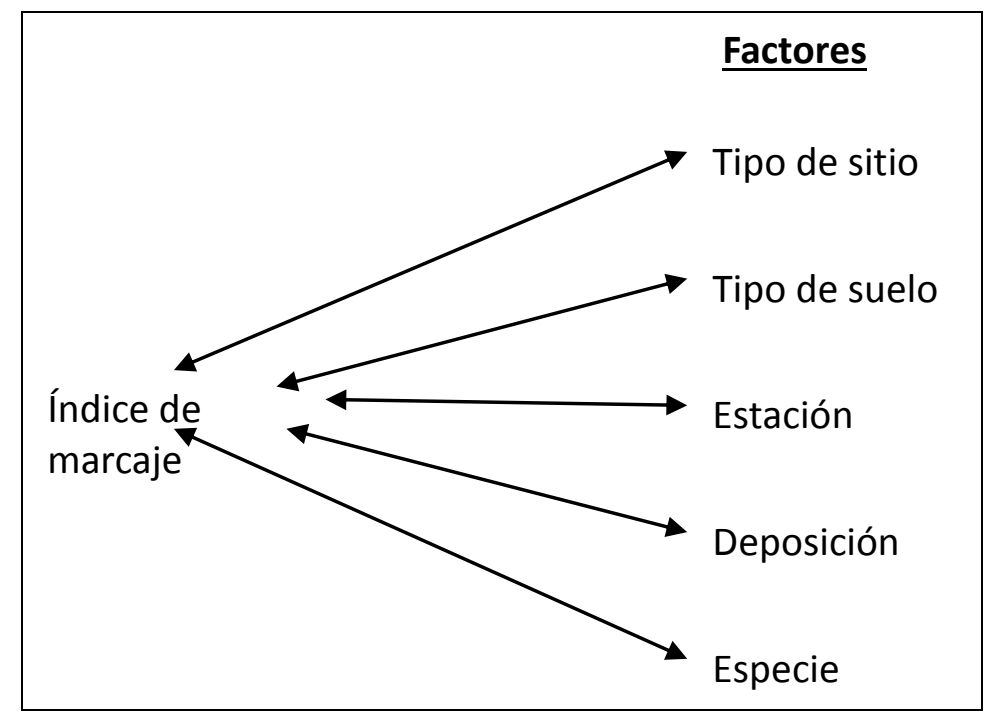

Figura 3. Relación entre variables para el análisis de datos. 


\section{Análisis Estadístico}

Al observar el tipo y la distribución de los datos, se determinó que lo más apropiado era utilizar estadística no-paramétrica, pues además de no obedecer a una distribución no normal, los tamaños de muestra no eran demasiado grandes.

El análisis estadístico no estuvo enfocado de ninguna forma a una interpretación ecológica de la población, pues, como ya se ha mencionado, se colectaron sólo aquellas muestras frescas, descartando aquellas que pudieran tener más de doce horas (Por ello, los cálculos tuvieron por objetivo general relacionar el índice de marcaje con los diferentes factores que pueden influir con el mismo. Para determinar la dependencia entre datos se utilizaron pruebas de $\mathrm{Ji}^{2}$.

Para todos los análisis se utilizó el programa NCSS 07.1.20 (2010).

\section{Clasificación de los datos}

La clasificación de los datos por cada especie a la cual correspondía cada muestra fue la primera y más obvia forma de organización para los datos.

Se consideraron dos estaciones, secas y lluvias, esta última inició en junio de 2012 y terminó a mediados de octubre del mismo año.

Para el análisis estadístico, los datos fueron organizados en categorías, lo que también permitió la organización de los datos en categorías con frecuencias correspondientes. En la base de datos final de frecuencias se resumieron todas las variables en nueve (Cuadro 4).

Cuadro 4. Variables resumidas para análisis estadístico.

\begin{tabular}{|l|l|l|}
\hline Variable & Categorías que integra & Descripción \\
\hline SP & $\begin{array}{l}\text { Bassariscus astutus; } \\
\text { Canis latrans; } \\
\text { Mefítidos; } \\
\text { Procyon lotor; } \\
\text { Urocyon cinereoargentus }\end{array}$ & $\begin{array}{l}\text { Especies o grupos } \\
\text { identificados por medio de las } \\
\text { excretas }\end{array}$ \\
\hline Estación & $\begin{array}{l}\text { Secas } \\
\text { Lluvias }\end{array}$ & $\begin{array}{l}\text { Estaciones climáticas de } \\
\text { referencia }\end{array}$ \\
\hline
\end{tabular}




\begin{tabular}{|l|l|l|}
\hline Nivel & $\begin{array}{l}\text { Arriba; } \\
\text { Suelo }\end{array}$ & $\begin{array}{l}\text { Referencia de la excreta sobre } \\
\text { su posición con relación al } \\
\text { nivel del suelo }\end{array}$ \\
\hline Tipo de suelo & $\begin{array}{l}\text { Desnudo; } \\
\text { Pedregoso; } \\
\text { Roca; } \\
\text { Mampostería; } \\
\text { Vegetal }\end{array}$ & $\begin{array}{l}\text { Tipo de suelo sobre el cual se } \\
\text { encontró la excreta }\end{array}$ \\
\hline Sitio de colecta & $\begin{array}{l}\text { Arroyo; } \\
\text { Camino; } \\
\text { Cruce; } \\
\text { Vereda }\end{array}$ & $\begin{array}{l}\text { Descripción general del sitio } \\
\text { sobre el cual se encontró la } \\
\text { excreta }\end{array}$ \\
\hline Deposición & $\begin{array}{l}\text { Aislada; } \\
\text { Letrina }\end{array}$ & $\begin{array}{l}\text { Referencia de la excreta con } \\
\text { relación a otras en el lugar de } \\
\text { colecta }\end{array}$ \\
\hline Cantidad & $\begin{array}{l}\text { Poca; } \\
\text { Considerable }\end{array}$ & $\begin{array}{l}\text { Clasificación de la excreta } \\
\text { dependiendo de la cantidad }\end{array}$ \\
\hline Índice de marcaje & $\begin{array}{l}\text { Nulo; } \\
\text { Bajo; } \\
\text { Medio; } \\
\text { Alto }\end{array}$ & $\begin{array}{l}\text { excreta dependiendo de los } \\
\text { respecto al acumarcaje }\end{array}$ \\
\hline Frecuencia & Numérico & $\begin{array}{l}\text { Número de excretas que } \\
\text { cumplen con los mismos } \\
\text { criterios }\end{array}$ \\
\hline & & \\
\hline
\end{tabular}

\section{$\underline{\text { Resultados }}$}

\section{Estadística descriptiva}

\section{Muestras colectadas por especie}

Del 16 de febrero de 2012, al 17 de abril de 2013, se recopilaron 136 muestras frescas de mesodepredadores, correspondientes a siete especies y una familia (Cuadro 5). Debido a que no fue posible diferenciar las excretas de Conepatus leuconotus y de Mephitis macroura, todas las excretas de zorrillo fueron organizadas en un grupo único correspondiente a la Familia Mefítidae.

La especie con menor cantidad de muestras fue el Lynx rufus (1), a la cual le siguen los mefítidos (7). Procyon lotor (15) y Bassariscus astutus (20) tuvieron una representación similar. Las especies de la cuales se colectó la mayor cantidad de muestras fue Urocyon cinereoargenteus (41) y Canis latrans (52) (Figura 4). 


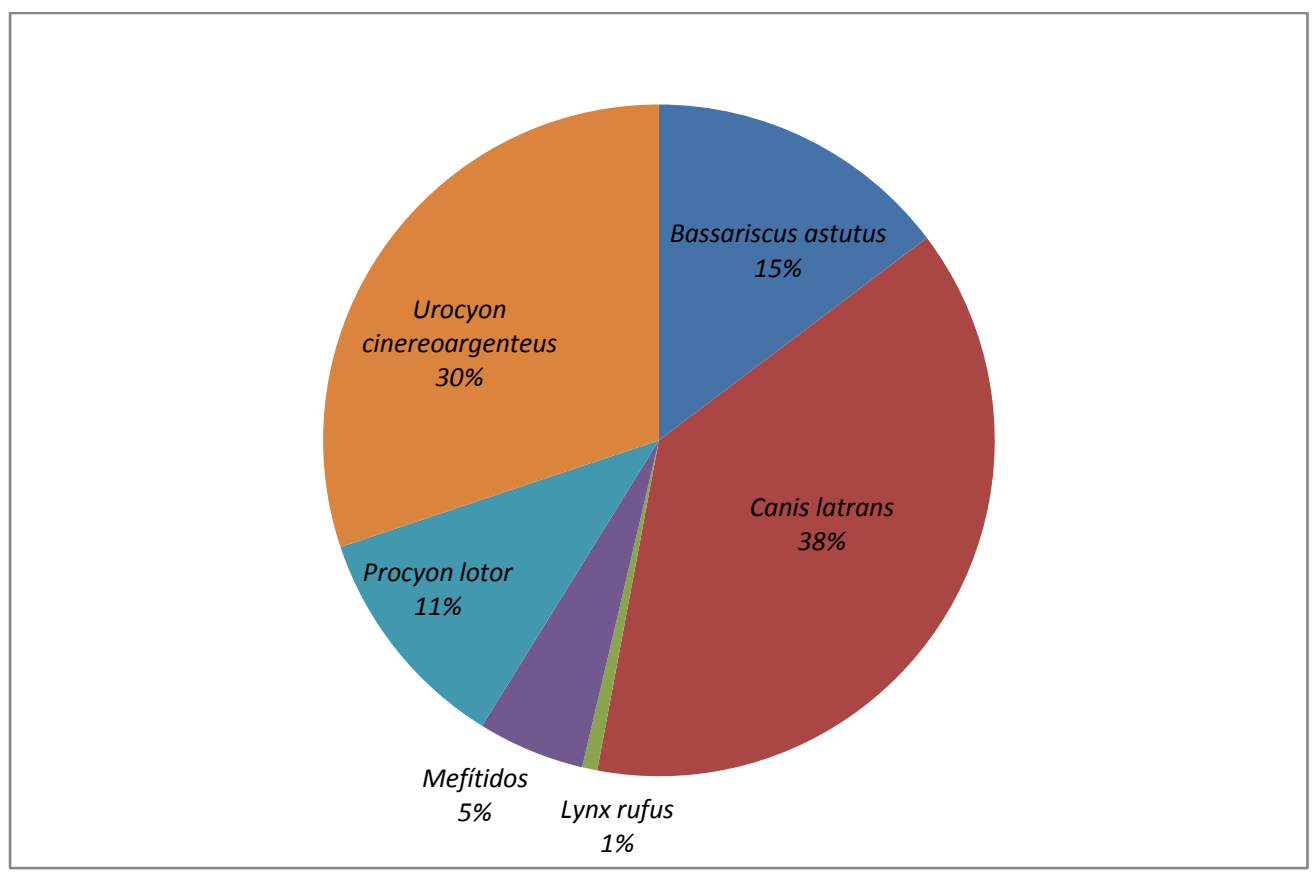

Figura 4. Total de muestras por especie colectadas en el periodo de estudio.

\section{Pruebas de $\mathrm{Ji}^{2}$ para cada uno de los factores que influyen en el marcaje}

Para todas los análisis de marcaje se realizaron pruebas de $J i^{2}$ con un nivel de significancia de $0.05(p=0.05)$. El postulado básico para las hipótesis en esta prueba es que si Ho se cumple (valor calculado de $J i^{2} \leq$ valor crítico de $J i^{2}$ ), los factores son independientes; de lo contrario si $\mathrm{HO}$ se rechaza (valor calculado de $J i^{2}>$ valor crítico de $J i^{2}$ ), son dependientes.

En el primer caso se analizó el marcaje por tipo de sitio y se encontró que el marcaje tiene una fuerte dependencia con el tipo de sitio (Cuadro 5). Los caminos y las veredas fueron los lugares donde se encontraron excretas con los mayores índices de marcaje aunque con frecuencias bajas. Las mayores frecuencias se encontraron en las veredas y los arroyos aunque los índices son menores (Figura 5).

Cuadro 5. Estadísticos de $\mathrm{Ji}^{2}$ para índice de marcaje por tipo de sitio.

\begin{tabular}{|l|l|l|}
\hline Estadístico & Valor & Conclusión \\
\hline Valor calculado de $J i^{2}$ & 49.056298 & \\
\hline Valor crítico de $J i^{2}$ & 16.919 & \\
\hline Grados de libertad & 9 & \\
\hline Nivel de Probabilidad (P) & 0.000000 & Se rechaza Ho \\
\hline
\end{tabular}




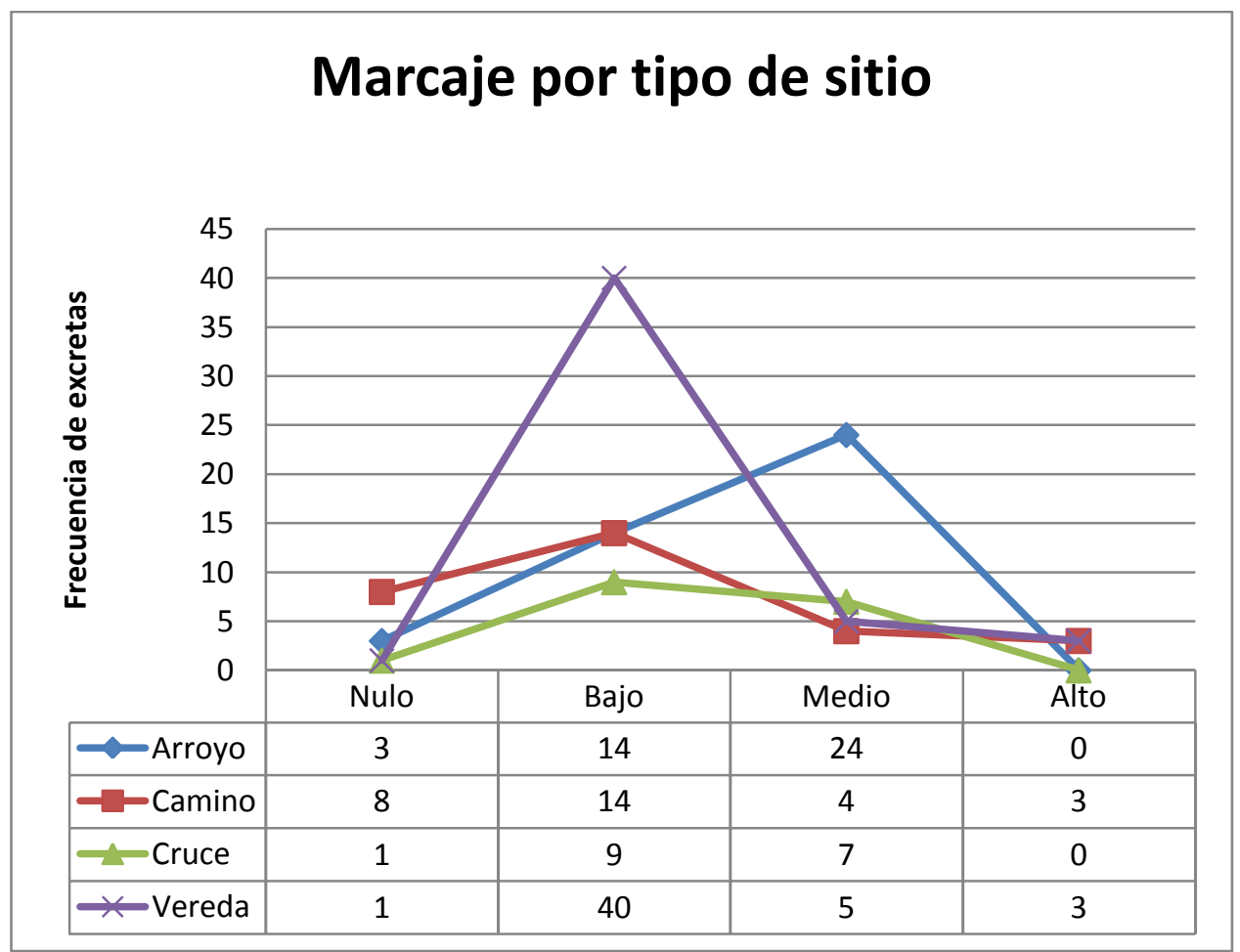

Figura 5. Marcaje por tipo de sitio.

También se analizó la relación entre el tipo de suelo donde fue depuesta la excreta y el índice de marcaje. Se encontró una fuerte dependencia entre ambos factores (Cuadro 6). Las excretas depuestas sobre plantas fueron aquellas que aportaron los valores más altos a la prueba (Figura 6).

Cuadro 6. Estadísticos de $\mathrm{Ji}^{2}$ para índice de marcaje por tipo de suelo.

\begin{tabular}{|l|l|l|}
\hline Estadístico & Valor & Conclusión \\
\hline Valor calculado de $J i^{2}$ & 79.676038 & \\
\hline Valor crítico de $J i^{2}$ & 21.026 & \\
\hline Grados de libertad & 12 & \\
\hline Nivel de Probabilidad (P) & 0.000000 & Se rechaza Ho \\
\hline
\end{tabular}




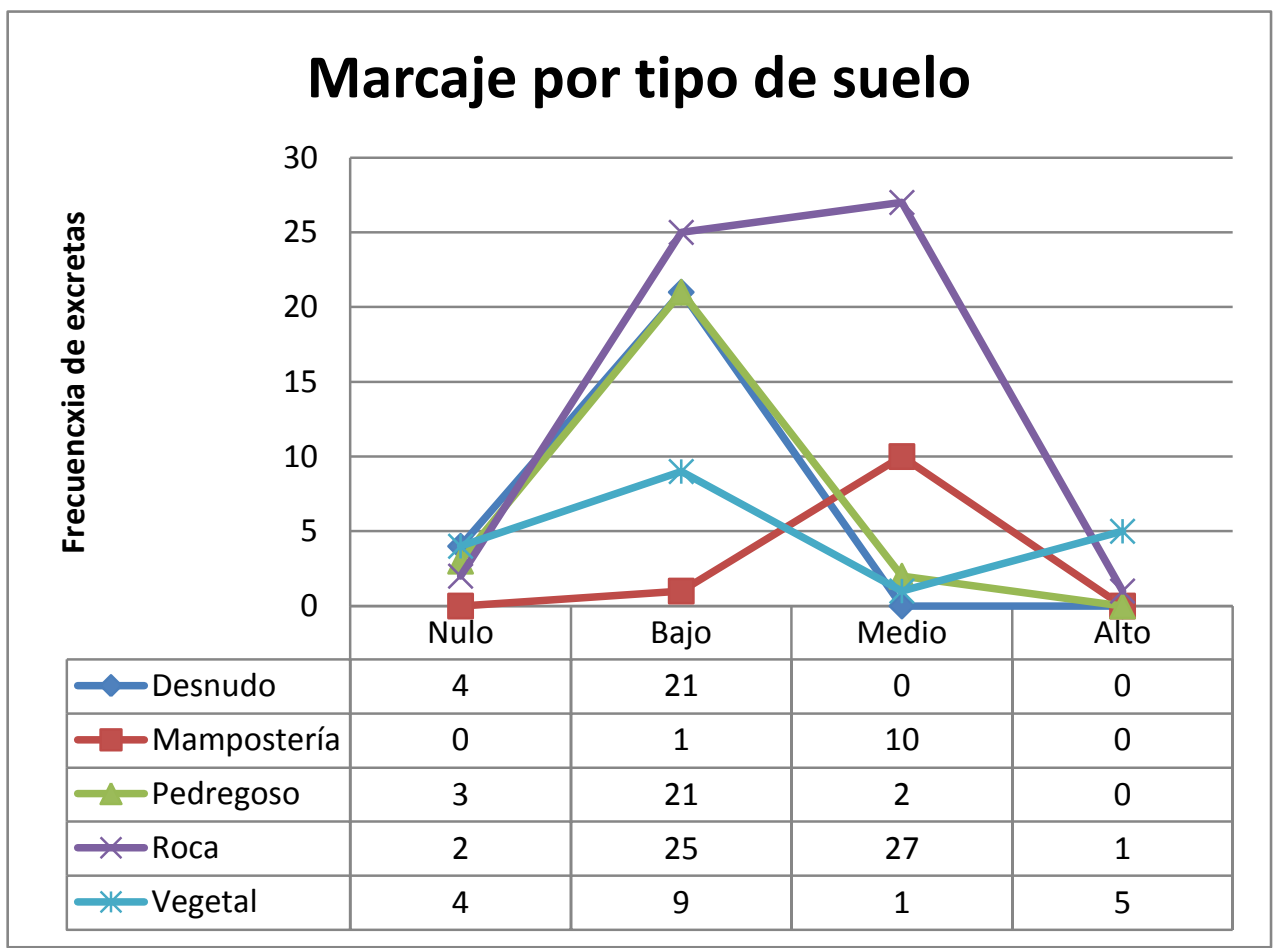

Figura 6. Marcaje por tipo de suelo.

También se analizó la dependencia entre el índice de marcaje de cada excreta y el tipo de deposición, es decir, si se trataba de una excreta aislada o se encontraba en una letrina. Ninguna de las excretas colectadas en letrinas obtuvo un índice de marcaje nulo (Figura 8). La prueba de $J i^{2}$ señala que existe dependencia entre el índice y el tipo de deposición (Cuadro 7).

Cuadro 7. Estadísticos de $\mathrm{Ji}^{2}$ para índice de marcaje por tipo de deposición.

\begin{tabular}{|l|l|l|}
\hline Estadístico & Valor & Conclusión \\
\hline Valor calculado de $J i^{2}$ & 24.573940 & \\
\hline Valor crítico de $J i^{2}$ & 7.815 & \\
\hline Grados de libertad & 3 & \\
\hline Nivel de Probabilidad (P) & 0.000019 & Se rechaza Ho \\
\hline
\end{tabular}




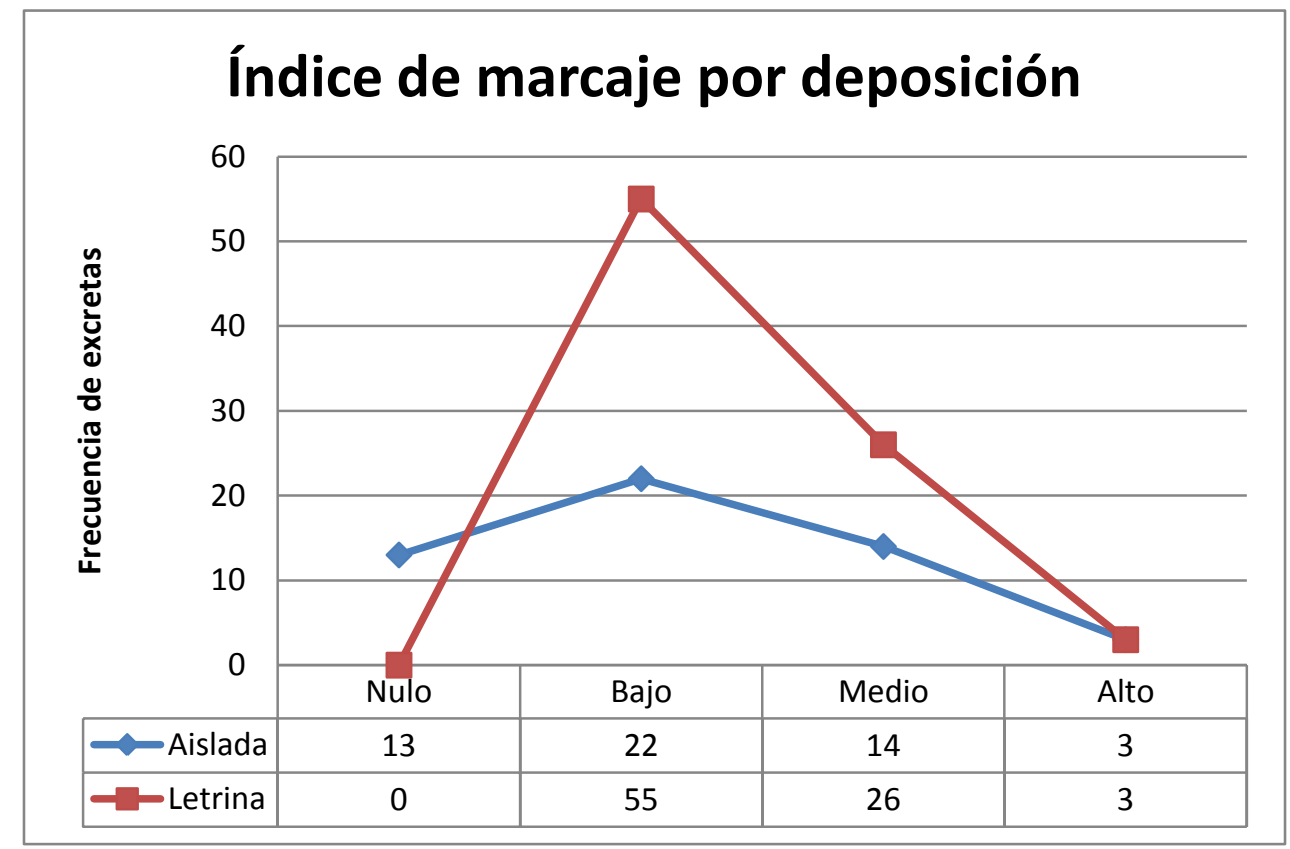

Figura 7. Marcaje por tipo de deposición.

También se consideró la posible dependencia de las estaciones de secas y lluvias con el índice de marcaje (Cuadro 8). Los resultados indican que ambos factores son independientes, de forma que el marcaje podría tener índices similares en ambas temporadas (Figura 8).

Cuadro 8. Estadísticos de $\mathrm{Ji}^{2}$ para índice de marcaje por estación.

\begin{tabular}{|l|l|l|}
\hline Estadístico & Valor & Conclusión \\
\hline Valor calculado de $J i^{2}$ & 2.000000 & \\
\hline Valor crítico de $J i^{2}$ & 3.841 & \\
\hline Grados de libertad & 1 & \\
\hline Nivel de Probabilidad (P) & 0.157299 & Se acepta Ho \\
\hline
\end{tabular}




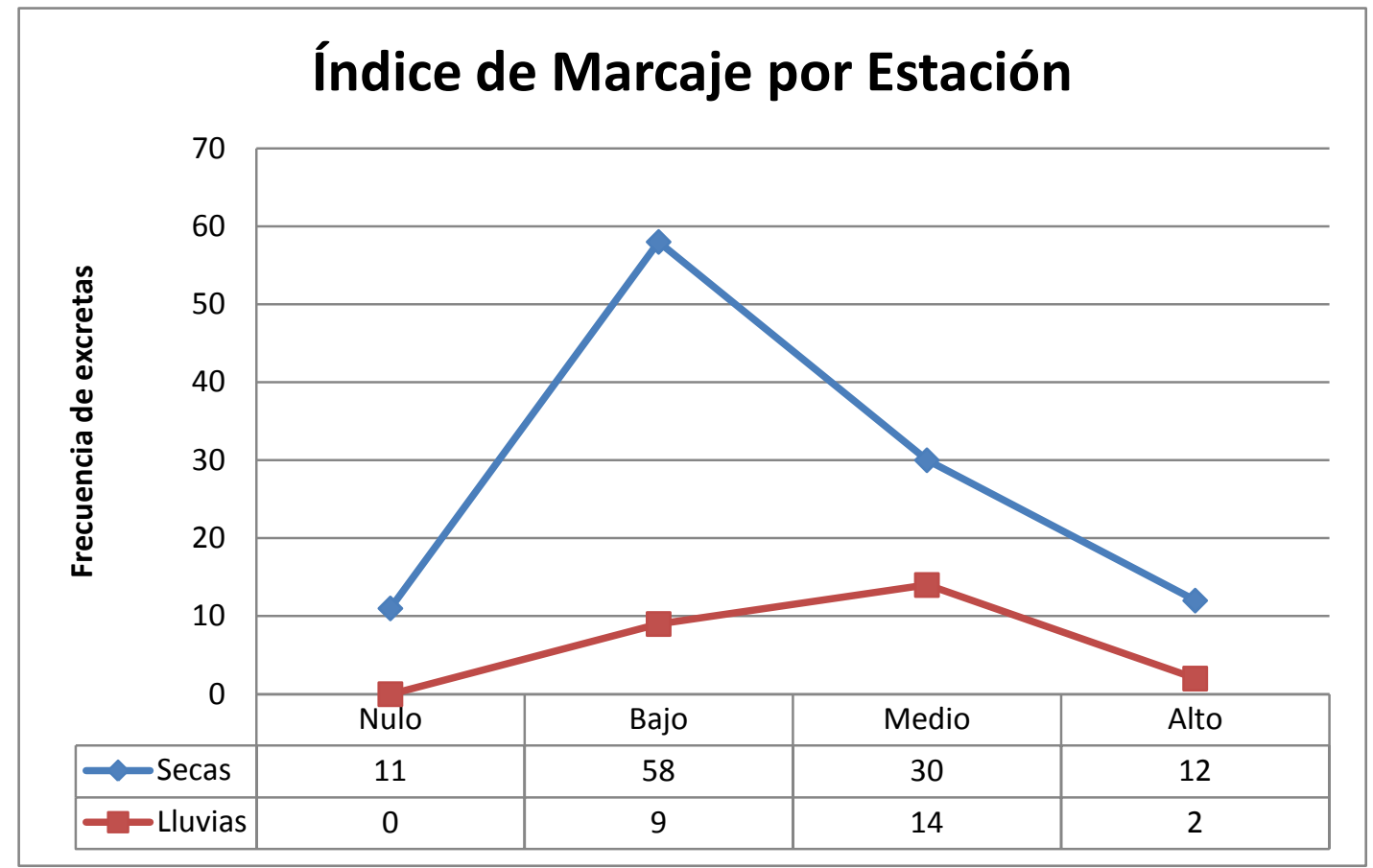

Figura 8. Marcaje por tipo de estación.

Finalmente se analizó la relación entre el índice de marcaje y las diferentes especies de mesodepredadores (Cuadro 9). La prueba indica que no se puede rechazar la independencia entre el marcaje y la especie, es decir, cada especie podría tener índices de marcaje similares (Figura 9).

Cuadro 9. Estadísticos de $\mathrm{Ji}^{2}$ para índice de marcaje por especie.

\begin{tabular}{|l|l|l|}
\hline Estadístico & Valor & Conclusión \\
\hline Valor calculado de $J i^{2}$ & 21.745882 & \\
\hline Valor crítico de $J i^{2}$ & 24.996 & \\
\hline Grados de libertad & 15 & \\
\hline Nivel de Probabilidad (P) & 0.114642 & Se acepta Ho \\
\hline
\end{tabular}




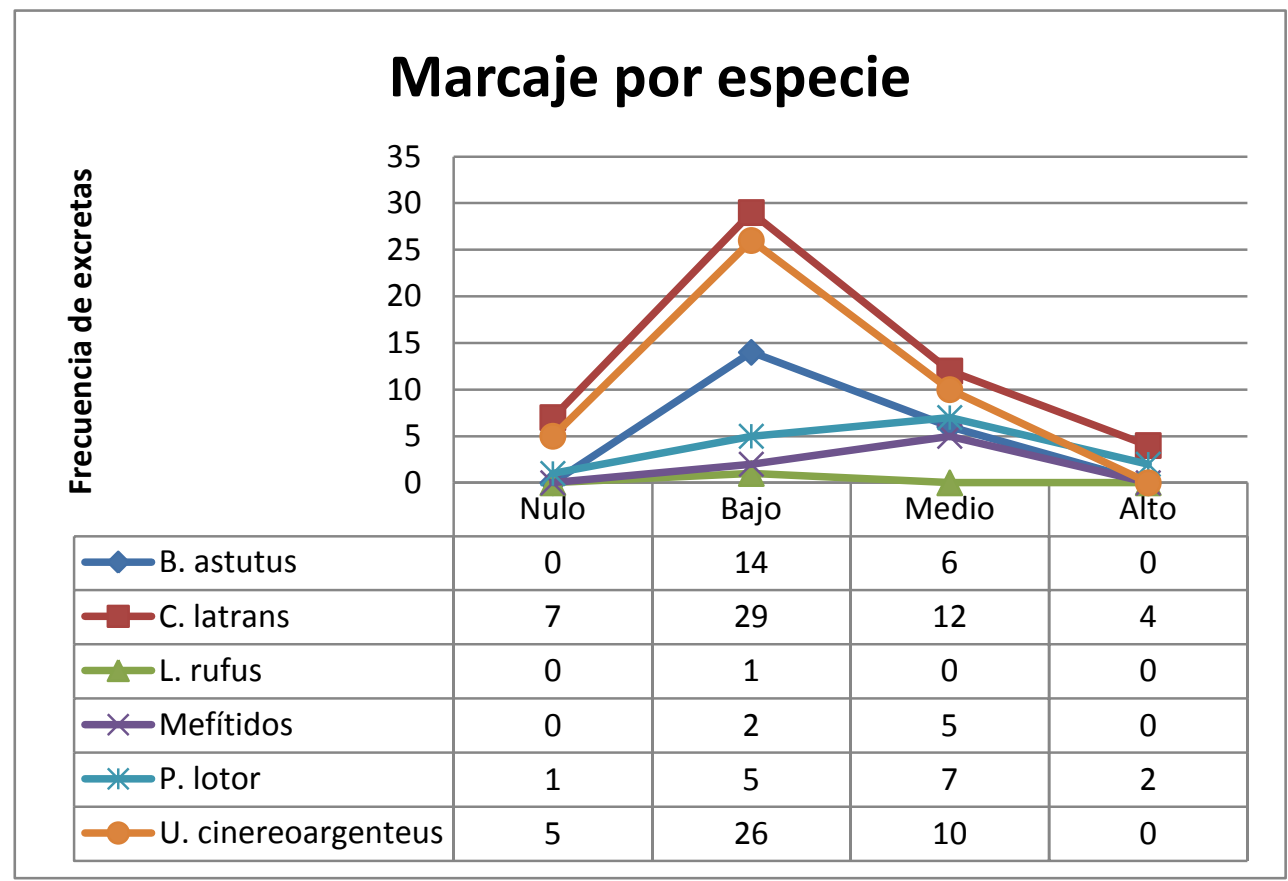

Figura 9. Índice de marcaje por especie.

\section{Discusión y Conclusiones}

A pesar del muestreo dirigido sólo a excretas frescas, el hecho de que las especies que aportaron más muestras al estudio fueron Canis latrans y Urocyon cinereoargenteus podría representar el papel dominante que juegan como depredadores tope en el gremio estas especies, pues demuestran mayor actividad y rango de desplazamiento en el área de estudio (Ritchie y Johnson, 2009). Sin embargo, esto no puede probarse con el método utilizado y no fue uno de los objetivos de este trabajo determinar la dominancia de las especies.

El $74.26 \%$ de las muestras se colectaron en la estación de secas. Esto no significa de ninguna manera un esfuerzo de muestreo mayor por parte de los colectores o una mayor tasa de defecación por parte de los animales.

Una de las explicaciones posibles de por qué se colectaron menos muestras entre los meses de junio-octubre tiene que ver con la disponibilidad de agua superficial, pues desde diciembre de 2011 hasta junio de 2012, no llovió en el área, por lo que los ojos de agua, los charcos y el jagüey estaban ya prácticamente secos en abril. Esto obligaría a las especies más pequeñas de mesodepredadores, como Procyon lotor, Bassariscus astutus y los 
mefítidos, a limitar su ámbito hogareño a sitios con agua disponible. Otra posibilidad sería que durante la estación de lluvias, la cual inició en junio y terminó a mediados de octubre de 2012, gran parte de las excretas en esa temporada fueran arrastradas por la lluvia, reduciendo así el número de muestras posibles de encontrar. Finalmente, también hay que considerar que ante la escases de alimento en los meses de abril a junio, algunas especies como Didelphis virginiana se alimentan comúnmente de las excretas de otros animales (Livingstone et. al., 2005).

En lo correspondiente a los sitios de colecta, se encontró la mayor cantidad de muestras en las veredas (36.03\%), seguidas de los arroyos (30.15\%). Aún y cuando en este estudio sólo se colectaron las muestras frescas, esto bien podría ser un indicador de que los sitios previamente mencionados son los más utilizados por los mesodepredadores en el área de estudio.

El índice de marcaje medio fue el que obtuvo una mayor cantidad de muestras (40.74\%), seguido de alto (20.74\%). Ciertamente la "calificación" asignada a cada excreta dependió mucho del criterio de los colectores, pero hay que enfatizar el hecho de que los valores usados para asignar el índice de marcaje final, son datos concretos y cuantificables, tal como el método usado por Barja et al. (2008) para asignar calificaciones a las excretas de Canis lupus signatus (lobo ibérico). La principal diferencia entre el método de Barja y este, es que en su estudio utilizaron una calificación dicotómica, mientras que en este, una excreta podía recibir cuatro diferentes categorías.

Al buscar una relación entre sitio de colecta e índice de marcaje, se encontró dependencia entre ambas variables (Cuadro 5, Figura 5), es decir, el marcaje necesariamente depende del tipo de sitio, pues de acuerdo al método de clasificación para valorar las excretas, los índices con valor alto se ubicaron únicamente en los caminos $(2.20 \%)$ y veredas $(2.20 \%)$.

También se encontró dependencia entre el tipo de suelo y el índice de marcaje (Cuadro 6, Figura 6), pues, de acuerdo al método utilizado, las excretas con índices de marcaje más altos muestran tendencia a encontrarse en los sustratos rocosos $(1.36 \%)$ y vegetales (6.8 $\%)$. Esto puede quedar explicado si consideramos que las excretas con mayor índice de marcaje se encuentran por arriba del nivel del suelo, por lo tanto, si uno de los 
mesodepredadores busca marcar por medio de la defecación, hacerlo sobre una roca que sobresale puede ser una de las mejores estrategias.

En el análisis de tipo de deposición e índice de marcaje (Cuadro 7, Figura 7), también se observa dependencia entre ambas variables, pues si bien, tanto las excretas aisladas como aquellas depuestas en letrinas tienen las mismas frecuencias (4.08\%), la mayoría de las excretas con valores medios $(35.36 \%)$ y bajos se encontraron en letrinas $(74.8 \%)$.

Uno de los factores que demostró independencia con relación al índice de marcaje, fue la estación en la cual se colectó una muestra. Aquí se puede observar claramente la diferencia entre la cantidad de muestras colectadas en la estación de secas (111) y la de lluvias (25). Ya se han explicado los posibles factores que podrían influir al respecto. La significancia de este análisis radica en que los mesodepredadores silvestres con una distribución cercana al neotrópico pueden presentar pautas de comportamiento relacionadas con un fotoperiodo y estacionalidad más regulares que los de latitudes más altas (Bronson, 2009). La independencia señalada por la prueba de $J i^{2}$ (Cuadro 9) sugiere que el índice de marcaje puede ser similar en ambas estaciones. En este caso, por lo menos en lo que corresponde al hecho de marcar por medio de la excreción, se podría decir que es un comportamiento que se mantiene regular sin importar la estación.

Finalmente, otro análisis que también demostró independencia fue el de la especie y el índice de marcaje. Al igual que con los otros análisis se realizó la prueba de $J i^{2}$ para determinar si existía independencia entre ambas variables. Puesto que el valor calculado de $J i^{2}$ es menor que el valor crítico, se acepta H0, y con ello se acepta que ambas variables son independientes. Esto podría explicarse porque al ser mamíferos territoriales cada especie necesita marcar su territorio y por ello el comportamiento de marcaje puede ser similar para todas las especies.

Este estudio debería tomarse en forma exploratoria, pues no hay trabajos que relacionen la función de marcaje de una excreta de estas especies con factores ambientales o con momentos reproductivos específicos, y ciertamente, los resultados obtenidos aquí necesitan abordarse con estudios a largo plazo. Una continuación de este trabajo sería valorar las 
hormonas reproductivas en las excretas a lo largo del ciclo anual y determinar si existe una relación con el índice de marcaje de cada excreta. 


\section{Capítulo III}

\section{Variación anual de hormonas esteroides en heces de una comunidad de mesodepredadores silvestres en Santo Tomás Otlaltepec, municipio de Atexcal, Puebla}

\section{Introducción}

Desde hace mucho tiempo se ha establecido que las hormonas esteroides sexuales (HES) regulan no sólo el patrón copulatorio del macho y del estro (celo) en la hembra, sino también se relacionan con otros aspectos de la conducta sexual, como la competencia intraespecífica (Beach, 1970; Asa, 1996), de aquí la utilidad de determinar los perfiles de las HES al desarrollar programas de conservación de especies (Soto et al., 2004).

Uno de los principales problemas que se enfrenta el investigador al estudiar procesos endocrinos de la biología reproductiva en mamíferos silvestres, es la obtención de muestras repetidas y consistentes ya sea de sangre, orina y/o la realización de frotis vaginales en las hembras, pues estos métodos implican serios problemas de manejo en los animales. Además, estos procedimientos pueden intensificar el estrés en los individuos dando por resultado una alteración en las concentraciones de hormonas esteroides (Soto et al., 2004).

Para estudios de endocrinología, el método que definitivamente tiene el menor efecto sobre los organismos estudiados, es la colecta de excretas. Éste puede tener varias aplicaciones: i) La búsqueda y colecta de excretas en un área determinada, a lo largo de un transecto o recorrido, permiten estimar tamaños poblacionales, abundancias, ámbitos hogareños y uso de hábitat de una especie determinada; ii) También permiten determinar la distribución y estructura de comunidades de mamíferos; iii) Determinación del estado reproductivo de los organismos y del estrés fisiológico debido al manejo y prácticas de mantenimiento, uso que se ha limitado por mucho tiempo a las rutinas de manejo en zoológicos (Valdespino et al., 2007).

La obtención de hormonas para su cuantificación a partir de muestras fecales es un método que resulta lógico, puesto que el intestino es el órgano principal de desactivación de las hormonas. Las hormonas pasan al intestino emulsificadas en los ácidos biliares, lo cual permite que sean eliminados en la materia fecal. Otras porciones son eliminadas en la orina después de ser filtradas en los riñones. Las hormonas esteroides se eliminan como tales o 
como metabolitos y su tasa de excreción y metabolismo varía de acuerdo a la físiología de cada especie (Nelson, 2000; Valdespino et al., 2007).

Es justamente esta ruta fisiológica la que permite determinar el funcionamiento gonadal y adrenal de un organismo por métodos no-invasivos. Al obtener excretas de los organismos de interés y evaluando en ellas las concentraciones de hormonas esteroides es posible conocer el estado de un organismo sin necesidad de capturarlo (Valdespino et al. 2007). Esto permite que las concentraciones de progesterona, testosterona y estradiol se puedan obtener por la técnica de ensayo inmunológico a partir de muestras fecales (Heymann et al., 2004; Soto et al., 2004).

Las técnicas de inmunoensayo enzimático (EIA, por sus siglas en inglés enzyme immunoassay), que se utilizan comúnmente en estos estudios, se constituyen en métodos analíticos que utilizan una enzima como marcador para amplificar la señal obtenida de la reacción entre un antígeno y un anticuerpo; en función de la necesidad o problema a resolver, el "analito" puede ser tanto el antígeno o el anticuerpo, para lo cual se emplean diferentes formatos. Las técnicas basadas en inmunoensayos permiten la cuantificación de analitos incluso a niveles de traza sin la necesidad de laboriosos procedimientos de purificación y/o concentración de la muestra, debido fundamentalmente a dos factores: i) el poder discriminante característico de los anticuerpos, y ii) la elevada actividad catalítica y sensibilidad enzimática en el caso de los inmunoensayos de enzimas ligadas. Estas técnicas se distinguen por su buena sensibilidad, por el elevado número de aplicaciones y su simplicidad (Betancur et al., 2006; Rodríguez, 2008)).

El mayor beneficio de emplear excretas para hacer seguimientos de perfiles hormonales es que el procedimiento de colecta puede extenderse por períodos largos sin necesidad de manipular - estresar- a los animales, lo cual es muy conveniente cuando los eventos que desean estudiarse son poco frecuentes, tienen lugar por períodos prolongados, o la disponibilidad de sangre que se puede colectar es limitada. Otra ventaja tiene que ver con el hecho de que la concentración de metabolitos es, en general, de 2 a 4 órdenes de magnitud mayor que la de los esteroides parentales en sangre. Por lo tanto, permiten el uso de kits o estuches comerciales para efectuar mediciones manuales o automatizadas (Nelson, 2000; Valdespino et al., 2007). 
Esta técnica se utiliza principalmente con animales en cautiverio, como el estudio realizado por Soto et al. (2004), donde, por medio de EIA, se realizó la valoración de progesterona, testosterona y estradiol en excretas de una pareja (hembra y macho) de C. lupus baileyi, durante el invierno y la primavera. Los resultados se expresaron en perfiles hormonales a partir de los promedios de las cuantificaciones. Para ambos, la variación de hormonas esteroides (HES) resultó ser de tipo cíclico. Sin embargo, para la hembra, la progesterona mostró incrementos de concentración significativos durante la segunda semana de enero y la segunda semana de marzo.

Rudert et al. (2011) realizaron el perfil hormonal del perro mapache (Nyctereutes procyonoides) a lo largo de todo el año utilizando la técnica de cromatografía líquida de alta resolución (HPLC). Los resultados también fueron expresados en gráficas de cajas y bigotes a partir de pruebas de Kruskal-Wallis para observar la distribución anual de los datos. Los niveles de testosterona en los machos, se mantuvieron en una línea base de abril hasta septiembre, comenzando a elevarse en octubre y alcanzando un pico máximo en febrero. Para el caso de las hembras, se detectaron estrógenos elevados en marzo, al igual que un incremento en la concentración de progesterona que se mantuvo desde de marzo a mayo, con su posterior disminución.

Entre los estudios más recientes de las hormonas esteroides en heces de especies en vida libre, se encuentran los trabajos de de Barja et al., (2006, 2008), en el cual colectaron 59 excretas frescas $(<12 \mathrm{~h}$ ) del lobo Ibérico Canis lupus signatus, registrando los lugares donde eran halladas y por medio de la técnica de RIA cuantificaron los niveles de metabolitos de cortisol, testosterona, progesterona y estradiol, encontrando una relación directa entre las hormonas sexuales y la función de marcaje de una excreta.

La mayoría de los trabajos relacionados con la reproducción de mesodepredadores silvestres se han realizado en latitudes correspondientes al hemisferio norte, donde los cambios estacionales son muy marcados y pueden influir en el estado fisiológico de los animales (McManus, 1974; Bekoff, 1977; Lotze y Anderson, 1979; Fritzell y Haroldson, 1982; Hwang y Larivière, 2001; Dragoo et al., 2003). Son precisamente las condiciones ambientales las que han llevado a las especies a tener plasticidad en sus respuestas y a desarrollar estrategias fisiológicas que permitan maximizar su éxito reproductivo. El clima 
es más estable a lo largo del año mientras más cerca se está del ecuador, lo que puede representar una variación en las temporadas reproductivas de especies de mamíferos con respecto a las poblaciones más septentrionales en las cuales la reproducción se restringe a un período reducido del año, es decir, tienen una estacionalidad muy definida (Malpaux, 2006; Bronson, 2009; Valdespino et al., 2007). Por ello, trabajos como este son esenciales para aumentar el conocimiento de la fisiología, reproducción, distribución y comportamiento de los mesodepredadores silvestres en centro y Sudamérica.

No se han encontrado trabajos de endocrinología en mesodepredadores en la zona de estudio, por lo que este trabajo e investigación debe ser considerado como exploratorio, con el ánimo de determinar qué tan factible es la aplicación de esta técnica con especies en vida libre, cuáles son sus aportaciones y limitaciones.

\section{Objetivos}

- Realizar la cuantificación de hormonas esteroides en las excretas de mesodepredadores.

- Establecer la distribución de las concentraciones de las hormonas esteroides fecales a lo largo de un año para cada una de las especies de mesodepredadores.

\section{Método}

\section{Colecta de excretas}

Como ya se ha mencionado, la colecta se realizó de febrero de 2012 a abril de 2013 para cubrir un ciclo anual incluir la temporada reproductiva y no reproductiva de los mesodepredadores del área. Sólo se colectaron excretas frescas, con 12 horas de deposición o menos. Para determinar la frescura de cada excreta se utilizó el método propuesto por Barja et al. (2008). Al amanecer se iniciaban los recorridos, para tener mayor posibilidad de encontrar excretas frescas y aprovechar lo más posible la luz del sol. Cada excreta se colectó y se colocó en un frasco de plástico con $10 \mathrm{ml}$ de etanol al 70\%. Las muestras se conservaron en refrigeración hasta su procesamiento.

En el capítulo II también se describen detalladamente los datos que se registraron en libreta de campo para cada muestra que se colectada. 
Si bien en la zona se registraron por medio de fototrampeo, las especies de zorrillo Conepatus leuconotus y Mephitis macroura, estas excretas se organizaron dentro de la categoría "Mefítidos", pues no se podía diferenciar entre las excretas de ambas especies.

\section{Extracción}

De cada muestra seleccionada, se extrajeron $3 \mathrm{ml}$ del etanol con una pipeta graduada y se colocó en un tubo de ensayo. Posteriormente fue centrifugada durante15 minutos a 3000

rpm y el sobrenadante se vertió en criotubos de $5 \mathrm{ml}$. Las muestras fueron mantenidas en congelación hasta su análisis.

\section{Determinación del peso seco}

Después de obtener la cantidad del líquido suficiente para la cuantificación, el sedimento fue secado en una báscula/desecadora marca Adam $^{\circledR}$, modelo AMB110. Una vez que las excretas estaban completamente secas, el peso seco de la muestra se obtuvo tamizando la excreta para separarla de cualquier material que no fuera propiamente alimento digerido por el animal. El material obtenido a partir del tamizado se pesó en una báscula de precisión.

Es necesario enfatizar que la alimentación generalista de los mesodepredadores implica que sus excretas están compuestas por restos de alimentos de diferente origen, por lo que las muestras podían contener una gran cantidad de restos de artrópodos, huesos de mamíferos pequeños, pasto o semillas. Esto representó un interés particular para el desarrollo del estudio, pues la mayoría de los trabajos de endocrinología con mesodepredadores han sido realizados con animales en cautiverio, donde su alimentación es controlada y poco variada, con excretas compuestas principalmente por pellets sólidos (Soto et al., 2004; Rudert et al., 2011).

Se descartaron todas aquellas muestras con un peso igual o menor a 0.050 gr, puesto que era insuficiente para tener un cálculo confiable en la cuantificación de hormonas. 


\section{Cuantificación}

Se seleccionaron muestras de aquellas especies que cubrieran la mayor parte del ciclo anual. Estas muestras se diluyeron en solución buffer de fosfato preparado específicamente para cada una de las hormonas con una dilución inicial de 1/10.

Las diluciones de cada muestra se realizaron en tubos eppendorf, se agitaron en un vortex por dos minutos antes de iniciar.

Antes de comenzar con la cuantificación, las excretas fueron extraídas del congelador y se dejaron a temperatura ambiente por 15 minutos. Estas fueron procesadas en kits de inmunoensayo enzimático de formato competitivo (EIA) AccuBind ELISA Microwells (diseñado y manufacturado por Monobind Inc. ${ }^{\circledR}$, USA), para progesterona (P4), estradiol (E2) y testosterona (T).

El procedimiento de prueba inicia con la preparación de las placas con los pocillos para el suero de referencia correspondiente a cada hormona. Se añaden por pipeteo $0.025 \mathrm{ml}(25 \mu \mathrm{l})$ del suero de referencia de cada muestra en el pocillo asignado. A continuación se agregaron $0.050 \mathrm{ml}(50 \mu \mathrm{l})$ del reagente, para inmediatamente agitar durante medio minuto la placa. Hay que agregar $0.050 \mathrm{ml}(50 \mu \mathrm{l})$ de biotina reagente a los pocillos, para después volver a agitar la placa por medio minuto. Después de este paso hay que cubrir la placa y dejarla en reposo a temperatura ambiente durante 60 minutos, este es el período de incubación. En el caso de la progesterona, el tiempo de incubación es de 90 minutos. Una vez pasado este tiempo, se descartan los contenidos de la placa por decantación o aspiración. Se añaden 300 $\mu 1$ de solución buffer para lavar los pocillos un total de cinco veces. La solución buffer de lavado se descarta por decantación, acto seguido, hay que agregar $100 \mu 1$ de solución working substrate a todos los pocillos. Nuevamente se cubre la placa y se deja incubando por 15 minutos. Al terminar esta segunda incubación, hay que añadir $50 \mu 1$ de stop solution a todos los pozos y agitar suavemente la placa de 15 a 20 segundos. Finalmente, se realiza la lectura en un espectrofotocolorímetro a $450 \mathrm{~nm}$. Para este trabajo se utilizó un equipo Microplate Reader, MR 600 Dynatech Product ${ }^{\circledR}$. En general, la cuantificación se podría resumir en los pasos que se indican en la Figura 1. 
Este proceso entregaba un primer resultado (EIA), el cual era utilizado a su vez para obtener el resultado calculado usando el peso seco y el volumen de alcohol como factores (REIA como se le denominará de aquí en adelante).

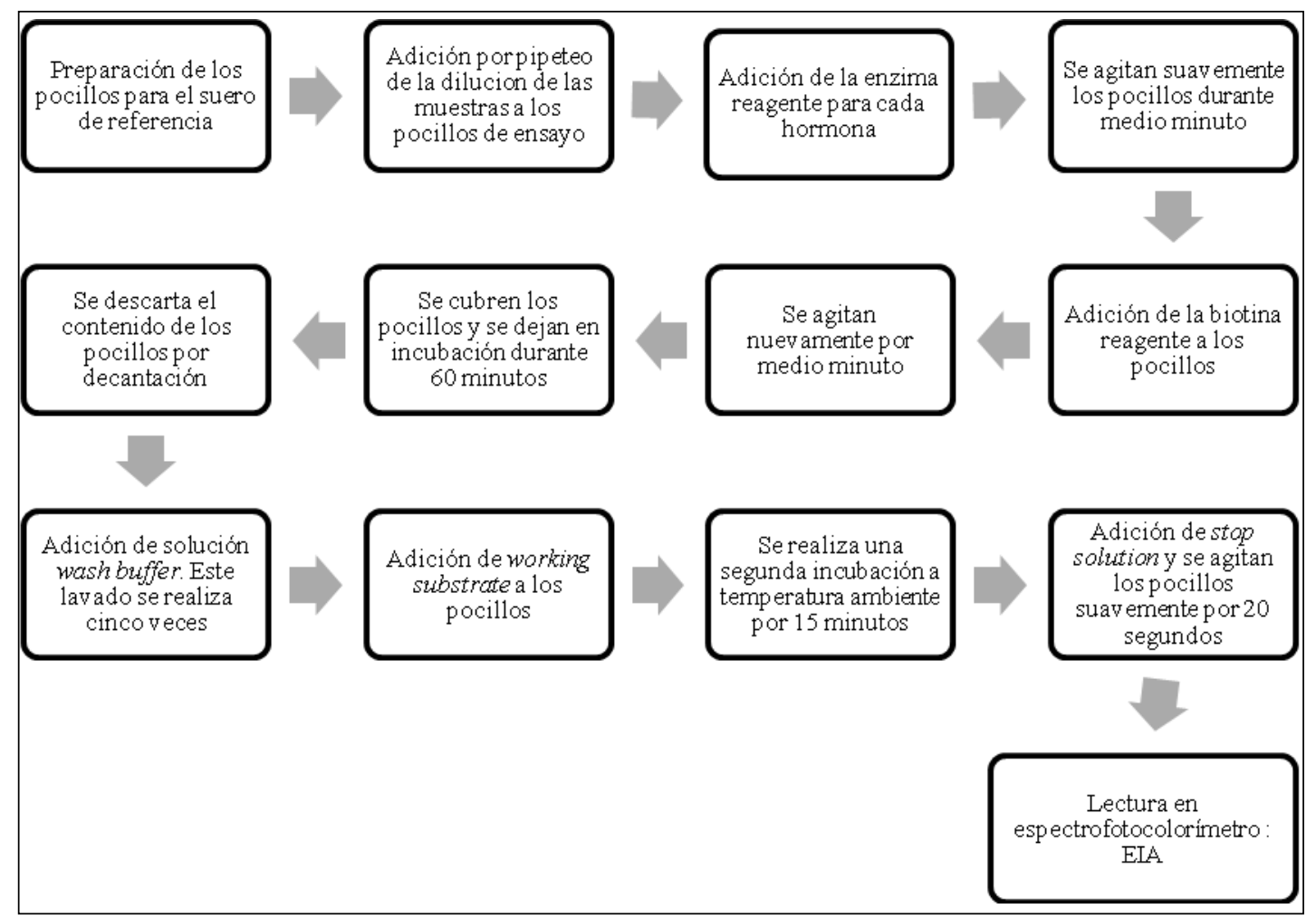

Figura 1. Pasos para el EIA de las muestras.

Los resultados del EIA de algunas muestras se salían de la curva de referencia $(>R E F)$, por lo que fue necesario realizar diluciones en diferentes proporciones hasta obtener una lectura que resultara confiable (e. g. 1/5, 1/10 o 1/20).

Para obtener el cálculo del REIA tomando el peso seco y el volumen de alcohol como factores se utilizó la siguiente fórmula:

$$
R E I A=\frac{E I A x 10}{\text { Pesoseco }(g r)}
$$

Donde

$E I A=$ resultado entregado por el fotocolorímetro.

$10=$ volumen original del etanol al $70 \%$ en $\mathrm{ml}$.

$\mathrm{Ng} / \mathrm{g}=$ ng de contenido hormonal por $\mathrm{g}$ de peso de la excreta 
El resultado final se obtuvo a partir del cálculo del REIA por el factor de la dilución utilizada:

$$
\text { Resultado final }=R E I A * D I L / \text { peso seco }
$$

Donde

REIA es el cálculo de ng de contenido hormonal por g de excreta.

DIL es el factor utilizado para diluir la extracción original de la muestra (e. g. 5, 10 ó 20).

\section{Análisis Estadístico}

La normalidad de los datos se determinó con base en las suposiciones de sesgo, curtosis y omnibus, pruebas que fueron realizadas con el programa NCSS 07.1.20 (2010).

\section{Perfiles hormonales Anuales}

Con el objetivo de observar la variación anual de hormonas esteorides (HES) en el período 2012-2013 se obtuvieron los promedios de las cuantificaciones hormonales por mes para cada especie a lo largo del año.

Usando el programa Microsoft Office Excel 2007®, se determinó la variación anual del REIA para obtener el perfil hormonal por especie. La variación se expresa obteniendo la concentración media mensual a partir el número de muestras por mes y la cuantificación de la hormona correspondiente para cada muestra. Estas variaciones se expresan en gráficas de línea. En el eje vertical primario de todas las gráficas se expresa la cuantificación de progesterona (P4) y estradiol (E2), mientas que el eje vertical secundario corresponde a la cuantificación de testosterona $(\mathrm{T})$. 


\section{Variación anual}

También se obtuvo la variación anual del REIA para cada especie y para cada hormona. Esta variación se determinó con el programa de estadística circular Oriana 4.01 (Kovach Computing Services). La variación se expresa tomando en cuenta el número de muestras por mes y la cuantificación de la hormona correspondiente para cada muestra. A cada cuantificación, con la respectiva escala de cada hormona, se le asignó una clasificación y un color para representarla en un diagrama lineal apilado, y que podríamos denominar en la siguiente forma:

- Línea base (azul).

- Media (rojo).

- Alta (amarillo).

- Muy alta (magenta.)

- Extremadamente alta (gris)

\section{Promedios de HES por estación}

Finalmente se comparó el promedio de cada HES por especie en las estaciones de lluvias y secas. Las muestras de cada especie fueron organizadas en dos grupos. Aquellas muestras colectadas entre los meses de junio a mediados de octubre de 2012 correspondían a la estación de lluvias. Para la estación de secas se consideraron las muestras que se colectaron en los meses de febrero a mayo y de noviembre a diciembre de 2012, así como de enero a abril de 2013.

También se utilizó la prueba no-paramétrica de comparación múltiple del valor-z de Kruskal-Wallis para determinar si existía una diferencia significativa entre las medianas de los promedio de las estaciones de lluvias y secas.

Esta comparación se realizó con el programa NCSS 07.1.20 (2010) por medio de una ANOVA. 


\section{$\underline{\text { Resultados }}$}

\section{Muestras procesadas}

Se colectó un total de 136 excretas, de las cuales se seleccionaron 58 para realizar la extracción de HES. Esta selección se realizó considerando que las excretas de las diferentes especies deberían cubrir en lo posible el ciclo 2012-2013 (Cuadro 1).

Cuadro 1. Total de excretas procesadas para la cuantificación de HES por especie.

\begin{tabular}{|l|c|c|c|c|}
\hline \multirow{2}{*}{ Especie } & \multirow{3}{*}{ Total de excretas } & \multicolumn{3}{|c|}{ Excretas utilizadas para cuantificación de } \\
\cline { 2 - 5 } & & $\mathbf{P 4}$ & $\mathbf{T}$ & E2 \\
\cline { 2 - 5 } $\begin{array}{l}\text { Bassariscus } \\
\text { astutus }\end{array}$ & 2 & 2 & 1 & 2 \\
\hline Canis latrans & 30 & 26 & 22 & 27 \\
\hline Lynx rufus & 1 & 1 & 1 & 1 \\
\hline Procyon lotor & 10 & 10 & 9 & 10 \\
\hline $\begin{array}{l}\text { Urocyon } \\
\text { cinereoargenteus }\end{array}$ & 14 & 14 & 12 & 13 \\
\hline Mefítidios & 1 & 1 & 0 & 1 \\
\hline Total & $\mathbf{5 8}$ & $\mathbf{5 4}$ & $\mathbf{4 5}$ & $\mathbf{5 4}$ \\
\hline
\end{tabular}

\section{a) Progesterona}

\section{P4 de Canis latrans}

Para Canis latrans fueron cuantificadas 26 muestras obtenidas en los meses de febrero de 2012 a marzo de 2013. Todas las muestras fueron procesadas siguiendo el método de inmuno-ensayo enzimático (EIA) mencionado previamente (Cuadro 2). Para cada grupo de muestras se presenta la media y los valores mínimo y máximo.

De acuerdo a las pruebas realizadas, estos datos tienen una distribución no-normal.

Cuadro 2. Resultados de EIA para P4 en muestras de Canis latrans ${ }^{1}$.

\begin{tabular}{|l|c|r|r|r|l|}
\hline & Fecha de colecta & $\begin{array}{l}\text { Contenido: } \\
\text { Peso seco de } \\
\text { excreta (gr) }\end{array}$ & REIA & DIL & $\begin{array}{l}\text { Resultado } \\
\text { final } \\
\text { (ng/gr) }\end{array}$ \\
\hline Clave & 17 -feb-12 & 0.578 & 14.4 & 10 & 2491.35 \\
\hline M8 & 17 -feb-12 & 0.095 & 10.4 & 10 & 10947.37 \\
\hline
\end{tabular}




\begin{tabular}{|c|c|c|c|c|c|}
\hline Clave & Fecha de colecta & $\begin{array}{l}\text { Contenido: } \\
\text { Peso seco de } \\
\text { excreta (gr) }\end{array}$ & REIA & DIL & $\begin{array}{l}\text { Resultado } \\
\text { final } \\
\text { (ng/gr) }\end{array}$ \\
\hline M9 & 18 -feb-12 & 0.747 & 21.2 & 10 & 2838.02 \\
\hline M11 & 18 -feb-12 & 0.563 & 21 & 10 & 3730.02 \\
\hline M16 & 19 -abr-12 & 0.121 & 17.6 & 10 & 14545.45 \\
\hline M18 & 10 -jun-12 & 0.149 & 13.7 & 10 & 9194.63 \\
\hline M19 & 10-jun-12 & 0.126 & 11.9 & 10 & 9444.44 \\
\hline M21 & 05-ago-12 & 0.179 & 215.4 & 5 & 60167.60 \\
\hline M31 & 06-sep-12 & 0.507 & 201.5 & 5 & 19871.79 \\
\hline M33 & 06-sep-12 & 0.199 & 1.3 & 5 & 326.63 \\
\hline M42 & 06-oct-12 & 0.215 & 15.4 & 10 & 7162.79 \\
\hline M43 & 07 -oct-12 & 0.126 & 13.8 & 10 & 10952.38 \\
\hline M46 & 07 -oct-12 & 0.071 & 8.9 & 10 & 12535.21 \\
\hline M50 & 28-nov-12 & 0.064 & 7.7 & 10 & 12031.25 \\
\hline M54 & 17-dic-12 & 0.881 & 34.6 & 10 & 3927.36 \\
\hline M57 & 18-dic-12 & 0.068 & 5.2 & 10 & 7647.06 \\
\hline M61 & 18-dic-12 & 0.134 & 9.2 & 10 & 6865.67 \\
\hline M75 & 10-ene-13 & 0.084 & 27.8 & 10 & 33095.24 \\
\hline M96 & 29-ene-13 & 0.133 & 12.7 & 10 & 9548.87 \\
\hline M100 & 29-ene-13 & 0.204 & 26.7 & 10 & 13088.24 \\
\hline M118 & 30-ene-13 & 0.166 & 7.3 & 20 & 8795.18 \\
\hline M152 & $14-f e b-13$ & 0.387 & 4.9 & 20 & 2532.30 \\
\hline M158 & 05-mar-13 & 0.054 & 27.1 & 20 & 100370.37 \\
\hline M164 & 05-mar-13 & 0.123 & 5.9 & 20 & 9593.50 \\
\hline M172 & 05-mar-13 & 0.183 & 6 & 20 & 6557.38 \\
\hline M176 & 05-mar-13 & 0.064 & 3.2 & 20 & 10000.00 \\
\hline \multicolumn{2}{|r|}{ Número de muestras: } & \multicolumn{4}{|r|}{26} \\
\hline \multicolumn{2}{|r|}{ Media } & \multicolumn{4}{|r|}{14933.08} \\
\hline & Mínimo: & \multicolumn{4}{|r|}{326.63} \\
\hline & Máximo: & \multicolumn{4}{|r|}{100370.37} \\
\hline
\end{tabular}




\section{P4 de Urocyon cinereoargenteus}

Se cuantificaron 14 muestras correspondientes a Urocyon cinereoargenteus, las cuales comprenden desde febrero de 2012 hasta enero de 2013 (Cuadro 3).

La distribución de estos datos también resultó no-normal.

Cuadro 3. Resultados de EIA para P4 en muestras de Urocyon cinereoargenteus ${ }^{1}$.

\begin{tabular}{|c|c|c|c|c|c|}
\hline Clave & Fecha de colecta & $\begin{array}{l}\text { Contenido: } \\
\text { Peso seco } \\
\text { de excreta } \\
\text { (gr) }\end{array}$ & REIA & DIL & $\begin{array}{l}\text { Resultado final } \\
\text { (ng/gr) }\end{array}$ \\
\hline M7 & $17-f e b-12$ & 0.194 & 15 & 10.00 & 7731.96 \\
\hline M10 & 18 -feb-12 & 0.262 & 9.6 & 10.00 & 3664.12 \\
\hline M12 & 18 -feb-12 & 0.479 & 9.7 & 10.00 & 2025.05 \\
\hline M13 & 18 -feb-12 & 0.42 & 7.4 & 10.00 & 1761.90 \\
\hline M22 & 05-ago-12 & 0.215 & 289.6 & 5.00 & 67348.84 \\
\hline M27 & 05-sep-12 & 0.287 & 190.1 & 5.00 & 33118.47 \\
\hline M47 & 10-nov-12 & 0.063 & 8.6 & 10.00 & 13650.79 \\
\hline M51 & 28-nov-12 & 0.057 & 9.5 & 10.00 & 16666.67 \\
\hline M52 & 28-nov-12 & 0.097 & 7.6 & 10.00 & 7835.05 \\
\hline M53 & 17-dic-12 & 0.051 & 5.5 & 10.00 & 10784.31 \\
\hline M60 & 18-dic-12 & 0.055 & 4.7 & 20.00 & 17090.91 \\
\hline M66 & 10-ene-13 & 0.138 & 12.6 & 10.00 & 9130.43 \\
\hline M81 & 10-ene-13 & 0.011 & 12.3 & 10.00 & 111818.18 \\
\hline M88 & 10 -ene-13 & 0.1 & 21.1 & 10.00 & 21100.00 \\
\hline \multicolumn{2}{|r|}{ Número de muestras: } & \multicolumn{4}{|r|}{14} \\
\hline & Media & \multicolumn{4}{|r|}{23123.335} \\
\hline & Mínimo: & \multicolumn{4}{|r|}{1761.905} \\
\hline & Máximo: & \multicolumn{4}{|r|}{111818.182} \\
\hline
\end{tabular}




\section{P4 de Procyon lotor}

Se colectaron 10 muestras de Procyon lotor, las cuales corresponden cubren el lapso desde enero de 2012 hasta febrero de 2013 (Cuadro 4).

Las pruebas realizadas sobre estos resultados muestran que la distribución de estos datos es no-normal.

Cuadro 4. Resultados de EIA para P4 en muestras de Procyon lotor ${ }^{1}$.

\begin{tabular}{|c|c|c|c|c|c|}
\hline Clave & Fecha de colecta & $\begin{array}{l}\text { Contenido: } \\
\text { Peso seco } \\
\text { de excreta } \\
\text { (gr) }\end{array}$ & REIA & DIL & $\begin{array}{l}\text { Resultado } \\
\text { final (ng/gr) }\end{array}$ \\
\hline M6 & $17-f e b-12$ & 0.42 & 14.6 & 10 & 3476.19 \\
\hline M25 & 05-ago-12 & 0.656 & 49.8 & 5 & 3795.73 \\
\hline M26 & 05-ago-12 & 0.182 & 139.4 & 5 & 38296.70 \\
\hline M28 & 05-sep-12 & 0.15 & 8.8 & 5 & 2933.33 \\
\hline M29 & 05-sep-12 & 0.125 & 80.5 & 5 & 32200.00 \\
\hline M38 & 22-sep-12 & 0.217 & 35.1 & 10 & 16175.12 \\
\hline M41 & 06-oct-12 & 0.189 & 0.8 & 20 & 846.56 \\
\hline M44 & 07-oct-12 & 0.189 & 23.5 & 10 & 12433.86 \\
\hline M112 & 30 -ene-13 & 0.106 & 3.9 & 20 & 7358.49 \\
\hline M127 & 30 -ene-13 & 0.238 & 4.5 & 20 & 3781.51 \\
\hline & \multicolumn{2}{|c|}{ Número de muestras: } & \multicolumn{3}{|r|}{10} \\
\hline & \multicolumn{2}{|r|}{ Media: } & \multicolumn{3}{|r|}{12129.75} \\
\hline & \multicolumn{2}{|r|}{ Mínimo: } & \multicolumn{3}{|r|}{846.56} \\
\hline & \multicolumn{2}{|r|}{ Máximo: } & \multicolumn{3}{|r|}{38296.70} \\
\hline
\end{tabular}

\section{P4 en especies con muestras pequeñas}

Se decidió no hacer un análisis comparativo en las muestras de Bassariscus astutus, mefítidos y Lynx rufus, pues en algunos casos la cantidad de muestras era muy pequeña. Al tener tan pocas muestras, no se puede tener una concentración anual representativa (Cuadro $5)$. 
Cuadro 5. EIA de P4 en muestras de Bassariscus astutus, mefítidos y Lynx rufus ${ }^{1}$.

\begin{tabular}{|l|l|l|l|r|r|r|}
\hline Clave & Especie & $\begin{array}{l}\text { Fecha de } \\
\text { colecta }\end{array}$ & $\begin{array}{l}\text { Contenido: } \\
\text { Peso seco } \\
\text { de excreta } \\
\text { (gr) }\end{array}$ & REIA & DIL & $\begin{array}{l}\text { Resultado } \\
\text { final } \\
\text { (ng/gr) }\end{array}$ \\
\hline M1 & $\begin{array}{l}\text { Bassariscus } \\
\text { astutus }\end{array}$ & 16 -feb-12 & 0.242 & 7.7 & 10 & 3181.82 \\
\hline M72 & $\begin{array}{l}\text { Bassariscus } \\
\text { astutus }\end{array}$ & 10 -ene-13 & 0.055 & 56.8 & 10 & 103272.73 \\
\hline M35 & Mefítidos & 22-sep-12 & 0.449 & 255.8 & 5 & 28485.52 \\
\hline M5 & Lynx rufus & $17-f e b-12$ & 1.003 & 13.9 & 10 & 1385.84 \\
\hline 1. El volumen de alcohol para todas las muestras fue de 10 ml. \\
\hline
\end{tabular}

\section{b) Estradiol}

\section{E2 de Canis latrans}

Para E2 de Canis latrans fueron cuantificadas 27 muestras correspondientes a al ciclo febrero de 2012 a abril de 2013. (Cuadro 6).

Estos resultados son de tipo no-normal, de acuerdo a las pruebas realizadas en NCSS.

Cuadro 6. Resultados de EIA para E2 en muestras de Canis latrans ${ }^{\mathbf{1}}$.

\begin{tabular}{|c|c|c|c|c|c|}
\hline Clave & Fecha de colecta & $\begin{array}{l}\text { Contenido: } \\
\text { Peso seco de } \\
\text { excreta (gr) }\end{array}$ & REIA & DIL & $\begin{array}{l}\text { Resultado final } \\
\text { (ng/gr) }\end{array}$ \\
\hline M3 & 17 -feb-12 & 0.578 & 385.7 & 10 & 66730.10 \\
\hline M8 & $17-f e b-12$ & 0.095 & 238.5 & 10 & 251052.63 \\
\hline M9 & 18 -feb-12 & 0.747 & 382.9 & 10 & 51258.37 \\
\hline M11 & 18 -feb-12 & 0.563 & 364.7 & 10 & 64777.98 \\
\hline M15 & 19-abr-12 & 0.263 & 705.9 & 20 & 536806.08 \\
\hline M16 & 19-abr-12 & 0.121 & 647.5 & 10 & 535123.97 \\
\hline M18 & 10 -jun-12 & 0.149 & 474.7 & 10 & 318590.60 \\
\hline M19 & 10 -jun-12 & 0.126 & 432.3 & 10 & 343095.24 \\
\hline M20 & 10-jun-12 & 0.33 & 987 & 20 & 598181.82 \\
\hline
\end{tabular}




\begin{tabular}{|c|c|c|c|c|c|}
\hline Clave & Fecha de colecta & $\begin{array}{l}\text { Contenido: } \\
\text { Peso seco de } \\
\text { excreta (gr) }\end{array}$ & REIA & DIL & $\begin{array}{l}\text { Resultado final } \\
\text { (ng/gr) }\end{array}$ \\
\hline M21 & 05-ago-12 & 0.179 & 1179 & 20 & 1317318.44 \\
\hline M31 & 06-sep-12 & 0.507 & 856.7 & 10 & 168974.36 \\
\hline M33 & 06-sep-12 & 0.199 & 2193 & 10 & 1102010.05 \\
\hline M42 & 06-oct-12 & 0.215 & 5025 & 10 & 2337209.30 \\
\hline M43 & 07 -oct-12 & 0.126 & 360 & 10 & 285714.29 \\
\hline M46 & 07 -oct-12 & 0.071 & 324.9 & 10 & 457605.63 \\
\hline M50 & 28-nov-12 & 0.064 & 485.9 & 10 & 759218.75 \\
\hline M54 & 17-dic-12 & 0.881 & 842.3 & 10 & 95607.26 \\
\hline M57 & 18-dic-12 & 0.068 & 346.3 & 10 & 509264.71 \\
\hline M61 & 18-dic-12 & 0.134 & 466.6 & 10 & 348208.96 \\
\hline M75 & 10-ene-13 & 0.084 & 494.2 & 10 & 588333.33 \\
\hline M118 & 30-ene-13 & 0.166 & 685.5 & 10 & 412951.81 \\
\hline M152 & $14-$ feb-13 & 0.387 & 877.5 & 10 & 226744.19 \\
\hline M158 & 05-mar-13 & 0.054 & 4856 & 10 & 8992592.59 \\
\hline M164 & 05-mar-13 & 0.123 & 1088 & 10 & 884552.85 \\
\hline M172 & 05-mar-13 & 0.183 & 1479 & 10 & 808196.72 \\
\hline M176 & 05-mar-13 & 0.064 & 829.3 & 10 & 1295781.25 \\
\hline M223 & 17 -abr-13 & 0.648 & 580.7 & 10 & 89614.20 \\
\hline \multicolumn{2}{|r|}{ Número de muestras: } & \multicolumn{4}{|r|}{27} \\
\hline \multicolumn{2}{|r|}{ Media: } & \multicolumn{4}{|r|}{85727.50} \\
\hline & Mínimo: & \multicolumn{4}{|r|}{5125.84} \\
\hline & Máximo: & \multicolumn{4}{|r|}{899259.26} \\
\hline 1. E & ara todas las muestras fue & de $10 \mathrm{ml}$ & & & \\
\hline
\end{tabular}




\section{E2 de Urocyon cinereoargenteus}

Se cuantificaron 13 muestras de Urocyon cinereoargenteus correspondientes al período febrero 2012 a enero 2013 (Cuadro 7).

En este caso, no se puede rechazar la normalidad de los datos, sin embargo se decidió no hacer otro tipo de análisis con los mismos.

Cuadro 7. Resultados de EIA para E2 en muestras de Urocyon cinereoargenteus ${ }^{1}$.

\begin{tabular}{|c|c|c|c|c|c|}
\hline Clave & Fecha de colecta & $\begin{array}{l}\text { Contenido: } \\
\text { Peso seco } \\
\text { de excreta } \\
\text { (gr) }\end{array}$ & REIA & DIL & \begin{tabular}{|l} 
Resultado \\
final (ng/gr)
\end{tabular} \\
\hline M7 & $17-f e b-12$ & 0.194 & 329.5 & 10 & 16984.54 \\
\hline M10 & 18 -feb-12 & 0.262 & 1057 & 10 & 40343.51 \\
\hline M12 & 18 -feb-12 & 0.479 & 322.4 & 10 & 6730.69 \\
\hline M13 & 18 -feb-12 & 0.42 & 264.4 & 10 & 6295.24 \\
\hline M22 & 05 -ago-12 & 0.215 & 1435 & 10 & 66744.19 \\
\hline M27 & 05-sep-12 & 0.287 & 4877 & 10 & 169930.31 \\
\hline M47 & 10-nov-12 & 0.063 & 906.3 & 10 & 143857.14 \\
\hline M51 & 28-nov-12 & 0.057 & 485.9 & 10 & 85245.61 \\
\hline M52 & 28-nov-12 & 0.097 & 313.5 & 10 & 32319.59 \\
\hline M53 & 17-dic-12 & 0.051 & 271.1 & 10 & 53156.86 \\
\hline M60 & 18-dic-12 & 0.055 & 570.5 & 10 & 103727.27 \\
\hline M66 & 10-ene-13 & 0.138 & 444.5 & 10 & 32210.15 \\
\hline M88 & 10-ene-13 & 0.1 & 461.7 & 10 & 46170.00 \\
\hline & Número de muestras: & & & & 13 \\
\hline & Media: & & & & 61824.238 \\
\hline & Mínimo: & & & & 6295.238 \\
\hline & Máximo: & & & & 169930.31 \\
\hline
\end{tabular}

\section{E2 de Procyon lotor}

Se cuantificaron diez muestras de Procyon lotor. Estas muestras comprenden desde febrero de 2012 hasta enero de 2013 (Cuadro 8).

Las pruebas con estos datos señalan que se rechaza la normalidad para los mismos. 
Cuadro 8. Resultados de EIA para E2 en muestras de Procyon lotor ${ }^{1}$.

\begin{tabular}{|c|c|c|c|c|c|}
\hline Clave & Fecha de colecta & $\begin{array}{l}\text { Contenido: } \\
\text { Peso seco de } \\
\text { excreta (gr) }\end{array}$ & REIA & DIL & $\begin{array}{l}\text { Resultado final } \\
\text { (ng/gr) }\end{array}$ \\
\hline M6 & $17-f e b-12$ & 0.42 & 1455 & 10 & 34642.86 \\
\hline M25 & 05-ago-12 & 0.656 & 396.9 & 20 & 12100.61 \\
\hline M26 & 05 -ago-12 & 0.182 & 3180 & 10 & 174725.28 \\
\hline M28 & 05-sep-12 & 0.15 & 2534 & 10 & 168933.33 \\
\hline M29 & 05-sep-12 & 0.125 & 8407 & 10 & 672560.00 \\
\hline M38 & 22-sep-12 & 0.217 & 5446 & 10 & 250967.74 \\
\hline M41 & 06-oct-12 & 0.189 & 3653 & 10 & 193280.42 \\
\hline M44 & $07-$ oct-12 & 0.189 & 316 & 10 & 16719.58 \\
\hline M112 & 30 -ene-13 & 0.106 & 409.8 & 10 & 38660.38 \\
\hline M127 & 30 -ene-13 & 0.238 & 3578 & 10 & 150336.13 \\
\hline & \multicolumn{2}{|c|}{ Número de muestras: } & \multicolumn{3}{|r|}{10} \\
\hline & \multicolumn{2}{|r|}{ Media: } & \multicolumn{3}{|r|}{171292.633} \\
\hline & \multicolumn{2}{|r|}{ Mínimo: } & \multicolumn{3}{|r|}{12100.61} \\
\hline & \multicolumn{2}{|r|}{ Máximo: } & \multicolumn{3}{|r|}{672560.00} \\
\hline
\end{tabular}

\section{E2 en especies con muestras pequeñas}

Se cuantificaron dos muestras de Bassariscus astutus las cuales sólo cubrían los primeros meses de 2012 y 2013. También fue cuantificada una muestras de mefítidos y una de Lynx rufus (Cuadro 9).

Cuadro 9. EIA de E2 en muestras de Bassariscus astutus, mefítidos y Lynx rufus ${ }^{1}$.

\begin{tabular}{|l|l|r|r|r|r|r|}
\hline Clave & Especie & $\begin{array}{l}\text { Fecha de } \\
\text { colecta }\end{array}$ & $\begin{array}{l}\text { Contenido: } \\
\text { Peso seco de } \\
\text { excreta (gr) }\end{array}$ & REIA & DIL & $\begin{array}{l}\text { Resultado } \\
\text { final (ng/gr) }\end{array}$ \\
\hline M1 & $\begin{array}{l}\text { Bassariscus } \\
\text { astutus }\end{array}$ & 16 -feb-12 & 0.242 & 286.5 & 10 & 118388.43 \\
\hline M72 & $\begin{array}{l}\text { Bassariscus } \\
\text { astutus }\end{array}$ & 10 -ene-13 & 0.055 & 499.4 & 20 & 1816000.00 \\
\hline M35 & Mefítidos & 22-sep-12 & 0.449 & 1925 & 10 & 428730.51 \\
\hline M5 & Lynx rufus & 17 -feb-12 & 1.003 & 1084 & 20 & 216151.55 \\
\hline 1. El volumen de alcohol para todas las muestras fue de $10 \mathrm{ml}$. \\
\hline
\end{tabular}




\section{c) Testosterona}

\section{T de Canis latrans}

Para el análisis de T de Canis latrans fueron cuantificadas 22 muestras, las cuales cubren el período de febrero de 2012 hasta marzo de 2013 (Cuadro 10).

La distribución para estos datos resultó ser no-normal.

Cuadro 10. Resultados de EIA para T en muestras de Canis latrans ${ }^{1}$.

\begin{tabular}{|c|c|c|c|c|c|}
\hline Clave & Fecha de colecta & \begin{tabular}{|l|} 
Contenido: \\
Peso seco de \\
excreta (gr)
\end{tabular} & REIA & DIL & $\begin{array}{l}\text { Resultado final } \\
\text { (ng/gr) }\end{array}$ \\
\hline M8 & $17-f e b-12$ & 0.095 & 0 & 10 & 0 \\
\hline M9 & 18 -feb-12 & 0.747 & 6.1 & 10 & 816.5997323 \\
\hline M11 & 18 -feb-12 & 0.563 & 1.2 & 10 & 213.1438721 \\
\hline M15 & 19 -abr-12 & 0.263 & 0.6 & 20 & 456.2737643 \\
\hline M16 & 19-abr-12 & 0.121 & 5.5 & 10 & 4545.454545 \\
\hline M18 & 10-jun-12 & 0.149 & 0 & 10 & 0 \\
\hline M19 & 10-jun-12 & 0.126 & 2.5 & 10 & 1984.126984 \\
\hline M21 & 05-ago-12 & 0.179 & 2.4 & 10 & 1340.782123 \\
\hline M33 & 06-sep-12 & 0.199 & 0.1 & 10 & 50.25125628 \\
\hline M42 & 06-oct-12 & 0.215 & 1.4 & 10 & 651.1627907 \\
\hline M43 & 07 -oct- 12 & 0.126 & 2.7 & 10 & 2142.857143 \\
\hline M46 & 07 -oct- 12 & 0.071 & 0.5 & 10 & 704.2253521 \\
\hline M50 & 28-nov-12 & 0.064 & 1 & 10 & 1562.5 \\
\hline M54 & 17-dic-12 & 0.881 & 2.8 & 10 & 317.8206583 \\
\hline M57 & 18-dic-12 & 0.068 & 1.2 & 10 & 1764.705882 \\
\hline M61 & 18 -dic-12 & 0.134 & 0.1 & 10 & 74.62686567 \\
\hline M75 & 10-ene-13 & 0.084 & 0 & 10 & $\overline{0}$ \\
\hline M100 & 29-ene-13 & 0.204 & 2.8 & 20 & 2745.098039 \\
\hline M118 & 30 -ene-13 & 0.166 & 1 & 20 & 1204.819277 \\
\hline M164 & $05-m a r-13$ & 0.123 & 2.6 & 20 & 4227.642276 \\
\hline M172 & $05-\operatorname{mar}-13$ & 0.183 & 5.3 & 20 & 5792.349727 \\
\hline
\end{tabular}




\begin{tabular}{|c|c|c|c|c|c|}
\hline Clave & Fecha de colecta & $\begin{array}{l}\text { Contenido: } \\
\text { Peso seco de } \\
\text { excreta (gr) }\end{array}$ & REIA & DIL & $\begin{array}{l}\text { Resultado final } \\
\text { (ng/gr) }\end{array}$ \\
\hline M176 & 05 -mar-13 & 0.064 & 3.6 & 20 & 11250 \\
\hline \multicolumn{2}{|r|}{ Número de muestras: } & \multicolumn{4}{|r|}{22} \\
\hline \multicolumn{2}{|r|}{ Media: } & \multicolumn{4}{|r|}{190.20} \\
\hline \multicolumn{2}{|r|}{ Mínimo: } & \multicolumn{4}{|r|}{0} \\
\hline \multicolumn{2}{|r|}{ Máximo: } & \multicolumn{4}{|r|}{1125.00} \\
\hline
\end{tabular}

\section{$T$ de Urocyon cinereoargenteus}

Las muestras correspondientes a T de Urucyon cinereoargenteus cubren el período de febrero de 2012 a enero de 2013, con 12 muestras (Cuadro 11).

Las pruebas correspondientes señalan que se rechaza la normalidad para estos datos.

Anexo 11. Resultados de EIA para T en muestras de Urocyon cinereoargenteus ${ }^{1}$.

\begin{tabular}{|c|c|c|c|c|c|}
\hline Clave & Fecha de colecta & $\begin{array}{l}\text { Contenido: } \\
\text { Peso seco de } \\
\text { excreta (gr) }\end{array}$ & REIA & DIL & $\begin{array}{l}\text { Resultado final } \\
\text { (ng/gr) }\end{array}$ \\
\hline M7 & $17-f e b-12$ & 0.194 & 91.2 & 10 & 47010.31 \\
\hline M10 & 18 -feb-12 & 0.262 & 4.1 & 10 & 1564.89 \\
\hline M13 & 18 -feb-12 & 0.42 & 0.3 & 10 & 71.43 \\
\hline M22 & 05-ago-12 & 0.215 & 8.1 & 10 & 3767.44 \\
\hline M27 & 05-sep-12 & 0.287 & 0.1 & 10 & 34.84 \\
\hline M47 & 10-nov-12 & 0.063 & 8.5 & 10 & 13492.06 \\
\hline M51 & 28-nov-12 & 0.057 & 2.1 & 10 & 3684.21 \\
\hline M52 & 28-nov-12 & 0.097 & 2.7 & 10 & 2783.51 \\
\hline M53 & 17-dic-12 & 0.051 & 1.4 & 10 & 2745.10 \\
\hline M60 & 18-dic-12 & 0.055 & 0.3 & 20 & 1090.91 \\
\hline M66 & 10-ene-13 & 0.138 & 0 & 10 & 0.000 \\
\hline M88 & 10-ene-13 & 0.1 & 21.1 & 10 & 21100.00 \\
\hline \multicolumn{2}{|r|}{ Número de muestras: } & \multicolumn{4}{|r|}{12} \\
\hline
\end{tabular}




\begin{tabular}{|r|r|}
\hline Media: & 8112.06 \\
\hline Mínimo: & 0.0 \\
\hline Máximo: & \\
\hline 1. El volumen de alcohol para todas las muestras fue de $10 \mathrm{ml}$. & 47010.31 \\
\hline
\end{tabular}

\section{T de Procyon lotor}

Se cuantificaron nueve muestras de testosterona de Procyon lotor, las cuales corresponden al período de febrero de 2012 a enero de 2013 (Cuadro 12).

La normalidad fue rechazada para los datos de T de esta especie.

Cuadro 12. Resultados de EIA para T en muestras de Procyon lotor ${ }^{1}$.

\begin{tabular}{|c|c|c|c|c|c|}
\hline Clave & Fecha de colecta & \begin{tabular}{|l|} 
Contenido: \\
Peso seco de \\
excreta (gr)
\end{tabular} & REIA & DIL & $\begin{array}{l}\text { Resultado final } \\
\text { (ng/gr) }\end{array}$ \\
\hline M4 & 17 -feb-12 & 0.358 & 3.5 & 20 & 1955.31 \\
\hline M6 & $17-f e b-12$ & 0.42 & 2.5 & 10 & 595.24 \\
\hline M25 & 05 -ago-12 & 0.656 & 5.7 & 10 & 868.90 \\
\hline M26 & 05 -ago-12 & 0.182 & 1.3 & 10 & 714.29 \\
\hline M29 & 05-sep-12 & 0.125 & 1.8 & 10 & 1440.00 \\
\hline M38 & 22-sep-12 & 0.217 & 3.5 & 10 & 1612.90 \\
\hline M44 & 07-oct-12 & 0.189 & 0.1 & 10 & 52.91 \\
\hline M112 & 30-ene-13 & 0.106 & 0.4 & 20 & 754.72 \\
\hline M127 & 30-ene-13 & 0.238 & 8.1 & 20 & 6806.72 \\
\hline \multicolumn{2}{|r|}{ Número de muestras: } & \multicolumn{4}{|r|}{9} \\
\hline \multicolumn{2}{|r|}{ Media: } & \multicolumn{4}{|r|}{1644.55} \\
\hline \multicolumn{2}{|r|}{ Mínimo; } & \multicolumn{4}{|r|}{52.91} \\
\hline \multicolumn{2}{|r|}{ Máximo: } & \multicolumn{4}{|r|}{6806.72} \\
\hline
\end{tabular}




\section{T en especies con muestras pequeñas}

Para T fueron cuantificadas dos muestras de Bassariscus astutus y una de Lynx rufus. Considerando el bajo número de muestras fue difícil realizar algún análisis que expresara la variación anual de testosterona en estas especies (Cuadro 13).

Cuadro13. REIA de T en muestras de Bassariscus astutus y Lynx rufus ${ }^{1}$.

\begin{tabular}{|c|c|c|c|c|c|c|}
\hline Clave & Especie & $\begin{array}{l}\text { Fecha de } \\
\text { colecta }\end{array}$ & $\begin{array}{l}\text { Contenido: } \\
\text { Peso seco de } \\
\text { excreta }(g r)\end{array}$ & REIA & DIL & $\begin{array}{l}\text { Rfinal } \\
(\mathbf{n g} / \mathrm{gr})\end{array}$ \\
\hline M1 & \begin{tabular}{|l|} 
Bassariscus \\
astutus
\end{tabular} & 16 -feb-12 & 0.242 & 1.1 & 10 & 454.545 \\
\hline M72 & $\begin{array}{l}\text { Bassariscus } \\
\text { astutus }\end{array}$ & 10 -ene-13 & 0.055 & 0.3 & 20 & 1090.909 \\
\hline M5 & Lynx rufus & 17 -feb-12 & 1.003 & 3.5 & 10 & 348.953 \\
\hline
\end{tabular}

\section{Perfiles Hormonales Anuales}

Para observar el perfil hormonal de HES por especie, se obtuvo la media mensual para las concentraciones de cada hormona.

En la Figura 2 se presenta el perfil hormonal para Canis latrans en el período del estudio (2012-2013). El E2 y la P4 tienen sus máximas concentraciones junio y agosto respectivamente, mientras que la T tiene su pico máximo en enero de 2013. 


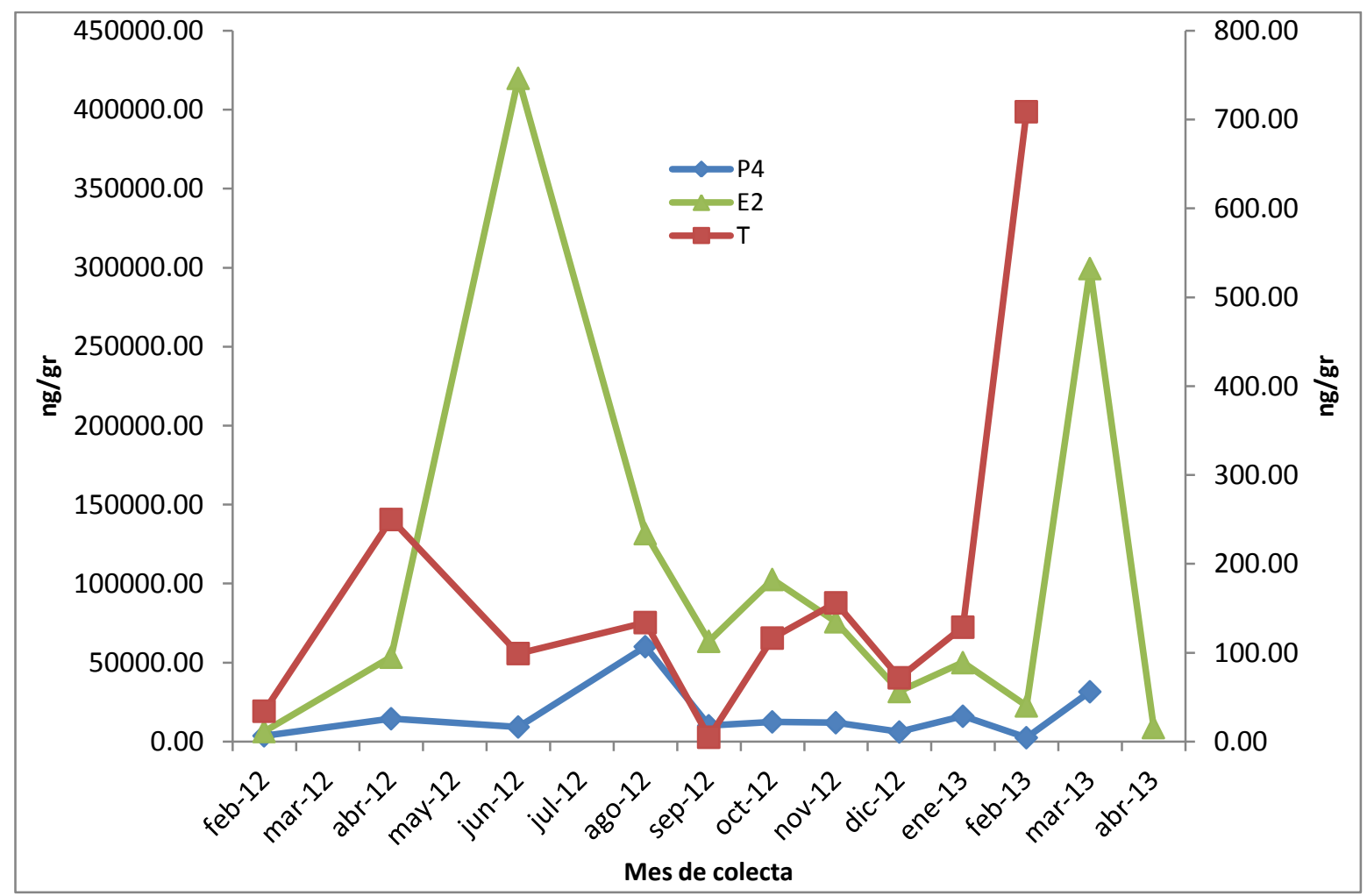

Figura 2. Perfil hormonal a partir de promedios de concentraciones de HES de Canis latrans para el período 2012-2013.

Para Urocyon cinereoargenteus, el perfil hormonal muestra gran variación en el período 2012-2013. En la Figura 3 se puede apreciar que la P4 y el E2 tienen una distribución muy similar hasta el mes de septiembre de 2012, momento en que se observa un decremento significativo para la P4. Esta situación se invierte en enero de 2013, pues la P4 aumenta mientras que el E2 se reduce. Para esta especie, tal como ocurre con Canis latrans, la variación de las concentraciones de T también fue notoria a lo largo del ciclo anual. Es sobresaliente el hecho de que las mayores concentraciones de $\mathrm{T}$ se encuentran al inicio de cada año. 


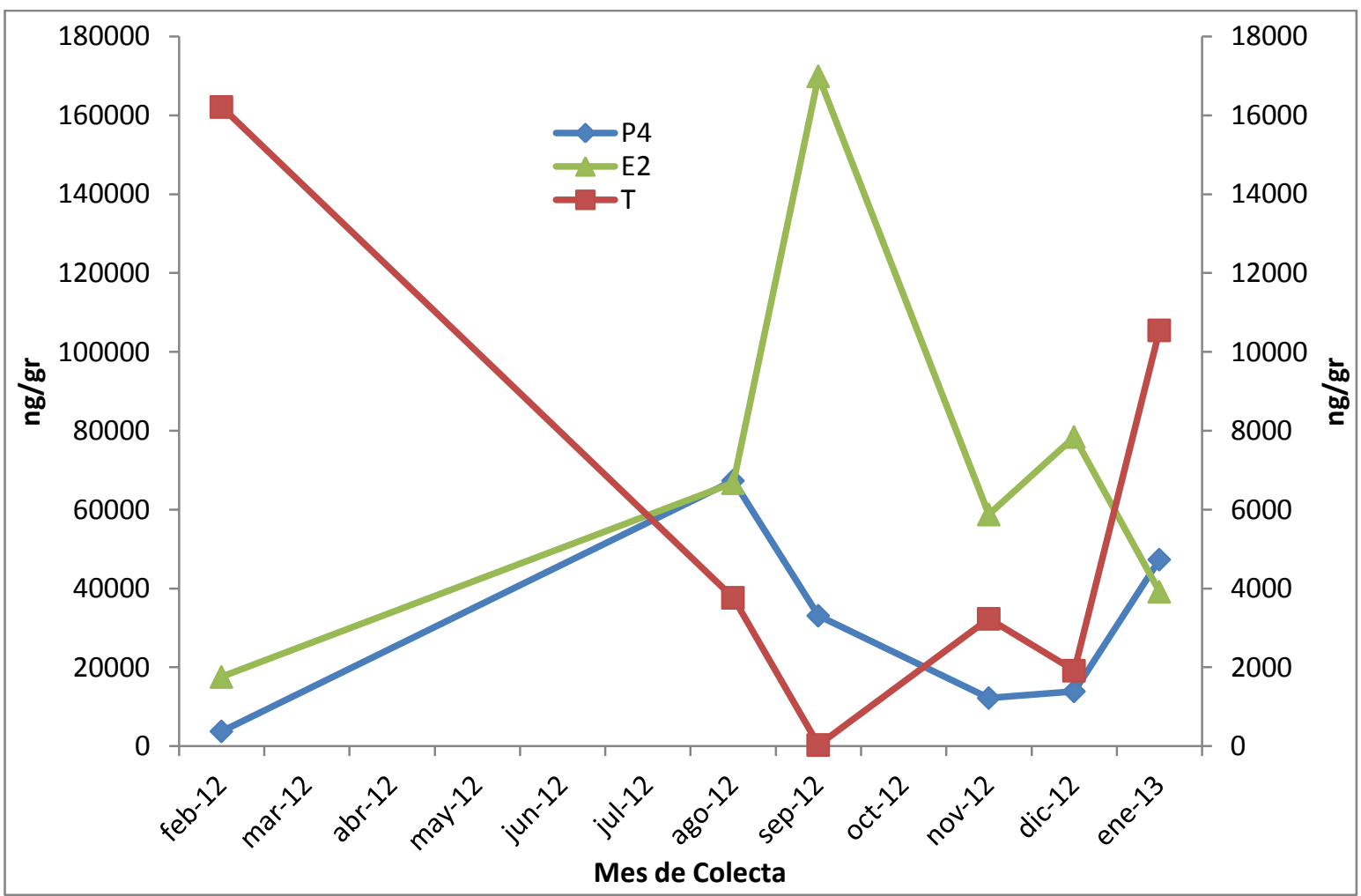

Figura 3. Hormonas esteroides de Urocyon cinereoargenteus para el período 2012-2013.

El perfil hormonal Procyon lotor (Figura 4) también muestra una notable variación de las tres hormonas a lo largo del año. Hay que enfatizar que las mayores concentraciones de $\mathrm{T}$ para las tres especies se encontraron durante la temporada invernal, entre los meses de diciembre-febrero. 


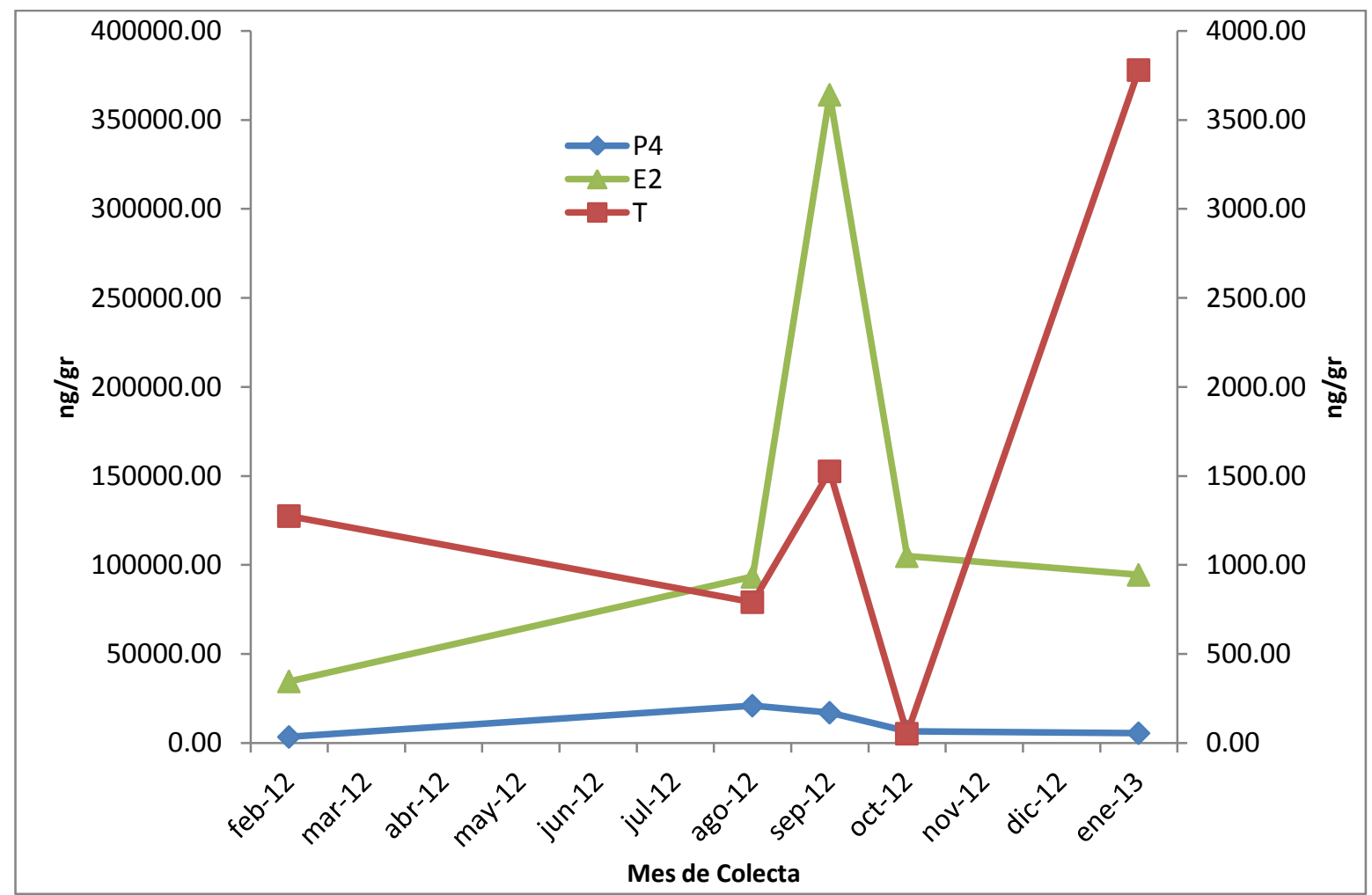

Figura 4. Hormonas esteroides de Procyon lotor para el período 2012-2013.

\section{Distribución anual de la cuantificación de HES}

Distribución anual en la cuantificación de HES en las muestras de Canis latrans

Usando estadística circular, se determinó la distribución anual de la concentración de HES para el período 2012-2013. En el caso de las concentraciones de HES de Canis latrans, en cada uno de los histogramas se puede observar una concentración extremadamente alta para el mes de marzo. Podemos encontrar una concentración de P4 muy alta para el mes de agosto, mientras que concentraciones altas de E2 y la $\mathrm{T}$ coinciden en el mes de octubre. Todos los histogramas son multimodales. (Figuras 5, 6 y 7). 

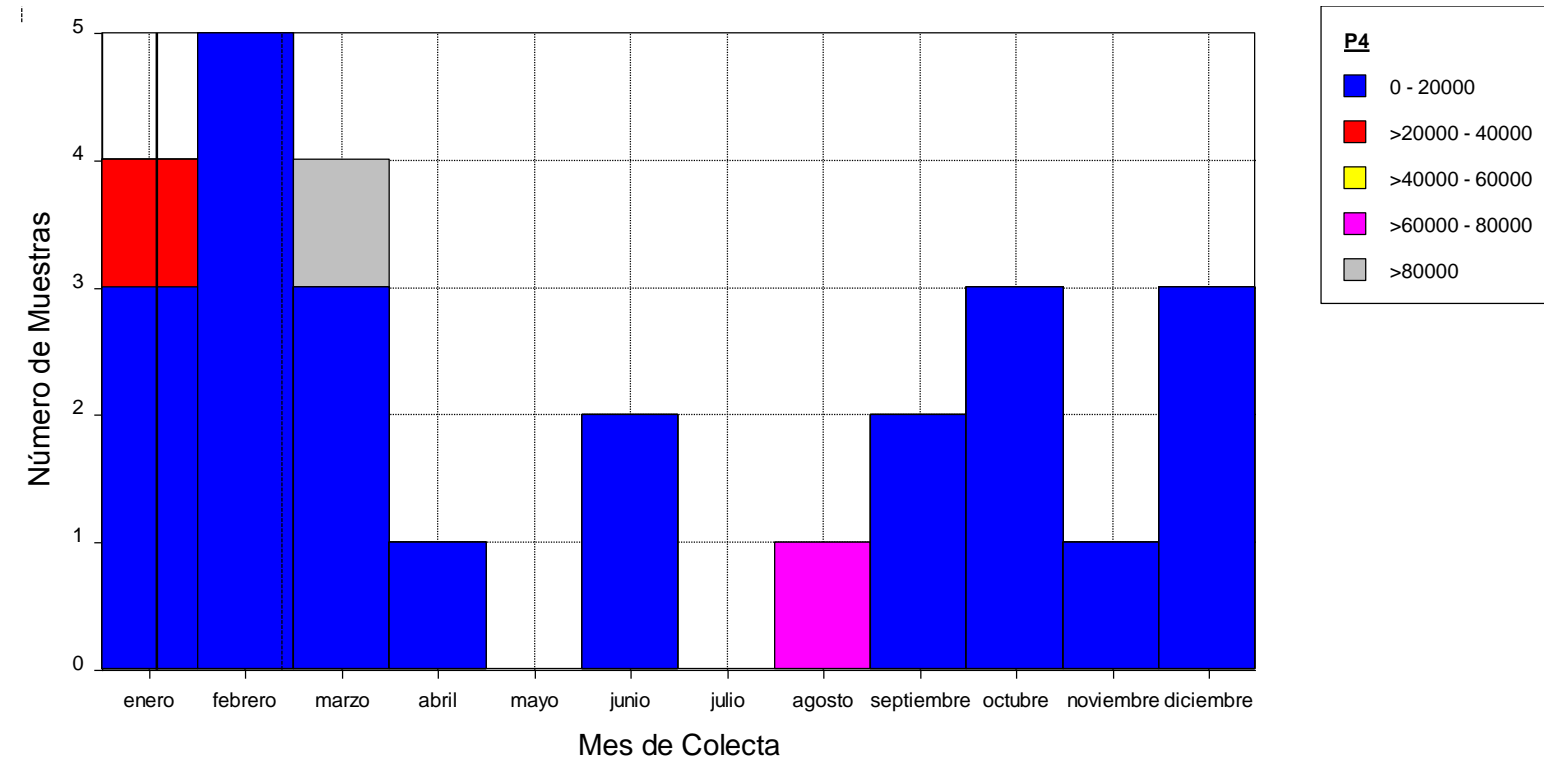

Figura 5. Distribución de P4 a lo largo de un ciclo anual en muestras de Canis latrans.
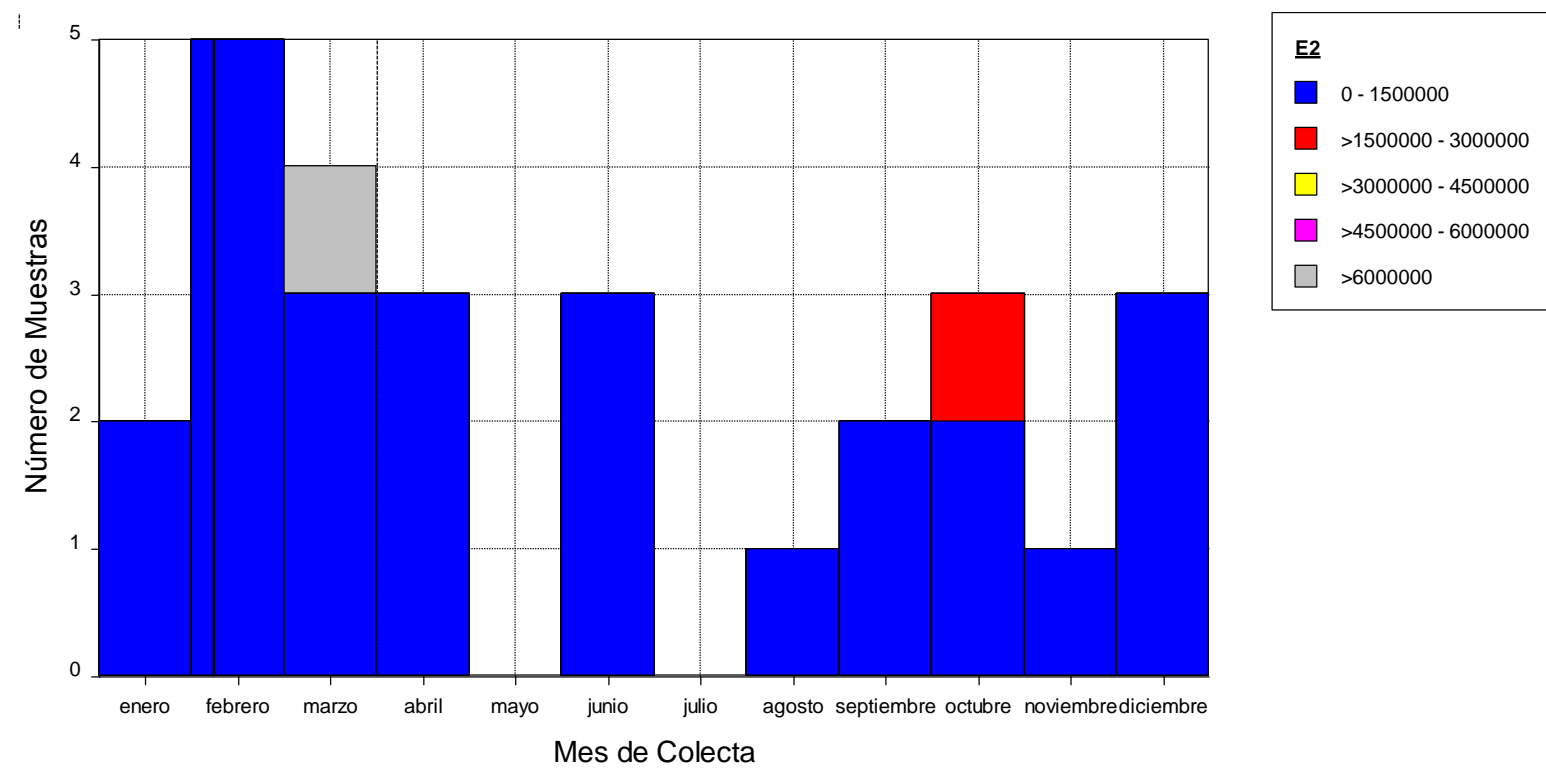

Figura 6. Distribución de E2 a lo largo de un ciclo anual en muestras de Canis latrans. 


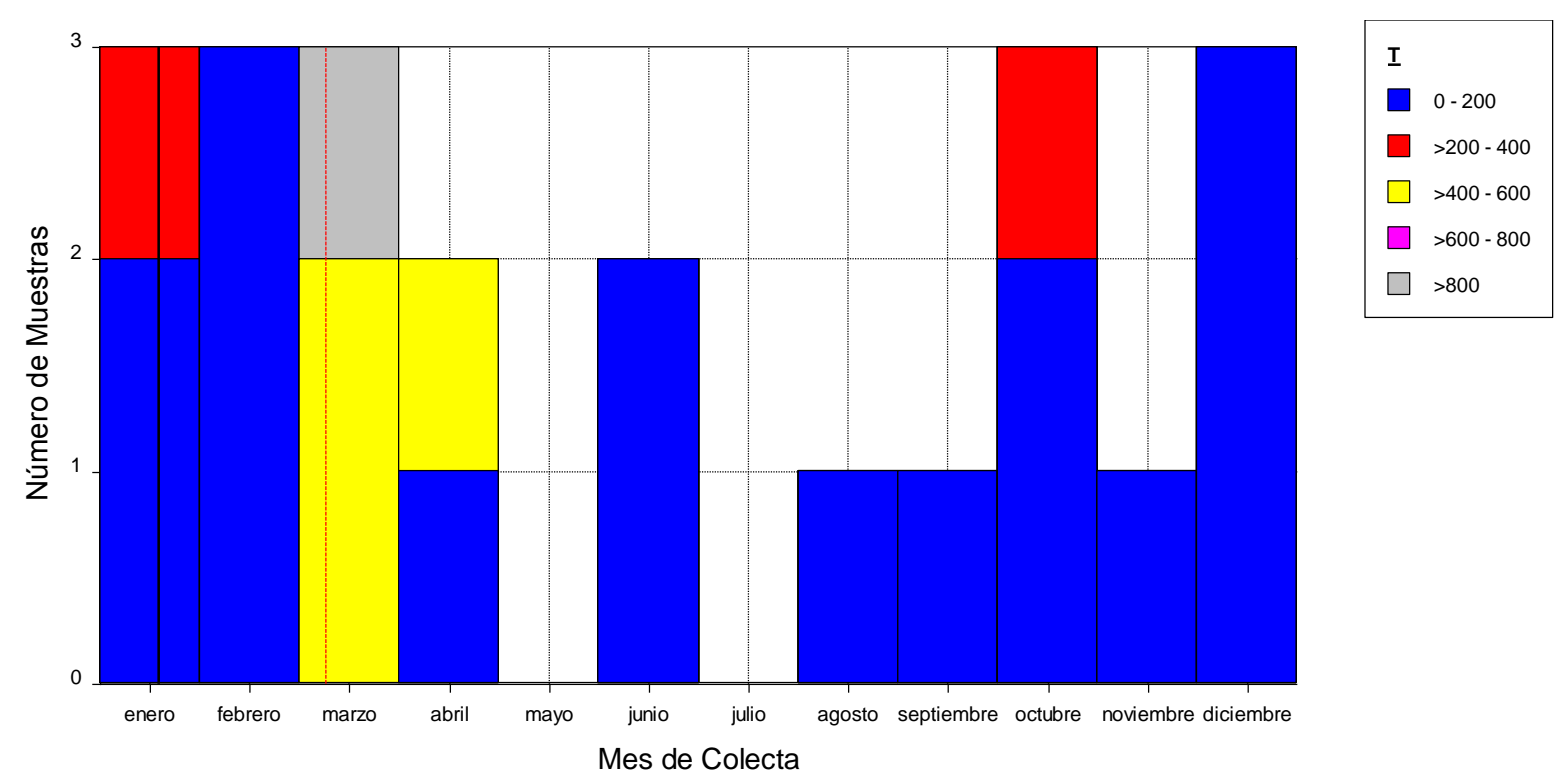

Figura 7. Distribución de $\mathbf{T}$ a lo largo de un ciclo anual en muestras de Canis latrans.

El resumen de resultados de estadística circular correspondiente a las HES de Canis latrans muestra que las distribuciones anuales de las tres hormonas tienen características similares de posición, concentración y varianza (Cuadro 14).

Cuadro 14. Estadísticos circulares para la distribución anual de HES de Canis latrans en el período 2012-2013.

\begin{tabular}{|l|l|l|l|}
\hline & P4 & E2 & T \\
\hline Variable & Mes de Colecta & Mes de Colecta & Mes de Colecta \\
\hline Tipo de dato & Mes del año & Mes del año & Mes del año \\
\hline Número de observaciones & 27 & 27 & 22 \\
\hline ¿Datos agrupados? & Sí & Sí & Sí \\
\hline Ancho de grupo (y número de grupos) & $30^{\circ}(12)$ & $30^{\circ}(12)$ & $30^{\circ}(12)$ \\
\hline Vector medio $(\boldsymbol{\mu})$ & $20.518^{\circ}$ & $37.369^{\circ}$ & $17.952^{\circ}$ \\
\hline Grupo medio & enero & febrero & enero \\
\hline Longitud del Vector Medio (r) & 0.337 & 0.282 & 0.327 \\
\hline Concentración & 0.717 & 0.588 & 0.692 \\
\hline Varianza circular & & & \\
\hline Desviación Estándar Circular & 0.663 & 0.718 & 0.673 \\
\hline
\end{tabular}


Distribución anual en la cuantificación de HES en las muestras de Urocyon cinereoargenteus

La distribución de las cuantificaciones de HES para Urocyon cinereoargenteus muestra gran variación para las tres hormonas a lo largo del año en las muestras analizadas. La mayor concentración de P4 se encuentra en enero de 2012, mientras que las concentraciones más altas del E2 se observan en los meses de septiembre, noviembre y diciembre del mismo año. Las mayores concentraciones de T se obtuvieron en los meses de enero y febrero. Los tres histogramas son bimodales (Figuras 8, 9 y 10).

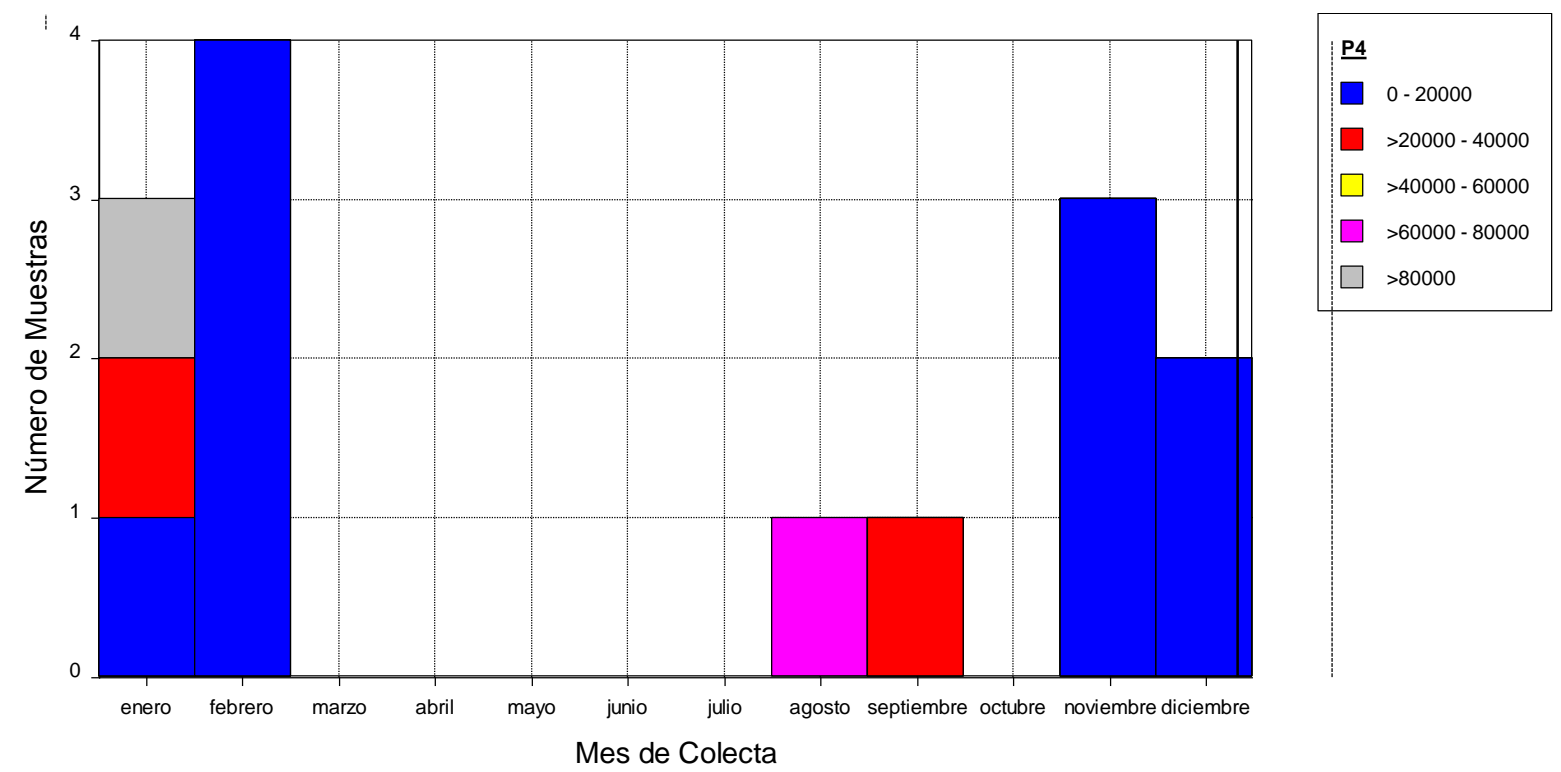

Figura 8. Distribución de P4 a lo largo de un ciclo anual en muestras de Urocyon cinereoargenteus. 


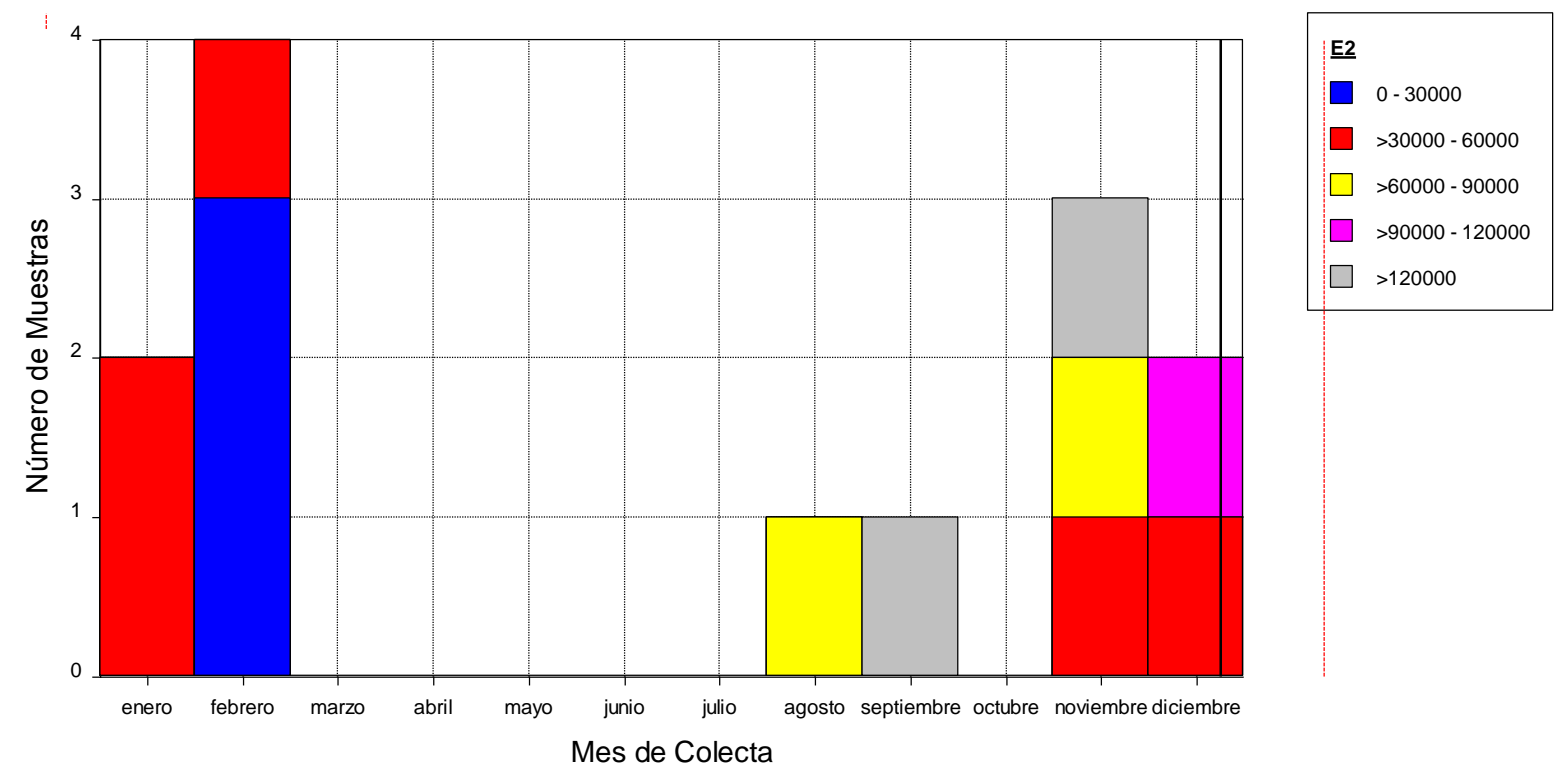

Figura 9. Distribución de E2 a lo largo de un ciclo anual en muestras de Urocyon cinereoargenteus.

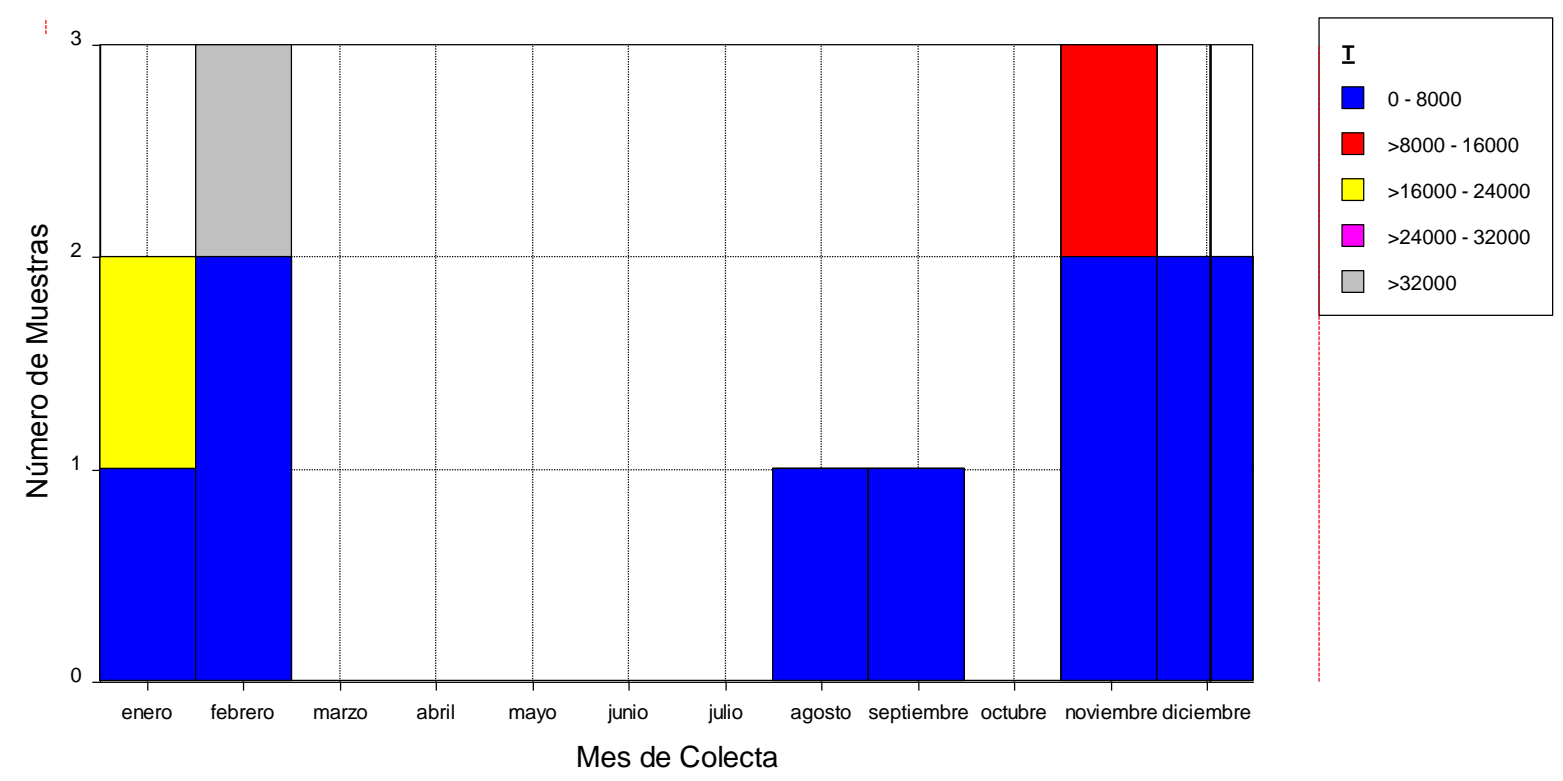

Figura 10. Distribución de T a lo largo de un ciclo anual en muestras de Urocyon cinereoargenteus.

Los estadísticos circulares para la distribución de las HES de Urocyon cinereoargenteus en el período 2012-2013 tienen características similares en cuanto a la posición del vector y el grupo medio, así como a la mediana y el grupo de mediana. También se puede observar que los valores de dispersión para las tres HES no son muy diferentes entre sí (Cuadro 15). 
Cuadro 15. Estadísticos circulares para la distribución anual de HES de Urocyon cinereoargenteus en el período 2012-2013.

\begin{tabular}{|l|l|l|l|}
\hline & P4 & E2 & T \\
\hline Variable & $\begin{array}{l}\text { Mes de } \\
\text { Colecta }\end{array}$ & $\begin{array}{l}\text { Mes de } \\
\text { Colecta }\end{array}$ & $\begin{array}{l}\text { Mes de } \\
\text { Colecta }\end{array}$ \\
\hline Tipo de dato & Mes del año & Mes del año & Mes del año \\
\hline Número de observaciones & 14 & 13 & 12 \\
\hline ¿Datos agrupados? & Yes & Yes & Yes \\
\hline $\begin{array}{l}\text { Ancho de grupo }(\mathbf{y} \text { número de } \\
\text { grupos) }\end{array}$ & $30^{\circ}(12)$ & $30^{\circ}(12)$ & $30^{\circ}(12)$ \\
\hline Vector medio $(\boldsymbol{\mu})$ & $355.413^{\circ}$ & $352.983^{\circ}$ & $346.813^{\circ}$ \\
\hline Grupo medio & diciembre & diciembre & diciembre \\
\hline Longitud del Vector Medio $(\mathbf{r})$ & 0.639 & 0.615 & 0.618 \\
\hline Concentración & 1.593 & 1.475 & 1.48 \\
\hline Varianza circular & 0.361 & 0.385 & 0.382 \\
\hline Desviación Estándar Circular & $54.242^{\circ}$ & $56.475^{\circ}$ & $56.194^{\circ}$ \\
\hline
\end{tabular}

Distribución anual en la cuantificación de HES en las muestras de Procyon lotor

En el caso del mapache, la distribución anual de HES fue consistente para P4 y E2, pues ambas presentan la máxima concentración en septiembre de 2012, mientras que la mayor concentración de $\mathrm{T}$ se obtuvo en el mes de enero. Los tres histogramas son bimodales (Figuras 11, 12 y 13). 


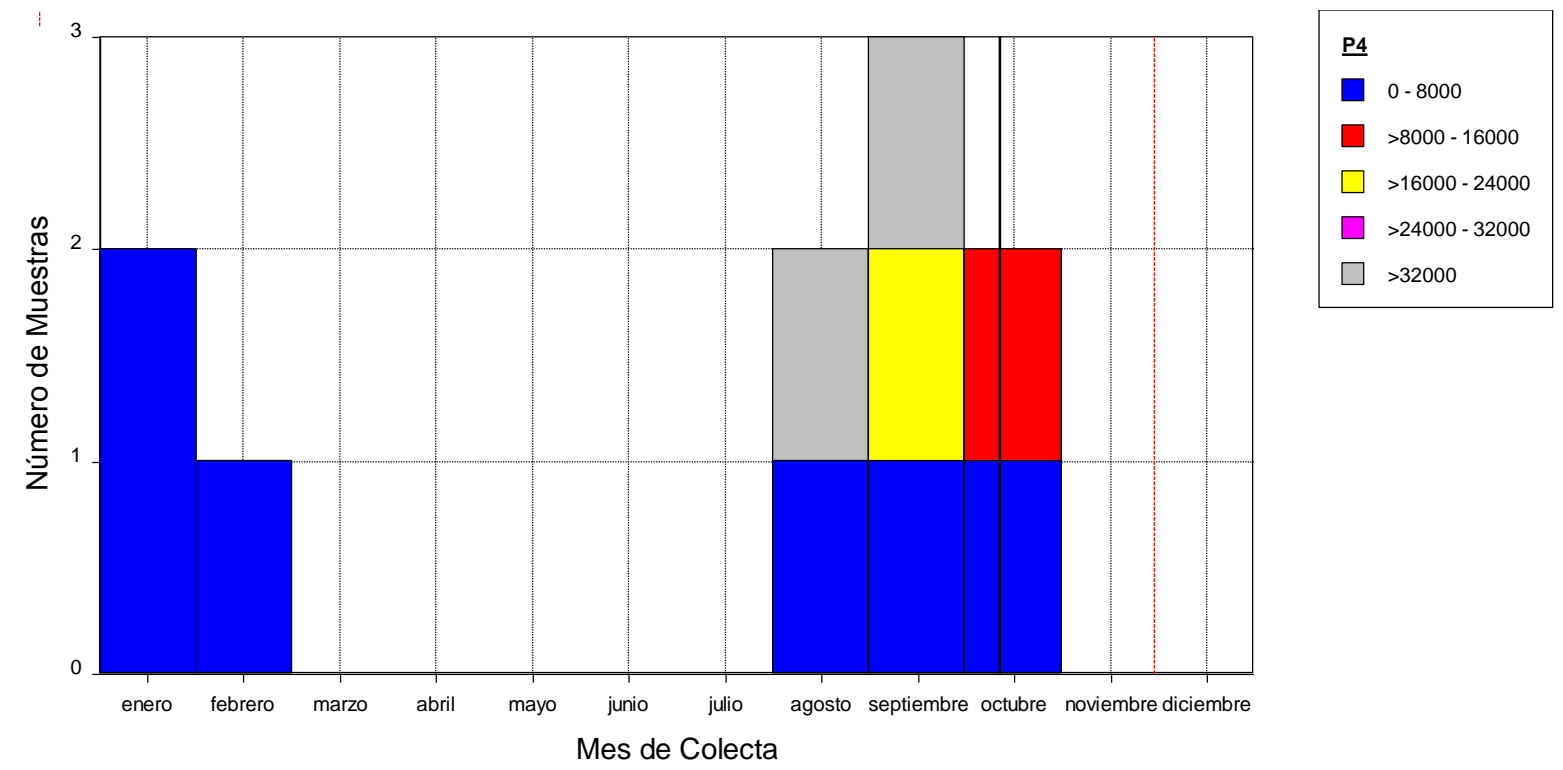

Figura 11. Distribución de P4 a lo largo de un ciclo anual en muestras de Procyon lotor.

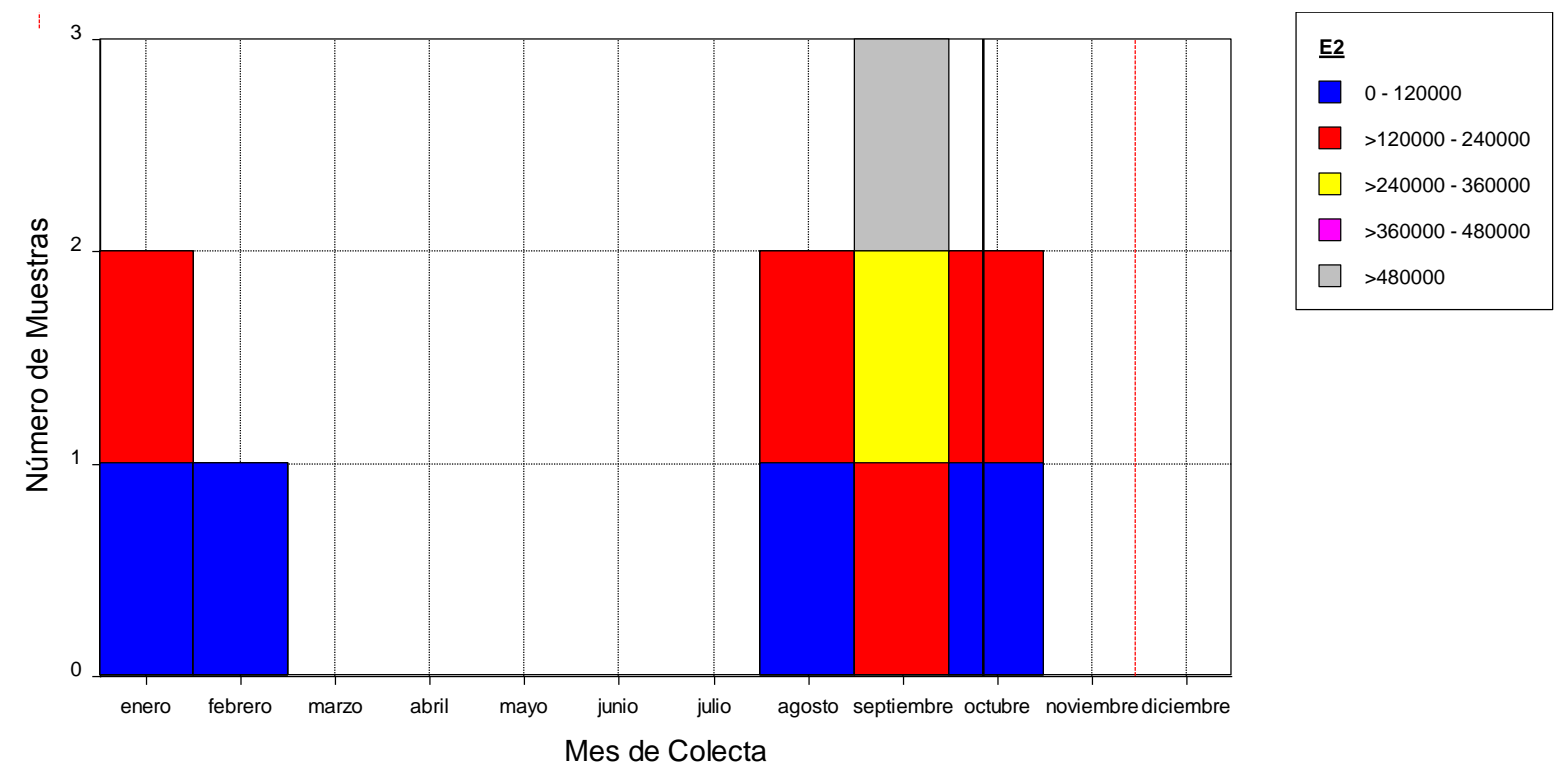

Figura 12. Distribución de E2 a lo largo de un ciclo anual en muestras de Procyon lotor. 


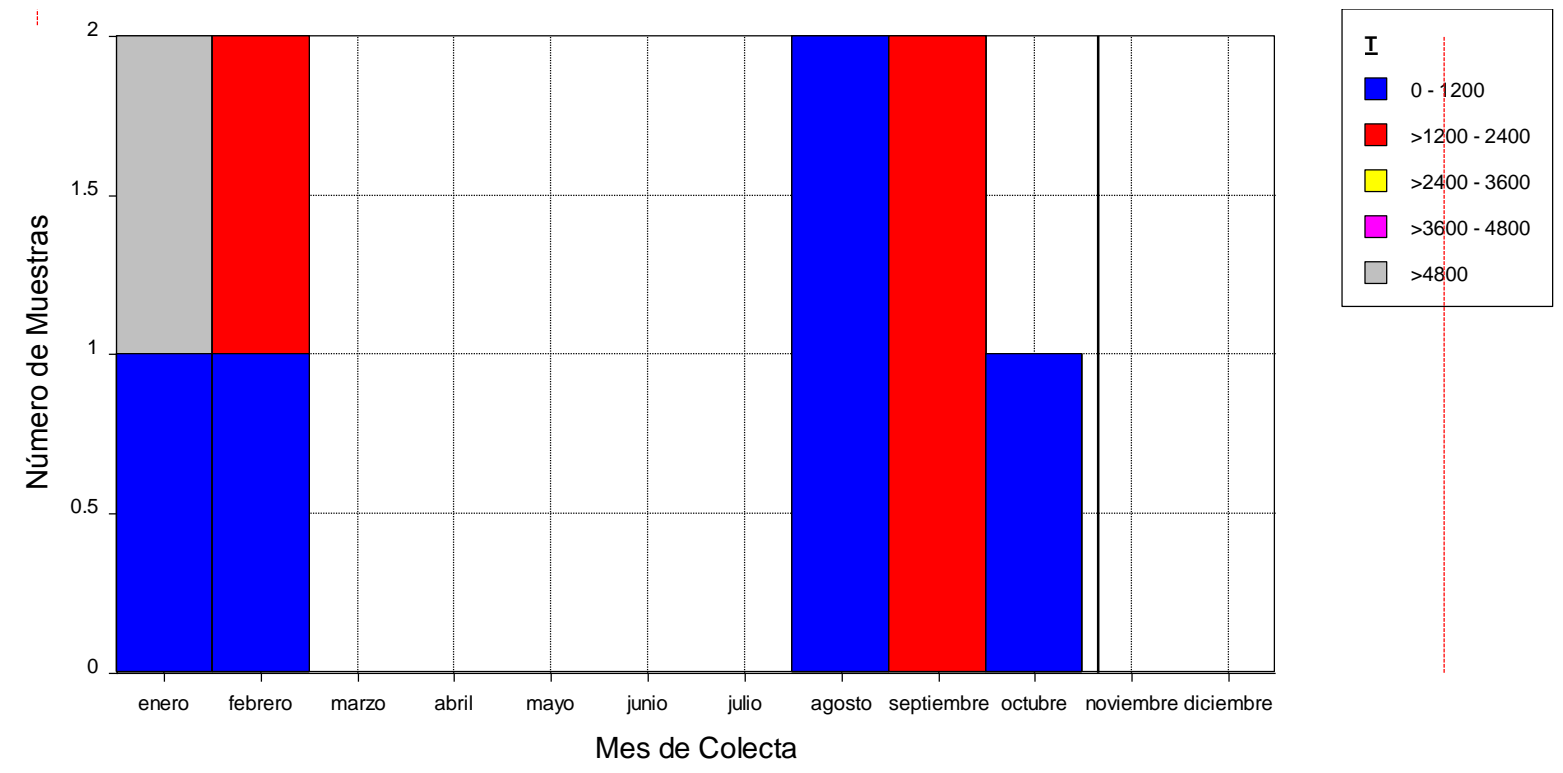

Figura 13. Distribución de T a lo largo de un ciclo anual en muestras de Procyon lotor.

De acuerdo a los estadísticos circulares, la distribución anual de HES de Procyon lotor para el período 2012-2013 tiene características de posición similares para las tres hormonas, sin embargo, la T muestra una dispersión significativa, mientras que los datos de P4 y E2 tienen una mayor concentración (Cuadro 15).

Cuadro 15. Estadísticos circulares para la distribución anual de HES de Procyon lotor en el período 2012-2013.

\begin{tabular}{|l|l|l|l|}
\hline & P4 & E2 & T \\
\hline Variable & Mes deColecta & Mes deColecta & Mes deColecta \\
\hline Tipo de dato & Mes del año & Mes del año & Mes del año \\
\hline Número de observaciones & 10 & 10 & 9 \\
\hline ¿Datos agrupados? & Yes & Yes & Yes \\
\hline Ancho de grupo (y número de grupos) & $30^{\circ}(12)$ & $30^{\circ}(12)$ & $30^{\circ}(12)$ \\
\hline Vector medio $(\boldsymbol{\mu})$ & $280.893^{\circ}$ & $280.893^{\circ}$ & $305.104^{\circ}$ \\
\hline Grupo medio & $0 c t u b r e$ & octubre & noviembre \\
\hline Longitud del Vector Medio (r) & 0.517 & 0.517 & 0.327 \\
\hline Concentración & 1.037 & 1.037 & 0.371 \\
\hline Varianza circular & 0.483 & 0.483 & 0.673 \\
\hline Desviación Estándar Circular & $65.813^{\circ}$ & $65.813^{\circ}$ & $85.67^{\circ}$ \\
\hline
\end{tabular}




\section{Promedios de HES por estación}

Con el objetivo de comparar las cuantificaciones de HES en las diferentes temporadas, las muestras colectadas de cada especie fueron organizadas en estación de lluvias y de secas del período 2012-2013.

Se presentan las gráficas de comparación de los promedios por estación para Canis

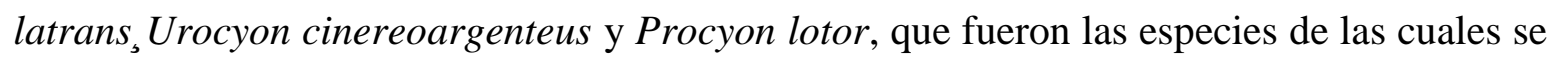
colectó el mayor número de muestras. La P4 y la T se presentan en nanogramos por gramo (ng/gr), mientras que el E2 se presenta en picogramos por gramo (pc/gr).

Promedios de HES de Canis latrans en las estaciones de lluvias y secas

En los promedios obtenidos de las cuantificaciones de HES de Canis latrans en las estaciones de lluvias y secas se aprecian diferencias en la distribución de la P4 y el E2 (Figura 14). 

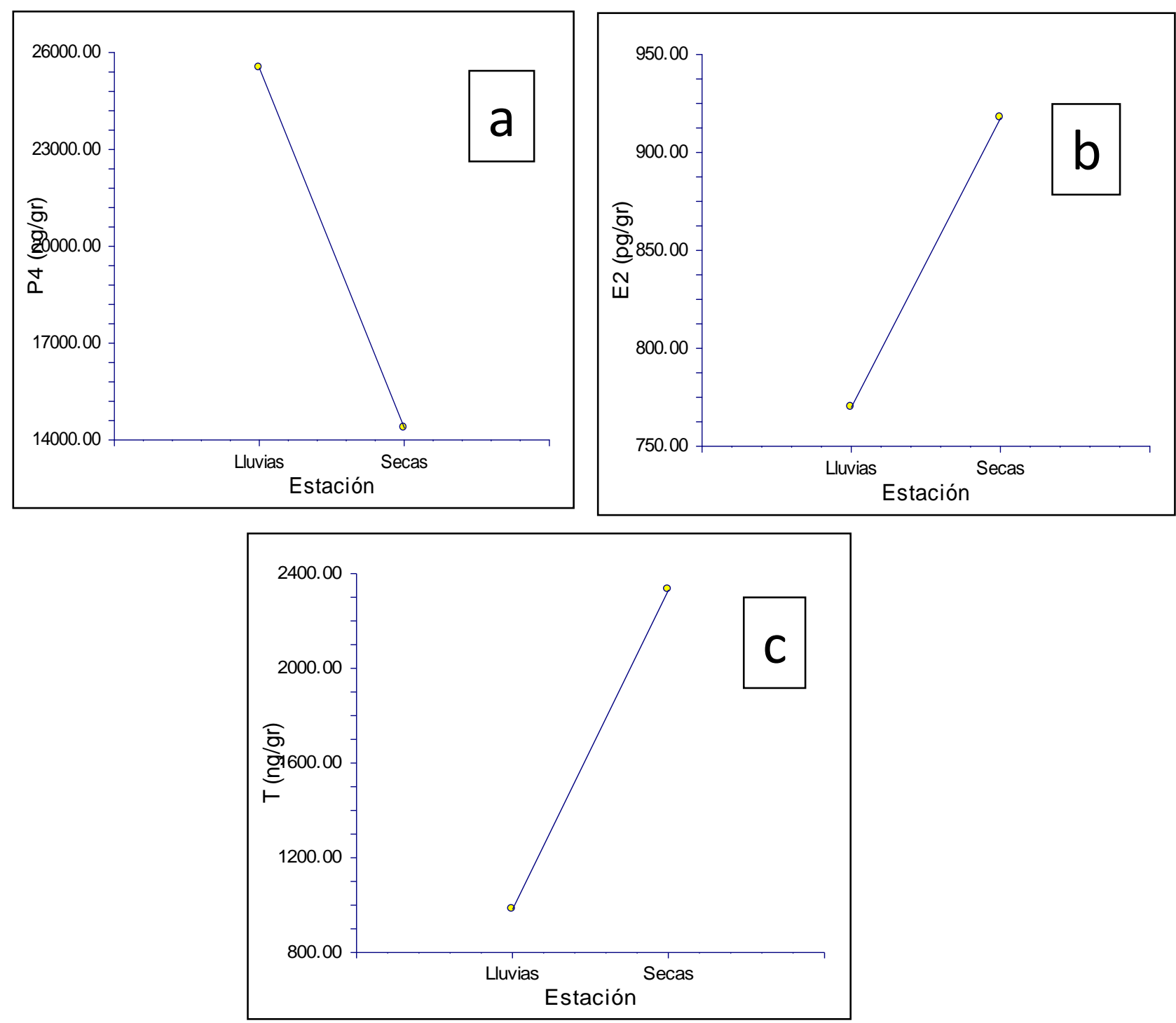

Figura 14. Comparaciones de promedios de HES de Canis latrans por estación: a) P4, b) E2 (en picogramos) y c) $\mathbf{T}$.

Para comprender la diferencia entre promedios de P4 y E2 entre las estaciones de lluvias y de secas es necesario recordar que Canis latrans es una especie social, que responde a diferentes factores como la densidad poblacional y la disponibilidad de alimento para iniciar su ciclo reproductivo.

La coincidencia de altas concentraciones de E2 y T podría ser evidencia de que, por lo menos una hembra y un macho, sincronizaron sus ciclos reproductivos como respuesta a factores ambientales o poblacionales. 
Promedios de HES de Urocyon cinereoargenteus en las estaciones de lluvias y secas

Para Urocyon cinereoargenteus, tanto el promedio de la P4 como del E2 tienen la misma distribución y muestran una clara diferencia en cuanto al promedio de la T (Figura 15).
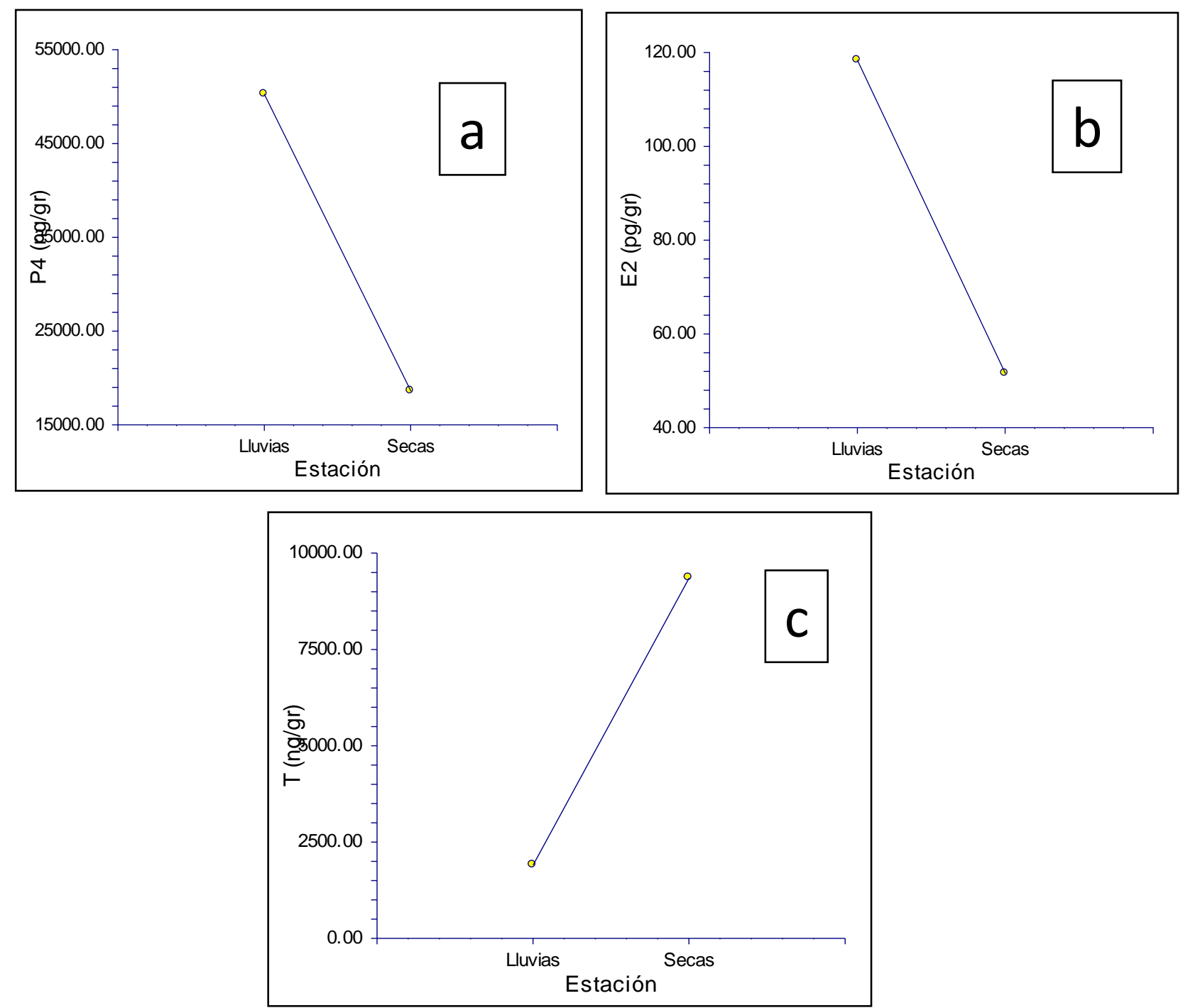

Figura 15. Comparaciones de promedios de HES de Urocyon cinereoargenteus por estación: a) P4, b) E2 (en picogramos) y c) T.

En el caso de Urocyon cinereoargenteus, los promedios de la P4 y el E2 parecen coincidir adecuadamente para describir el ciclo reproductivo de una hembra, pues ambas hormonas tendrían su pico máximo durante la época de mayor disponibilidad de recursos, en este caso, la estación de lluvias. 
Promedios de HES de Procyon lotor en las estaciones de lluvias y secas

Tanto la P4 y el E2 para Procyon lotor tienen los mayores promedios durante la estación de lluvias (Figura 16). Esta distribución es diferente para la T, pues el mayor promedio se presenta durante la temporada de secas.
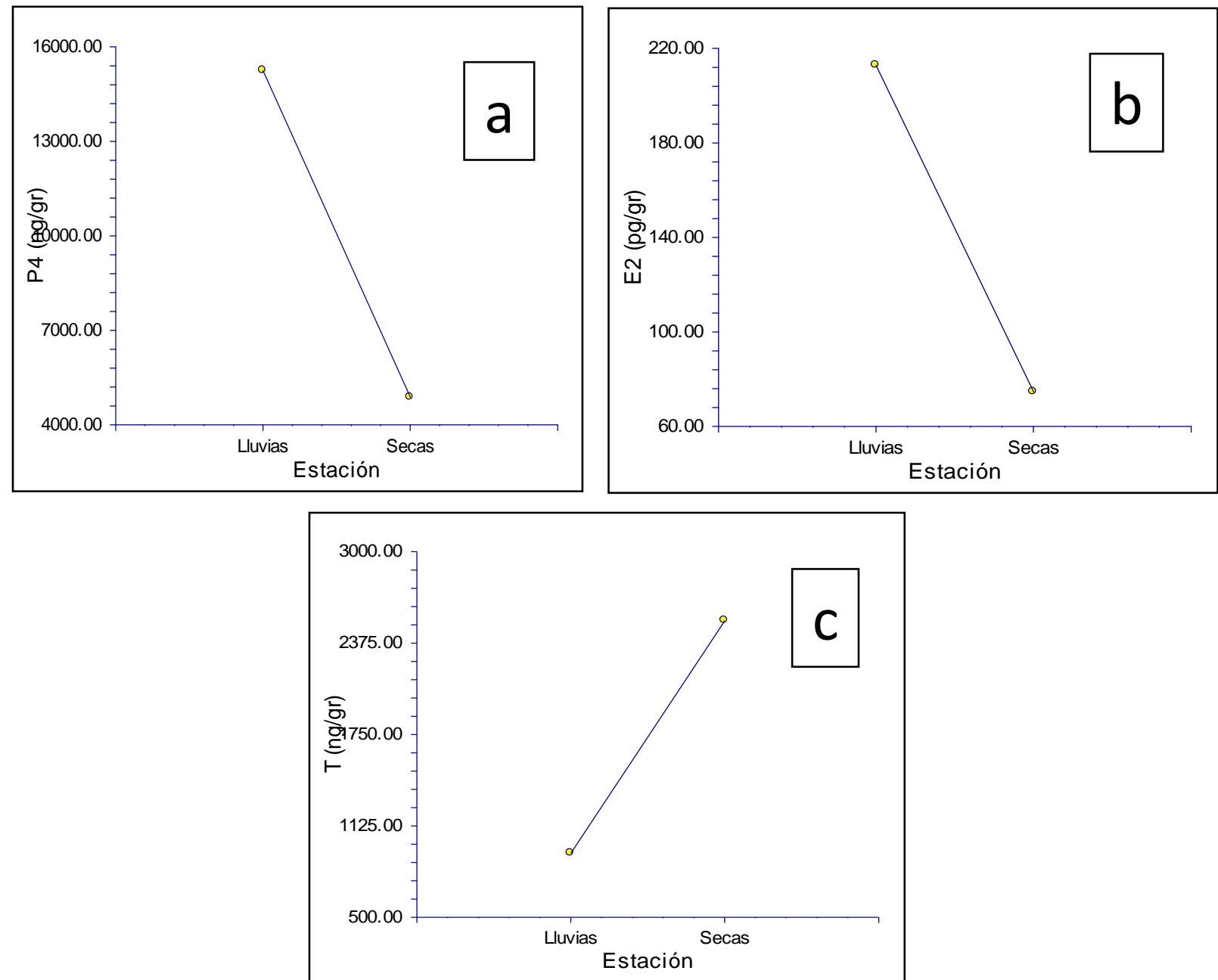

Figura 16. Comparaciones de promedios de HES de Procyon lotor por estación: a) P4, b) E2 (en picogramos) y c) $\mathbf{T}$.

Estas distribuciones por estación podrían corresponder a una hembra, pero no hay que olvidar que con este método no es posible identificar a qué sexo corresponde cada muestra. 


\section{Discusión y Conclusiones}

Las formas para expresar los resultados de las cuantificaciones de HES de los mesodepredadores en vida libre pueden tener diferentes interpretaciones y limitaciones. Se puede observar que los perfiles anuales (Figuras 2, 3 y 4) permiten expresar en una sola gráfica los contenidos promedio de las HES a lo largo del ciclo de estudio. Sin embargo, su obtención a partir de los promedios puede ser su principal limitante. Al desconocer el sexo de los animales de los cuales provienen las muestras se están mezclando resultados de hembras y macho por igual, sin establecer diferencias entre las mismas. En estudios con animales en cautiverio, donde se conoce el sexo y la cantidad de animales, este tipo de gráficas pueden ser muy prácticas, sin embargo, en estudios con fauna silvestre, en los cuales se desconoce el sexo e incluso el número de animales de los cuales provienen las muestras, los perfiles pueden ser inexactos. Aun así, los perfiles anuales pueden ser un indicador de la distribución anual de HES a nivel especie.

Por otro lado, las distribuciones anuales de HES realizadas con estadística circular (Figuras 5 a 13), permiten entregar un resultado gráfico en el cual se observa la concentración para cada una de las muestras, y por consiguiente, se puede observar también la variación de HES por especie a lo largo del período de estudio. Otros datos como el ángulo promedio, la dispersión y la concentración también son muy útiles en casos como este, donde todos los datos tuvieron una distribución no-normal. La estadística circular aplicada permitió observar en qué meses del período de estudio se encontraron muestras con mayores concentraciones de HES, como es el caso de la T, que para las tres especies siempre mostró las concentraciones más altas en los meses de diciembre a febrero, meses en que hace mayor frío y hay menos recursos disponibles, puesto que la temporada de lluvias termina a mediados de octubre. Si las muestras que tienen las concentraciones más altas de T, correspondiesen a machos, podría deberse a que se encuentran en temporada reproductiva, pero no hay una clara correspondencia con la P4 y el E2. Otra posibilidad es que durante este período de escases de recursos, tanto hembras como machos se ven sometidos a una mayor competencia intra e interespecífica, lo que también puede llevar a un aumento de T (Albert et al.,1989). 
Tomando en cuenta las distribuciones anuales con estadística circular, se podría pensar que los momentos de mayor concentración de hormonas no necesariamente coinciden con la temporada reproductiva que reporta la bibliografía. En el caso del Canis latrans, autores como Bekoff (1977), Carlson y Gese (2008), señalan que la temporada de reproducción de esta especie es principalmente en los meses de enero a marzo y que las hembras sólo tienen un período de estro por año. En nuestro estudio encontramos la mayor concentración de P4 en septiembre y lo mismo para E2. Solamente la $\mathrm{T}$ parece coincidir con el período reportado por los autores mencionados, pues podemos observar que la concentración más alta se obtuvo en el mes de enero.

Para Urocyon cinereoargenteus, Sullivan (1956), Fritzell y Hardoldson (1982), ubican la actividad reproductiva desde finales de enero hasta mayo. En las muestras que obtuvimos las concentraciones más altas de P4 y T para esta especie se encontraron en enero, lo que coincide con los autores mencionados. Sin embargo, el E2 muestra un comportamiento muy irregular, pues podemos observar concentraciones significativas desde agosto hasta diciembre (Figuras 8, 9 y 10).

Algo similar ocurre con los datos Procyon lotor, pues las mayores concentraciones de P4 y E2 se ubican en el mes de septiembre, mientras que la T tiene su mayor expresión en enero (Figuras 11, 12 y 13). Para esta especie, Lotze y Anderson (1979) han ubicado la temporada reproductiva desde diciembre hasta junio, dependiendo de la latitud.

Para analizar las diferencias de los datos obtenidos con las temporadas reproductivas reportadas para cada especie, hay que considerar en primer lugar lo mencionado por Asa y Valdespino (1998) y Kleiman y Eisenberg (1973), quienes hacen énfasis en que la reproducción de especies como estas, en estado natural y sin ninguna intervención humana, depende de una combinación clave de elementos fisiológicos, de comportamiento social y por supuesto de disponibilidad de recursos.

También hay que señalar que gran parte de la biología de estas especies ha sido estudiada en latitudes correspondientes al zona neártica, donde los cambios estacionales son muy marcados y obviamente la disponibilidad de alimento y la temperatura varían mucho, mientras que en la zona del estudio, que se encuentra en una ubicación cercana al neotrópico, el clima es más estable a lo largo del año (Valdespino, 2007; Bronson, 2009). 
Todos estos factores pueden dar como resultado que las temporadas reproductivas de los mesodepredadores en las áreas cercanas a Santo Tomás Otlaltepec ocurran en momentos diferentes a los que señalan autores como Bekoff (1977), Fritzell y Haroldson (1982) y Lotze y Anderson (1979).

Lo anterior también podría sustentarse con los resultados de las comparaciones de promedios de HES por estación para Urocyon cinereoargenteus y Procyon lotor, donde se aprecian las mayores concentraciones de estrógenos en la estación de lluvias (Figuras 15 y 16).

En la distribución de HES de Canis latrans el E2 es más alto durante la temporada de secas (Figura 14), pero al observar la figura 9, se puede apreciar que la mayor concentración de esta hormona se presenta en marzo, es decir, antes de la temporada de lluvias, así que podría tratarse de una hembra que inicia el proestro (Bekoff, 1977). No hay que olvidar que los machos también pueden llegar a tener altas concentraciones de estrógenos, como se muestra en el estudio de Canis lupus baileyi realizado por Soto et al. (2004).

En cuanto a la extracción de metabolitos de hormonas a partir de excretas provenientes de animales en vida libre, hay varios factores a tomar en cuenta. Consideramos que la alimentación de las especies de interés es un factor clave en la aplicación de esta técnica, pues es necesario obtener el peso seco de las excretas para el cálculo del EIA. Muchas de las excretas que procesamos en laboratorio estaban compuestas por un gran porcentaje de pelo y contenido vegetal, restos de animales, y en menor medida, componentes inorgánicos como restos de piedras o arena. Esto resulta en un muy bajo peso seco de excremento final. Esta situación no ocurre con especies en cautiverio, pues la alimentación es muy controlada. La aplicación de la técnica en especies cuya alimentación es estrictamente carnívora también favorece la obtención del peso seco, pues las excretas correspondientes a estas especies están compuestas por pellets macizos y casi siempre uniformes.

En el caso de los mesodepredadores de Santo Tomás Otlaltepec, todas las especies de interés tienen una alimentación generalista. La única especie con una alimentación carnívora estricta es Lynx rufus, cuya muestra colectada coincidía con la descripción citada: un pellet macizo y uniforme. 
Consideramos que el método por sí mismo se puede tomar como referente para futuros trabajos similares, principalmente en la obtención del peso seco. Excretas de especies como el coyote pueden tener un gran contenido de pelo y semillas, dependiendo de la temporada. Algo similar ocurre con las excretas de Urocyon cinereoargenteus y Bassariscus astutus, las cuales tienen también gran contenido de semillas. Las excretas de zorrillos suelen estar compuestas principalmente por aglomerados de restos de insectos, los cuales son sus principales presas.

Otro factor que habría que considerar, es precisamente el número de especies de estudio. En trabajos posteriores, sería preferible limitarse a una o dos especies. Esto podría ser especialmente útil en estudios de excretas las dos especies de zorrillo presentes en la zona, Conepatus leuconotus y Mephitis macroura. Las excretas de ambas especies son muy similares, pues su alimentación es prácticamente la misma.

Es muy recomendable la continuación de estudios escatológicos con mesodepredadores en esta área. Esto enriquecería el conocimiento acerca de las especies y su comportamiento. Como ya se ha mencionado, la endocrinología de campo es sólo una de las vertientes que tiene el trabajo con excretas y quizá es esta disciplina en la que se necesita más información y por lo tanto más investigaciones. 


\section{Conclusión general}

Los tres capítulos de este trabajo ofrecen, en forma individual, indicadores sobre el comportamiento de los mesodepredadores en vida libre.

El capítulo I, nos permite comprobar, por medio del uso de las cámaras-trampa, que los horarios de actividad de los mesodepredadores en áreas semi-rurales se apegan bastante a lo reportado por los especialistas en estas especies (Bekoff, 1977; Fritzell y Haroldson, 2009; Larivière y Walton, 1997; Dragoo y Sheffield, 2009; Hwang y Larivière, 2001; Lotze y Anderson, 1979; McManus, 1974; Poglayen-Neuwall yToweill, 1988). Habiendo sido utilizado en forma extensiva en este trabajo, queda demostrado que es un método no invasivo y resulta efectivo en los inventarios de fauna, ya que se registró el $75 \%$ de las especies que potencialmente se encontraban listadas para la zona. El objetivo de comprobar la presencia de las especies de interés y de evaluar sus horarios de actividad se cumplió plenamente.

En el capítulo II podemos encontrar indicadores sobre cómo usan el ambiente los mesodepredadores para marcar por medio de excretas. Los resultados de este capítulo pueden mostrar cómo utilizar la colecta de excretas y las calificaciones del marcaje para posibles estudios de competencia intra- e interespecífica. La ubicación de las letrinas también ofrece vertientes interesantes para estudios de ecología del comportamiento. Se podrían retirar todas las excretas de las letrinas y registrar cuánto tardan en volver a usarla los mesodepredadores, y si, de alguna forma, esto afecta en su distribución o uso de recursos.

En el capítulo III, se considera la posibilidad de que las temporadas de reproducción de Canis latrans, Urocyon cinereoargenteus y Procyon lotor que mencionan autores como Bekoff (1977), Fritzell y Haroldson (2009) y Lotze y Anderson (1979), no coinciden estrictamente con las temporadas de reproducción para los mesodepredadores del área de estudio. Esto hace necesario que exista más investigación con mesodepredadores en estado silvestre en esta zona. Como se menciona en ese capítulo, podrían hacerse estudios escatológicos y de endocrinología de campo para especies como Canis latrans, o bien analizar las diferencias entre las excretas de Urocyon cinereoargenteus y Bassariscus 
astutus, las cuales son muy similares, e incluso se pueden realizar estudios para comparar las excretas de las dos especies de zorrillo que se encuentran en el área. Los contenidos de las excretas ofrecen un campo de estudio por sí mismo, pues se puede analizar el contenido dependiendo de la temporada, la presencia de ganado, la disponibilidad de agua y otros factores. La determinación de peso seco para estas excretas también es un área poco estudiada y que merece atención por parte de los biólogos que estudian la ecología del comportamiento.

Desde una perspectiva de la ecología del comportamiento, los tres capítulos están conectados por la forma en la que los individuos usan los recursos. El primer capítulo se refiere al tiempo, el segundo al espacio y el tercero a la temporada reproductiva de cada especie. Es muy claro que la actividad de los individuos aumenta después de la temporada de lluvias, cuando hay mayor disponibilidad de agua y hay mayores recursos alimenticios. Podemos observar asimismo, el carácter generalista de estas especies, y más aún, su posible dominancia. Los indicadores señalan que Canis latrans y Urocyon cinereoargenteus son las especies que tienen una mayor área de actividad, pues fue posible encontrar excretas de estas especies en prácticamente toda el área de trabajo, mientras que especies como los zorrillos, limitan su área de actividad a zonas cercanas a los arroyos. Esto mismo se aplica para los horarios de actividad, pues la zorra y el coyote son las que muestran horarios de actividad más amplios. Los resultados del análisis de marcaje con las excretas sugieren esta misma dominancia, si se consideran como señales delimitadoras del territorio.

Este estudio, aún con su carácter exploratorio, forma parte una base de conocimiento para posibles estudios en los que se puedan utilizar los tres métodos: el uso de cámaras-trampa, la calificación del marcaje y el contenido de hormonas esteroides en heces. Si se logra depurar el método para determinar el peso seco de las excretas de estas especies, sería posible relacionar el comportamiento de marcaje con el contenido hormonal, y al mismo tiempo usar cámaras-trampa para obtener registros fotográficos y de video para explorar el comportamiento de marcaje de las especies. 


\section{Bibliografía}

Albert, D., Petrovic, D., Walsh, M. 1989. Competititive experience activates testosteronedependent social aggression towards unfamiliar males. Physiology \& Behavior. Vol. 45. Pp. 723-727.

Aranda, M. 2000. Huellas y otros rastros de los mamíferos grandes y medianos de México. CONABIO. Instituto de Ecología, A.C. México. 211 pp.

Arriaga, L., J.M., Espinoza, C. Aguilar, E., Martínez, L. y Gómez, E. (coordinadores). 2000. Regiones terrestres prioritarias de México. Comisión Nacional para el Conocimiento y uso de la Biodiversidad. México. (Disponible en línea: http://www.conabio.gob.mx/conocimiento/regionalizacion/doctos/terrestres.html).

Asa, Ch. 1996. Reproductive Physiology. En: Holly, S.H., D.G.Kleiman, M.E: Allen, K.V. Thompson, y S. Lumpkin, (Eds.) Wild mammals in captivity. Principles and techniques. The University of Chicago Press. Chicago, U.S.A. pp. 390-417.

Asa, Ch., Valdespino, C. 1998. Canid Reproductive Biology: An Integration of Proximate Mechanisms and Ultimate Causes. American Zoologist. Vol. 38. Pp. 251-259.

Bang, P., Dahlsrom, P. 1974. Animal tracks and signs. Collins, London. 240 pp.

Barja, I. 2006. La cuantificación de hormonas esteroides sexuales en heces de lobo ibérico (Canis lupus signatus): Un método no invasivo de sexado como alternativa a los análisis moleculares. Oppidum. Núm. 2. Pp. 363-380.

Barja, I., Silván, G., Ilera, J. 2006.La cuantificación de hormonas esteroides sexuales en heces de lobo ibérico (Canis lupus signatus): Un método no invasivo de sexado como alternativa a los análisis moleculares. Oppidum. Núm. 2. Pp. 363-380.

Barja, I., Silván, G., Ilera, J. 2008. Relationships between sex and stress hormone levels in feces and marking behavior in a wild population of iberian wolves (Canis lupus signatus). J. Chem. Ecol. Vol. 24. Pp. 697 -701.

Barja. I. y List, R. 2006. Faecal marking behavior in ringtails (Bassariscus astutus) during the non-breeding period: spatial characteristics of latrines and single faeces. Chemoecology. Vol. 16. Pp. 219-222. 
Barnard, C.J. 2004. Animal Behaviour: Mechanism, Development, Function and Evolution. Harlow, England. Pearson/Prentice Hall. 726 pp.

Beach, F. 1970. Sexo y conducta. Siglo XXI editors, S.A. 416 pp.

Bekoff, M. 1977. Canis latrans. Mammalian Species. No. 79. Pp. 1-9.

Betancur, L., Fernández, J., Ocampo, R., Ríos, L. 2006. Técnicas inmunoquímicas para análisis en residuos pesticidas. Revista Universidad de Caldas. Enero- Diciembre 2006. Pp. 105-122.

Botello, F., Illoldi, P., Linaje, M. y Sánchez, V. 2006. Primer registro del tigrillo ( Leopardus wiedii, Schinz 1821) y del gato montés (Lynx rufus, Kerr 1792) en la Reserva de la Biósfera de Tehuacán-Cuicatlán, Oaxaca, México. Acta Zoológica Mexicana. Vol. 22. Pp. 135-139.

Bronson, F. 2009. Climate Change and Seasonal Reproduction un Mammals. Philosophical Transactions of the Real Society. Vol. 364. Pp: 3331-3340.

Brousset, D. M., Galindo, F., Valdez, R., Romano, M., Schuneman, A. 2005. Cortisol en saliva, orina y heces: evaluación no invasiva en mamíferos silvestres. UNAM. Veterinaria México. Vol. 36. Núm. 003. Pp. 325-337.

Carlson, D., Gese, E. 2008. Reproductive Biology of the Coyote (Canis latrans): Integration of Matin Behavior, Reproductive Hormones, and Vaginal Cytology. Journal of Mammalogy. Vol. 89. Pp. 654-664.

Castellanos, G. 2006. Sobre el ámbito hogareño y los hábitos alimentarios de un carnívoro en ambiente suburbano. El Cacomixtle (Bassariscus astutus) en la reserva ecológica “El Pedregal de San Ángel”. Ciudad Universitaria. México, D.F. Tesis. Facultad de Ciencias. UNAM. 94 pp.

Cuthill, I.C. 2005. The study of function in behavioural ecology. Anim. Biol. Vol. 55. Pp: 399-417.

Cutler, T. y Swann, D. 1999. Using remote photography in wildlife ecology: a review. Wildlife Society Bulletin. Vol. 27. No. 3. Pp. 571-581. 
Dragoo, J. y Sheffield, S. 2009. Conepatus leuconotus (Carnivora: Mephitidae). Mammalian Species. No. 827. Pp. 1-8.

Dragoo, J., Honeycutt, R. y Schmidly, D. 2003. Taxonomix status of white-backed hognosed skunks, genus Conepatus (Carnivora: Mephitidae). Journal of Mammalogy. Vol. 84. Pp. 159-176.

Espejo, I., Fernández, F., López, M.A., Muñoz, M., Rodríguez, A., Sánchez, A., Valero, C. 2007. Inferencia Estadística. Servicio de Publicaciones de la Universidad de Chile. $263 \mathrm{pp}$.

Fritzell, E. y Haroldson, J. 1982. Urocyon cinereoargenteus. Mammalian Species. No. 189. Pp. $1-8$.

García-Chávez, J., De la Fuente-Palacios, C., Alonso-Pérez, N. y Martínez-Romero, E. 1994. Listado y abundancia de mamíferos carnívoros en los alrededores de Zapotitlán Salinas, Puebla. Memorias del Segundo Congreso Nacional de Mastozoología. Jalisco, México. Pág. 37.

Gese, E. y Ruff, R. 1997. Scent-marking by coyotes, Canis latrans: the influence of social and ecological factors. Animal Behavior. Vol. 54. Pp. 1155-1166.

Giman, B., Stuebing, R., Megun, N., McShea, W. y Stewart, W. 2007. A camera trapping inventory for mammals in a mixed use planted forest in Sarawak. The Raffles Bulletin of Zoology. Vol. 55. No. 1. Pp. 209-215.

Gompper, M. 1995. Nasua narica. Mammalian Species. No. 487. Pp. 1-10.

Gwinn, N., Palmer, G. y Koprowski, J. 2011. Virginia opossum (Didelphis virginiana virginiana) from Yavapai County, Arizona. Western North American Naturalist. Vol. 71. Pp. 113-114.

Harrison, R., Clarke, P. y Clarke, C. 2004. Indexing swift fox populations in New Mexico using scats. American Midland Naturalist. Vol. 151. Pp: 42-49.

Heymann, E.W. , Heistermann, M., Löttker, P., Huck, M., Böhle, U. 2004. Monitoreo noinvasivo de animales silvestres -análisis genéticos y endocrinológicos a base de muestras fecales en "pichicos barba blanca" (Saguinus mystax, Callitrichidae, 
Primates) en la estación biológica Quebrada Blanco (EBQB), Perú. Memorias: Manejo de Fauna Silvestre en Amazonia y Latinoamérica. VI Congreso sobre Manejo de Fauna Silvestre en la Amazonía y Latinoamérica. 7 pp.

Hwang, Y.; Larivière, S. 2001. Mephitis macroura. Mammalian Species. No. 686. Pp. 1-3.

INEGI. 2009. Prontuario de Información Geográfica Municipal de los Estados Unidos Mexicanos. Atexcal, Puebla. (Disponible en línea: http://www.inegi.org.mx/geo/contenidos/topografia/compendio.aspx)

Kasper, C., Fontoura-Rodrigues, M., Cavalcante, G., Freitas, T., Rodrigues, F., Oliveira, T. y Eizirik, E. 2009. Recent advances in knowledge of Molina's hog-nosed skunk Conepatus chinga and striped hog-nosed skunk C. semistriatus in South America. Small Carnivore Conservation. Vol. 41. Pp. 25-28.

Kleiman, D., Eisenberg, J. 1973. Comparisons of Canid and Felid Social Systems from an Evolutionary Perspective. Animal Behavior. Vol. 21. 637-659.

Krebs, J.R. ; Davies, N.B. 1993. An Introduction to Behavioural Ecology, 3rd ed. Oxford. Blackwell. $520 \mathrm{pp}$

Larivière, S.; Walton, L. 1997. Lynx rufus. Mammalian Species. No. 563. Pp. 1-8.

Livingstone, T., Gipson, P., Ballard, W., Sanchez, D. y Krausman, P. 2005. Scat removal: a source of bias in feces-related studies. Wildlife Society Bulletin. Vol. 33. No. 1. Pp. 172-178.

Lorenz, K. 1986. Fundamentos de Etología. Paidós. Barcelona. 349 pp.

Lotze, J.; Anderson, S. 1979. Procyon lotor. Mammalian Species. No. 119. Pp. 1-8.

Lyra-Jorge, M., Ciocheti, G., Pivello, V. y Meirelles, S. 2008. Comparing methods for sampling large- and medium-sized mammals: Camera traps and track plots. Eur J Wildl Res. Vol. 54.Pp. 739-744.

Malpaux, B. 2006. Seasonal Regulation of Reproduction in Mammals. Pp: 2231-2281. En: Neil, J., Plant, T., Pfaff, D., Challis, J., Kretser, D., Richards, J., Wassarman, P. (Eds.). 2006. Knobil and Neil's Physiology of Reproduction. Third Edition. Volume 2. USA. 
McCullough D., Pei K. y Wang Y. 2000. Home range, activity patterns, and habitat relations of Reeeves' muntjacs in Taiwan. Journal of Wildlife Management.Vol. 64. No. 2. Pp. 430-441.

McManus, J. 1974. Didelphis virginiana. Mammalian Species. No. 40. Pp. 1-6.

McManus, J. 1974. Didelphis virginiana. Mammalian Species. No. 40. Pp. 1-6.

Monroy-Vilchis, O., Zarco-González, M., Rodríguez-Soto, C., Soria-Díaz, L. y Urios. V. 2011. Fototrampeo de mamíferos en la Sierra de Nanchititla, México: abundancia relativa y patrón de actividad. Rev. Biol. Trop. Vol 59. Núm. 1. Pp. 373-383.

Murie, J. 1974. A field guide to animal tracks. Second Edition. Houghton Mifflin Co., Boston. Peterson Field Guide Series. 375 pp.

Nelson, R.J. 2000. An introduction to behavioral endocrinology. Sinauer Ass. Inc. Pub.Massachusetts, EUA. 724 pp.

Poglayen-Neuwall, I. y Toweill, D. 1988. Bassariscus astutus. Mammalian Species. No. 327. Pp. 1-8.

Ramírez, J. y Martínez, J. 2007. Diversidad de los mamíferos de la Reserva de la Biosfera de Tehuacán-Cuicatlán. Puebla-Oaxaca, México. Informe final SNIB-CONABIO proyecto No. BK022. $16 \mathrm{pp}$.

Reed, S. 2011. Non-invasive methods to assess co-ocurrence of mammalian carnivores. The Southwestern Naturalist. Vol. 56. No. 2. Pp. 231-240.

Reynolds, J. y Aebischer, N. 1991. Comparison and quantification of carnivore diet by faecal analysis: a critique, with recommendations, based on a study of the fox Vulpes vulpes. Mammal review. Vol. 21. Pp :97-122.

Ritchie, E. y Johnson, C. 2009. Predator interactions, mesopredator realease and biodiversity conservation. Ecology Letters. Vol. 12. Pp.982-998.

Rodríguez, G. 2008. Asesor Técnico: Otro campo laboral para el Químico Farmacéutico Biólogo. TESIS. UNAM. FES Cuautitlán. 97 pp.

Roemer, G., Gompper, M. y Van Valkengurgh, B. 2009. The ecological role of the mammalian mesocarnivore. Bioscience. Vol. 59. Pp. 165-173. 
Rudert, S., Brown, J., Ganslober, U., Möbius, G., Songsasen, N. 2011. Activity pattern, reproductive behaviors and gonadal hormones in the raccoon dog (Nyctereutes procyonoides). Zoo Biology. Vol. 30. Pp: 134-148.

Sacks, B. 2005. Reproduction and body condition of California coyotes (Canis latrans). Journal of mammalogy. Vol. 86. No. 5. Pp: 1036-1041.

Sánchez, D., Krausman, P., Livingston, T. y Gipson, P. 2004. Persistence of carnivore scat in the Sonoran desert. Wildlife Society Bulletin. Vol. 32. Pp. 366-372.

Soto M.A., Vázquez, C., Ramos, X., Yañez M.L., y Armella M.L. 2013. Presencia de doble estro anual en una hembra de lobo mexicano (Canis lupus baileyi) en cautiverio. Therya 4(3):539-549.

Soto, M.A., Salame, A., Ramírez, J., Yañez, L., Armella, M.A. 2004 Valoración de Hormonas Esteroides en heces de una pareja de Lobo Mexicano (Canis lupus baileyi) en cautiverio. Acta Zoológica (nueva serie). Año/vol. 20, núm. 002. Instituto de Ecología, A.C. 11 pp.

Sullivan, E. 1956. Gray Fox Reproduction, Denning, Range and Weights in Alabama. Journal of Mammalogy. Vol. 37. Pp. 346-351.

Tinbergen, N. 1963. On aims and methods of ethology. Z. Tierpsychol. Vol.20. Pp: 410433.

Valdespino, C. 2007. Physiological Constraints and Latitudinal Breeding Season in the Canidae. Physiological and Biochemical Zoology. Vol. 80. Pp.: 580-591.

Valdespino, C., Martínez-Mota, R., García-Fería, L., Martínez-Romero, L. 2007. Evaluación de eventos reproductivos y estrés fisiológico en vertebrados silvestres a partir de sus excretas: Evolución de una metodología no invasiva. Acta Zoológica Mexicana (nueva serie) 23 (3). 30 pp.

Wells, M. y Bekoff, M. 1981. An observational study of scent-marking in coyotes, Canis latrans. Animal Behaviour. Vol. 29 Pp.:332-350. 


\section{Anexos}

\section{$\underline{\text { Anexo I. Mesodepredadores registrados en el área de estudio. }}$}

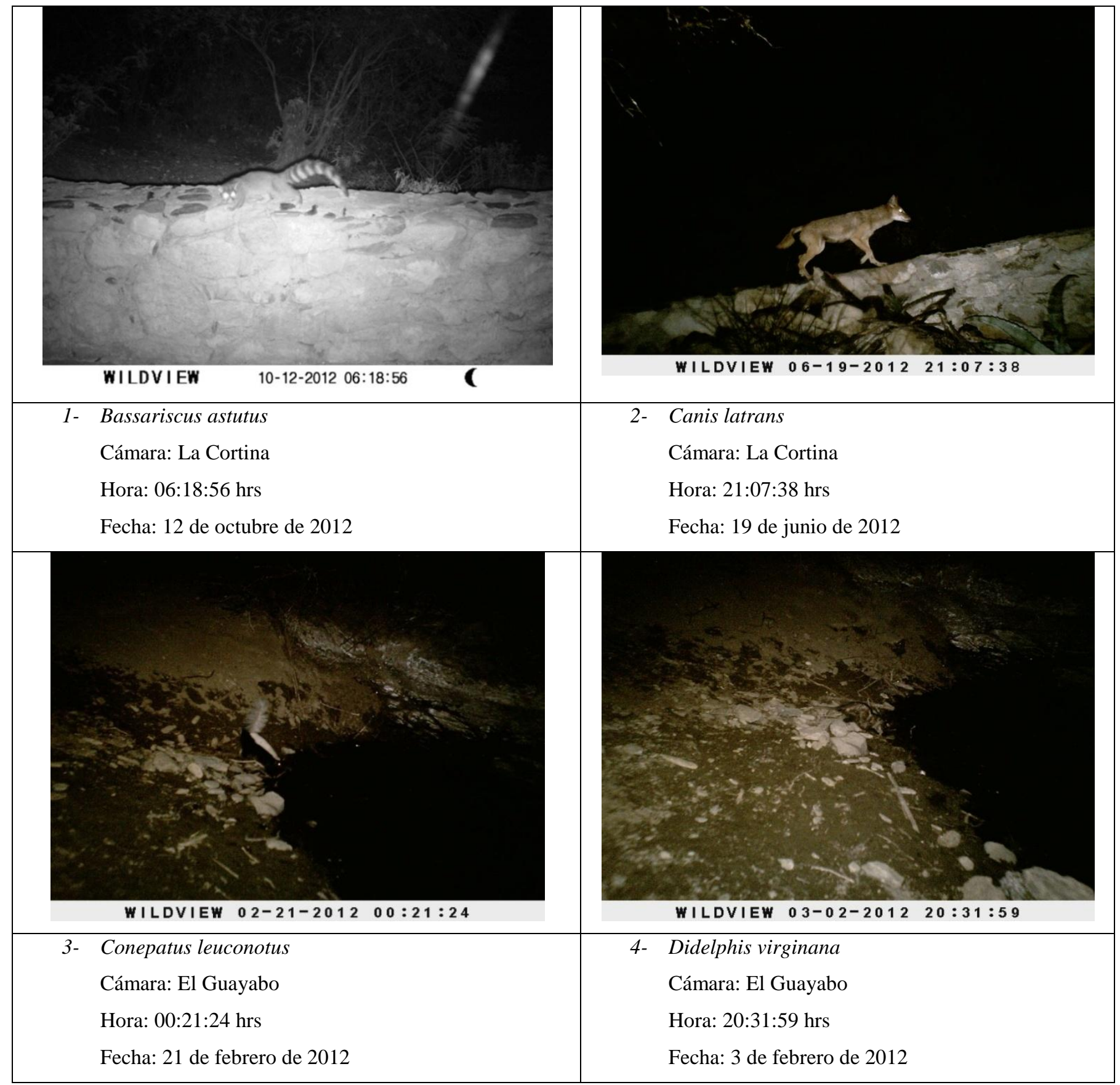




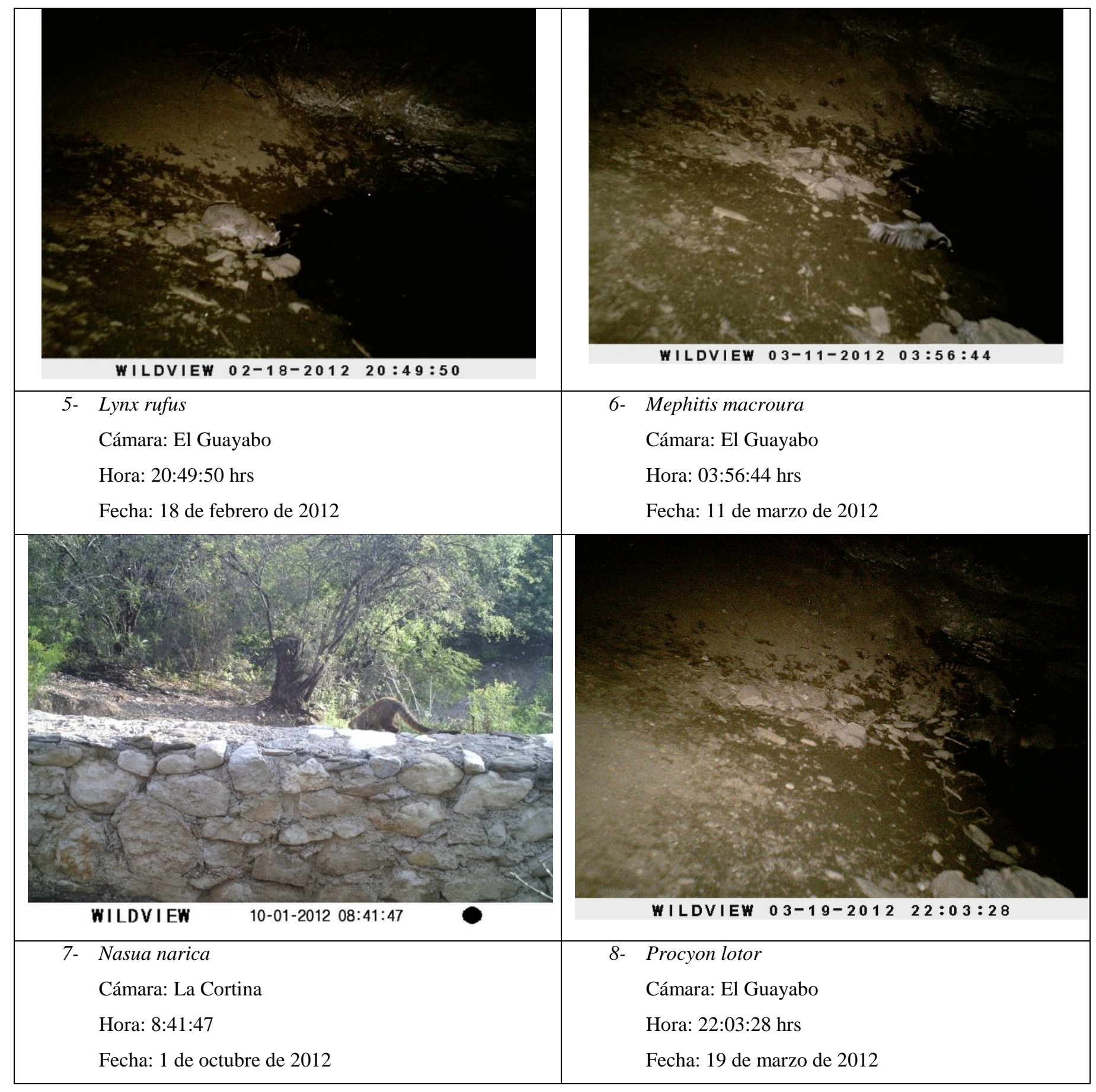




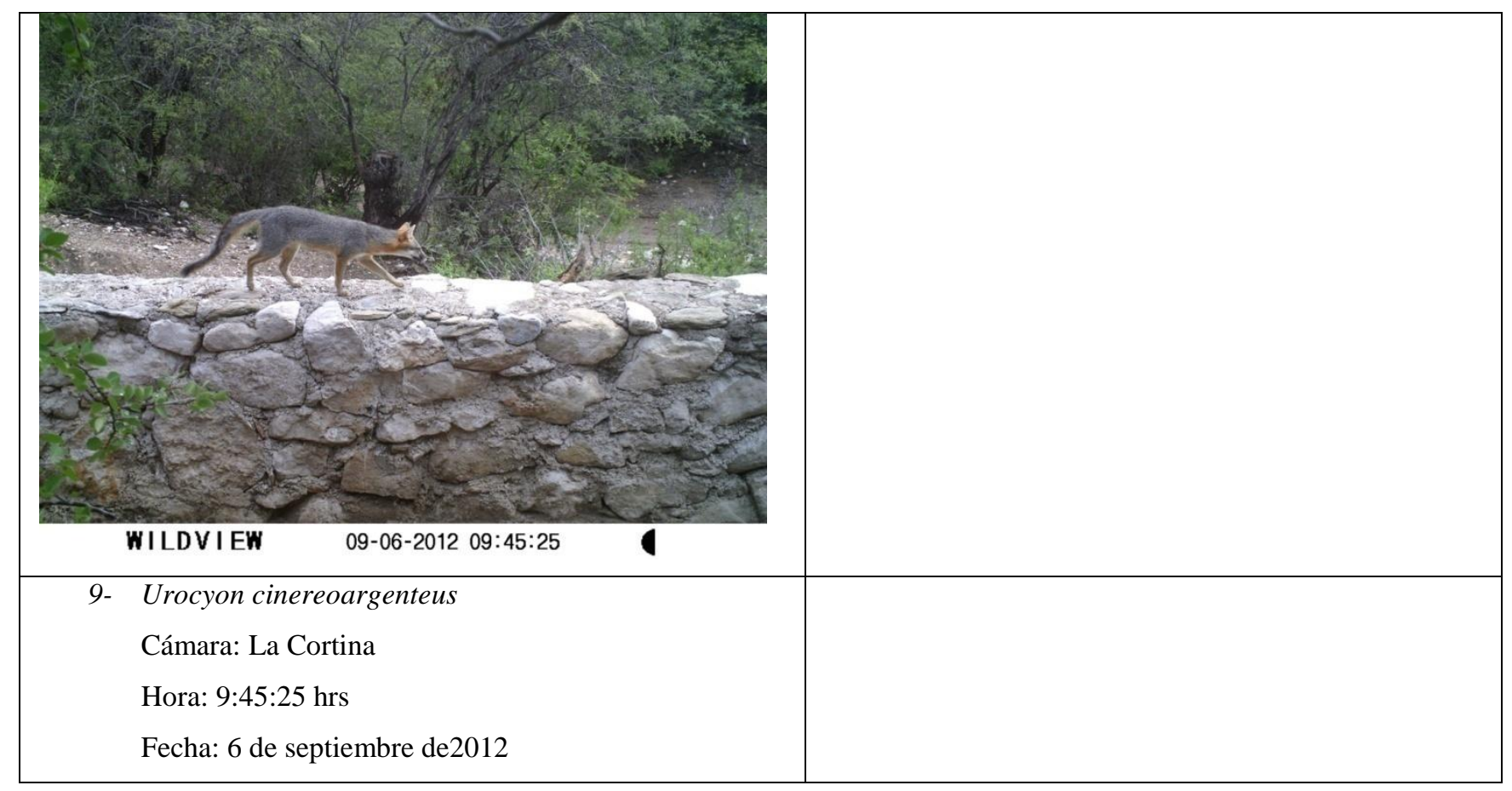




\section{$\underline{\text { Anexo II. Otras especies de fauna silvestre registradas en el área de estudio }}$}

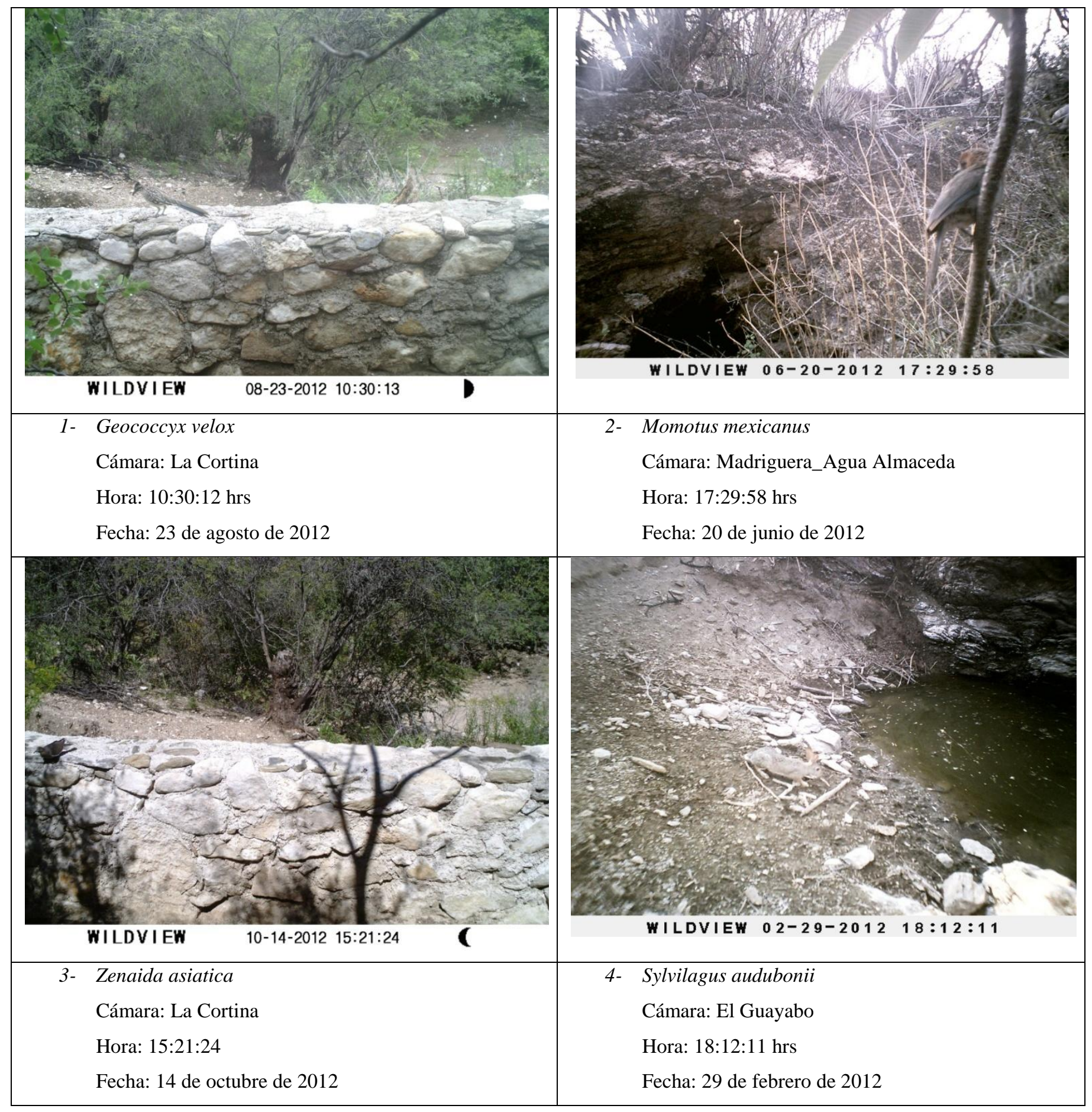


Anexo III . Especies de mesodepredadores registradas por fototrampeo.

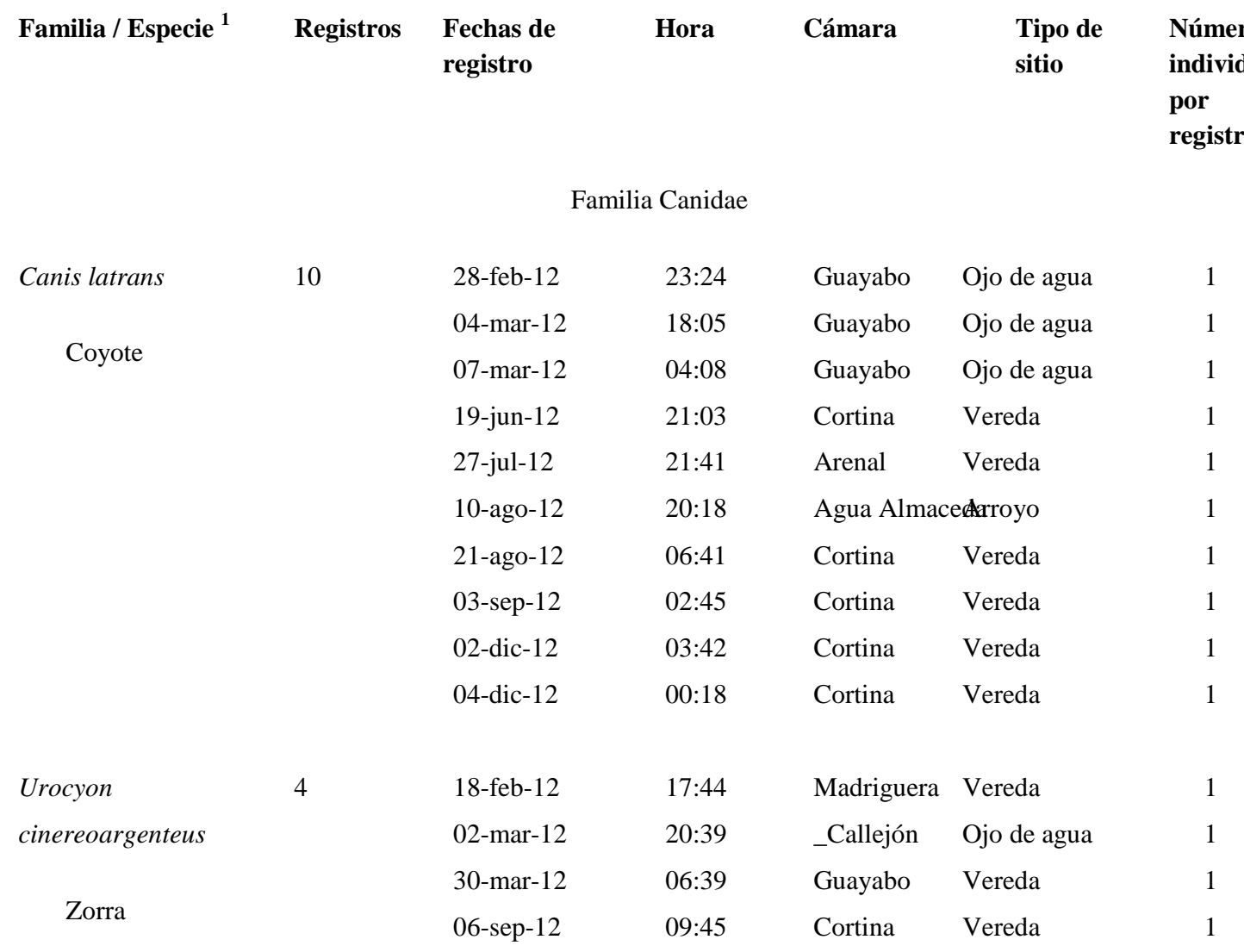

Familia Didelphidae

\section{Didelphis virginiana \\ Tlacuache \\ 2}

02-mar-12

20:31

09-oct-12

$00: 47$
Guayabo

Cortina

Ojo de agua

Vereda
Familia Feliidae 
Familia Mephitidae

$\begin{array}{cclllll}\text { Conepatus leuconotus }^{2} & 4 & & & & \\ \text { Zorrillo cadeno } & & 05 \text {-sep-12 } & 21: 00: 31 & \text { Cortina } & \text { Vereda } & 1 \\ & & 17 \text {-sep-12 } & 06: 24: 55 & \text { Cortina } & \text { Vereda } & 1 \\ \text { Mephitis macroura } & 2 & 19 \text {-sep-12 } & 03: 00: 47 & \text { Cortina } & \text { Vereda } & 1 \\ \text { Zorrillo rayado } & & 11 \text {-mar-12 } & 03: 56 & \text { Guayabo } & \text { Ojo de agua } & 1 \\ & & 25 \text {-ago-12 } & 05: 39 & \text { Cortina } & \text { Vereda } & 1\end{array}$

Familia Procyonidae

\begin{tabular}{|c|c|c|c|c|c|}
\hline Bassariscus astutus & 12 & 23 -ago-12 & $23: 52: 45$ & Mezquite 1 & Ojo de agua \\
\hline & & 25 -ago-12 & 05:02 & Cortina & Vereda \\
\hline Cacomixtle & & 08-sep-12 & $06: 24: 17$ & Cortina & Vereda \\
\hline & & 15 -sep-12 & $20: 52$ & Cortina & Vereda \\
\hline & & 19-sep-12 & $05: 34: 46$ & Cortina & Vereda \\
\hline & & 07 -oct- 12 & $05: 47: 48$ & Cortina & Vereda \\
\hline & & 08 -oct- 12 & 01:07:16 & Cortina & Vereda \\
\hline & & 10 -oct-12 & $20: 59: 42$ & Cortina & Vereda \\
\hline & & 12 -oct- 12 & $06: 18: 56$ & Cortina & Vereda \\
\hline & & 13 -oct- 12 & $00: 15: 51$ & Cortina & Vereda \\
\hline & & 17 -oct- 12 & $23: 38: 43$ & Cortina & Vereda \\
\hline & & 18 -oct- 12 & $01: 17: 28$ & Cortina & Vereda \\
\hline Procyon lotor & 3 & 19-mar-12 & $21: 24: 00$ & Guayabo & Ojo de agua \\
\hline & & 19-mar-12 & $22: 03$ & Guayabo & Ojo de agua \\
\hline Mapache & & 10 -sep-12 & $21: 37: 49$ & Cortina & Vereda \\
\hline Nasua narica & 2 & 01 -oct-12 & $08: 41: 47$ & Cortina & Vereda \\
\hline & & 18 -oct-12 & $05: 31: 27$ & Cortina & Vereda \\
\hline
\end{tabular}


1. Se utilizan los nombres hasta el nivel de especie de acuerdo con Ramírez \& Martínez 2007 para los mamíferos de la zona.

2. El nombre científico para el zorrillo cadeno en los inventarios de la zona es Conepatus mesoleucus. En este trabajo se usará el nombre Conepatus leuconotus, que es el nombre válido.

\section{Anexo IV. Otras especies de fauna registradas por fototrampeo.}

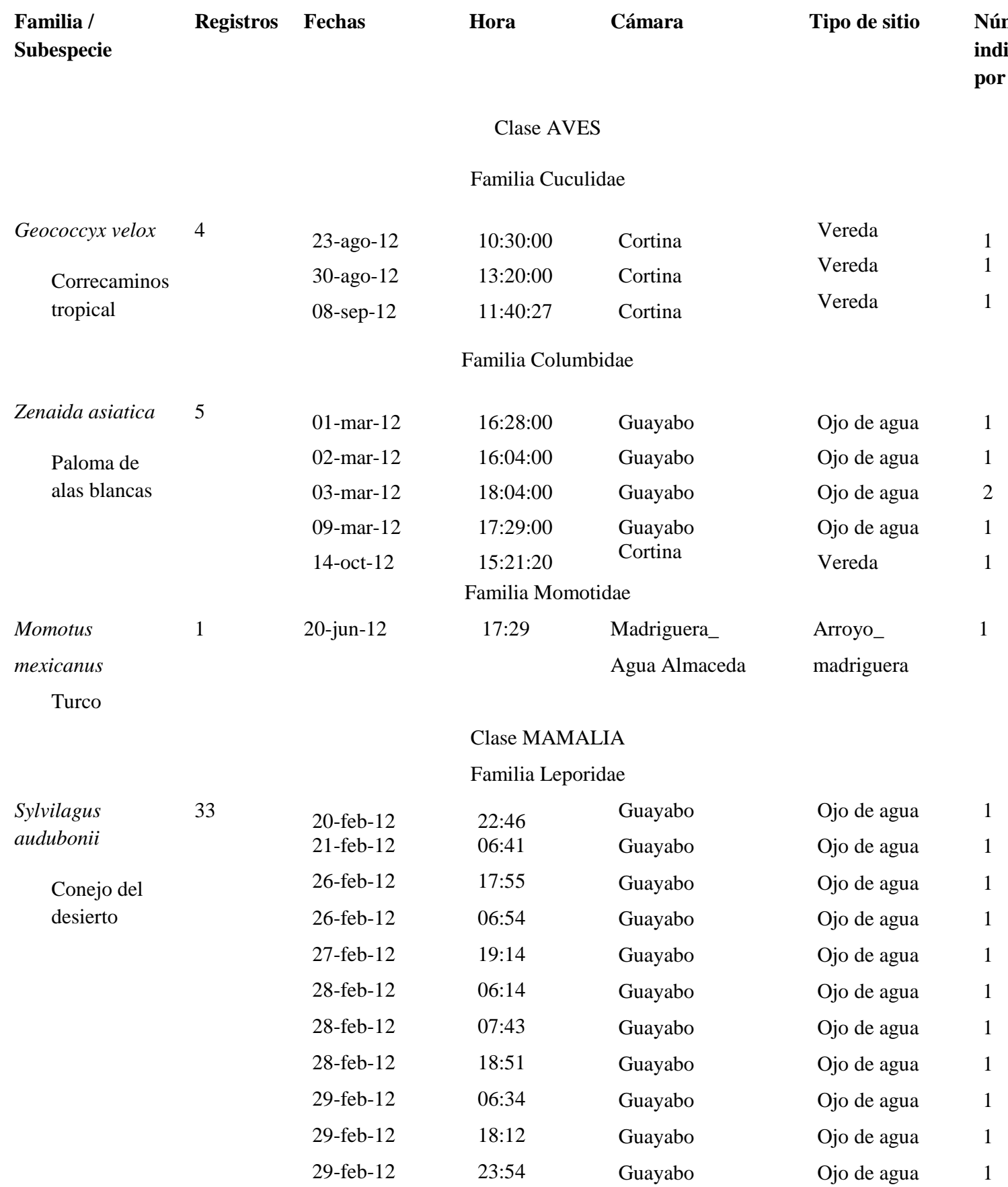


Familia / Subespecie
Registros Fechas

Hora

Cámara

$\begin{array}{lll}\text { 02-mar-12 } & 18: 20 & \text { Guayabo } \\ \text { 03-mar-12 } & 02: 27 & \text { Guayabo } \\ \text { 04-mar-12 } & 02: 24 & \text { Guayabo } \\ \text { 04-mar-12 } & 19: 07 & \text { Guayabo } \\ \text { 06-mar-12 } & 06: 09 & \text { Guayabo } \\ \text { 06-mar-12 } & 18: 07 & \text { Guayabo } \\ \text { 06-mar-12 } & 21: 18 & \text { Guayabo } \\ \text { 07-mar-12 } & 03: 27 & \text { Guayabo } \\ \text { 08-mar-12 } & 05: 01 & \text { Guayabo } \\ \text { 10-mar-12 } & 05: 34 & \text { Guayabo } \\ \text { 10-mar-12 } & 23: 38 & \text { Guayabo } \\ \text { 11-mar-12 } & 17: 58 & \text { Guayabo } \\ \text { 11-mar-12 } & 18: 01 & \text { Guayabo } \\ \text { 11-mar-12 } & 21: 22 & \text { Guayabo } \\ \text { 13-mar-12 } & 03: 20 & \text { Guayabo } \\ \text { 14-mar-12 } & 07: 45 & \text { Guayabo } \\ \text { 16-mar-12 } & 06: 38 & \text { Guayabo } \\ \text { 16-mar-12 } & 06: 48 & \text { Guayabo } \\ \text { 16-mar-12 } & 06: 50 & \text { Guayabo } \\ \text { 16-mar-12 } & 06: 52 & \text { Guayabo } \\ \text { 17-mar-12 } & 18: 05 & \text { Guayabo } \\ \text { 17-mar-12 } & 23: 14 & \text { Guayabo } \\ \text { 18-mar-12 } & 20: 30 & \text { Guayabo } \\ \text { 19-mar-12 } & 02: 34 & \text { Guayabo } \\ \text { 19-mar-12 } & 17: 18 & \text { Guayabo } \\ \text { 19-mar-12 } & 23: 59 & \text { Guayabo }\end{array}$

Tipo de sitio

Número de individuos por registro

Ojo de agua 1

Ojo de agua 1

Ojo de agua 1

Ojo de agua 1

Ojo de agua 1

Ojo de agua 1

Ojo de agua 1

Ojo de agua 1

Ojo de agua 1

Ojo de agua 1

Ojo de agua 1

Ojo de agua 1

Ojo de agua 1

Ojo de agua 1

Ojo de agua 1

Ojo de agua $\quad 1$

Ojo de agua 1

Ojo de agua $\quad 1$

Ojo de agua 1

Ojo de agua 1

Ojo de agua 1

Ojo de agua 1

Ojo de agua 1

Ojo de agua 1

Ojo de agua 1

Ojo de agua $\quad 1$ 